Failure detection and monitoring in polymer matrix composites subjected to static and dynamic loads using carbon nanotube networks

\title{
Mohammadreza Nofar
}

\author{
A Thesis \\ in \\ The Department \\ of \\ Mechanical and Industrial Engineering \\ Presented in Partial Fulfillment of the Requirements \\ Concordia University \\ Montreal, Quebec, Canada
}

for the Degree of Master of Applied Science (Mechanical Engineering) at

Aug 2008

(C) Mohammadreza Nofar, 2008 
Library and Archives

Canada

Published Heritage

Branch

395 Wellington Street

Ottawa ON K1A ON4

Canada
Bibliothèque et

Archives Canada

Direction du

Patrimoine de l'édition

395, rue Wellington

Ottawa ON K1A ON4

Canada
Your file Votre reférence

ISBN: 978-0-494-67291-4

Our file Notre ráférence

ISBN: 978-0-494-67291-4
NOTICE:

The author has granted a nonexclusive license allowing Library and Archives Canada to reproduce, publish, archive, preserve, conserve, communicate to the public by telecommunication or on the Internet, loan, distribute and sell theses worldwide, for commercial or noncommercial purposes, in microform, paper, electronic and/or any other formats.

The author retains copyright ownership and moral rights in this thesis. Neither the thesis nor substantial extracts from it may be printed or otherwise reproduced without the author's permission.
AVIS:

L'auteur a accordé une licence non exclusive permettant à la Bibliothèque et Archives Canada de reproduire, publier, archiver, sauvegarder, conserver, transmettre au public par télécommunication ou par l'Internet, prêter, distribuer et vendre des thèses partout dans le monde, à des fins commerciales ou autres, sur support microforme, papier, électronique et/ou autres formats.

L'auteur conserve la propriété du droit d'auteur et des droits moraux qui protège cette thèse. $\mathrm{Ni}$ la thèse ni des extraits substantiels de celle-ci ne doivent être imprimés ou autrement reproduits sans son autorisation.
In compliance with the Canadian Privacy Act some supporting forms may have been removed from this thesis.

While these forms may be included in the document page count, their removal does not represent any loss of content from the thesis.
Conformément à la loi canadienne sur la protection de la vie privée, quelques formulaires secondaires ont été enlevés de cette thèse.

Bien que ces formulaires aient inclus dans la pagination, il n'y aura aucun contenu manquant. 


\section{Abstract \\ Failure detection and monitoring in polymer matrix composites subjected to static and dynamic loads using carbon nanotube networks

\author{
Mohammadreza Nofar
}

In this work, multiwall carbon nanotubes (MWCNTs) have been used as a network of sensors to predict the failure region and to monitor the degradation of mechanical properties in laminated composites subjected to tensile and cyclic fatigue loadings. This is achieved by measuring the electrical resistance change in the semi-conductive MWCNT-fiber glassepoxy polymer matrix composites. By partitioning the tensile and fatigue samples with electrically conductive probes, it has been shown that with both increasing tensile load and number of cycles, different resistance changes are detected in different regions and failure happens in the part in which higher resistance change was detected. In cyclic loading, in which the maximum load is higher than the elastic limit of the laminate, a sharp increase in resistance occurs within the first several cycles. There is also a change in resistance during long term cyclic loading. In cyclic loading, when compared to strain gauge readings, resistance change measurements show more sensitivity in identifying the crack initiation site, which gives this technique a good potential for monitoring strength degradation during fatigue.

Keywords: composites; Carbon nanotubes; Electrical properties; Sensors; 


\section{Acknowledgements}

I would like to express my gratitude to my supervisors, Dr. S. V. Hoa and Dr. M. D. Pugh, for their support and guidance in my thesis. Their encouragement and useful comments have enabled me to reach this education level.

I would like to appreciate Dr. Ming Xie, Mr. Heng Wang, Mr. Robert Oliver, and my friends for their precious comments and critiques in fulfillment of my thesis.

I profoundly thank my mother. Without her love and encouragement, this work would not have been possible. 


\section{Table of Contents}

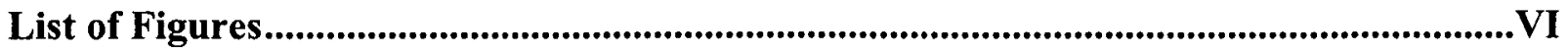

List of Tables ........................................................................................................................................... X

Chapter 1: Introduction ............................................................................................................... 1

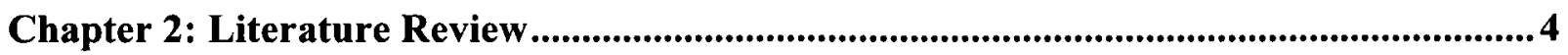

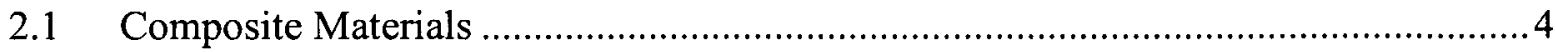

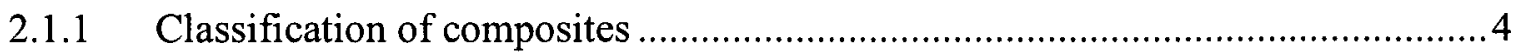

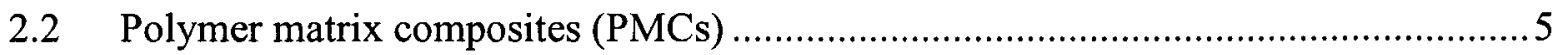

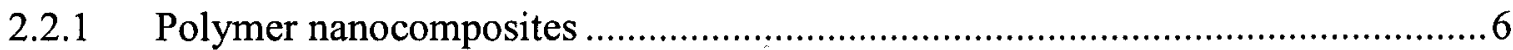

2.2.2 General fabrication processes for polymer matrix composites........................... 6

2.3 Carbon nanotubes and their composites................................................................ 10

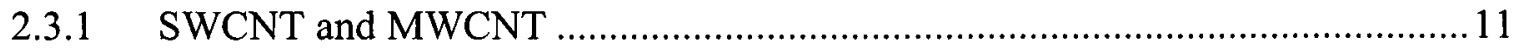

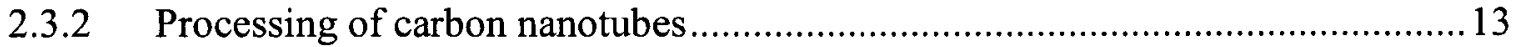

2.3.3 Carbon nanotubes used in polymer matrix composites and their properties ......16

2.3.4 Processing of carbon nanotube polymer composites .........................................2 21

2.3.5 Carbon nanotubes as a percolation network of sensors .......................................28

Chapter 3: Objectives of the present work..................................................................................40

Chapter 4: Experimental Procedure .................................................................................................4 4

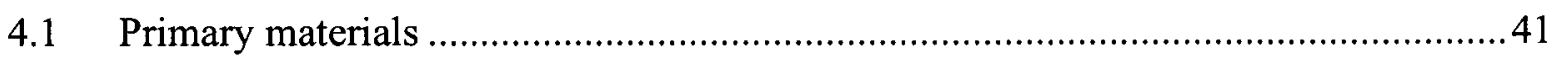

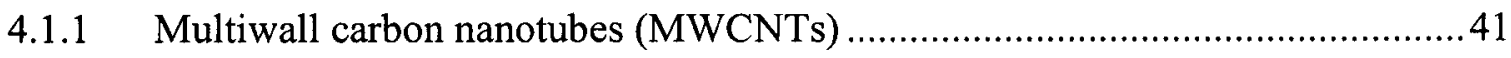

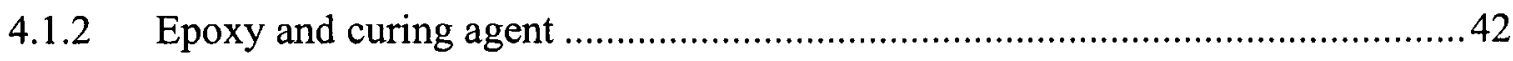

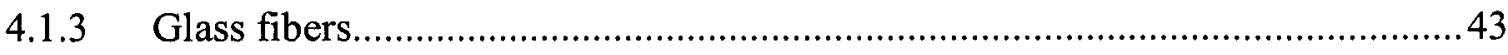

4.2 Fabrication of nanotube-glass fiber-epoxy composites............................................4

4.3 Electrical measurments under mechanical loads (tensile and fatigue)........................46

Chapter 5: Results and Discussion ...........................................................................................48

$5.1 \quad$ Nanotube dispersion in epoxy resin ....................................................................... 49

5.2 Tensile Test ……...........................................................................................

5.2.1 Tensile test while measuring electrical resistance along the sample ..................51

5.2.2 Tensile test while measuring electrical resistance in three zones of a sample....51

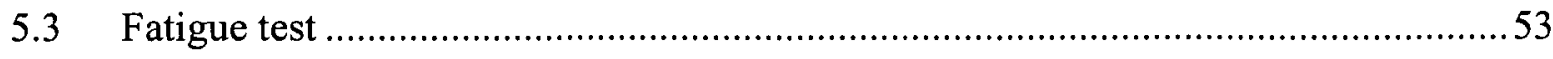

5.3.1 Fatigue test while measuring electrical resistance along the sample ..................53

5.3.2 Comparison of electrical resistance and strain gauges during cyclic loading ....57

5.3.3 Measurements in two regions during fatigue with unloading every four cycles.......................................................................61 
Chapter 6: Conclusions, contributions, and suggestions for future work ........................74

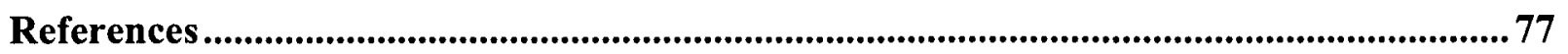




\section{List of Figures}

Fig 1) Wet Lay-up Technique ........................................................................................

Fig. 2) Schematic of nano-clay/glass fiber/epoxy preparation, using VARTM .......................... 8

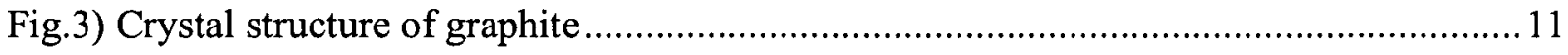

Fig. 4) Atomic structures of (a) armchair and (b) zig-zag carbon nanotubes ...........................11

Fig 5) TEM micrograph of a MWCNT, indicating the outer (d) and inner (di) diameter ........12

Fig. 6) Modulus vs. density and modulus-to-weight ratio vs. price for different materials .....13

Fig. 7) Schematic illustration of the arc-discharge technique by which the primary nanotubes

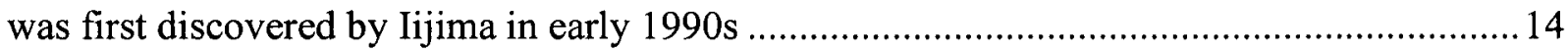

Fig. 8) SEM Photos showing control over the nanotube diameter grown via PECVD:(a) 40-

$50 \mathrm{~nm}$ and (b) 200-300 nm aligned carbon nanotubes ......................................................... 15

Fig. 9) SEM Photos showing the straightness of MWCNTs grown via PECVD .....................15

Fig. 10) Young modulus of a polymer composite versus amount of MWNT ……...................17

Fig. 11) Stress/strain curves of a LDPE/ CNT composite as a function of MWNT content ....17

Fig. 12) TEM micrograph and computer simulation of nanotube buckling ............................. 18

Fig. 13) Stress-strain curve from flexural test of amino-functionalized composites with

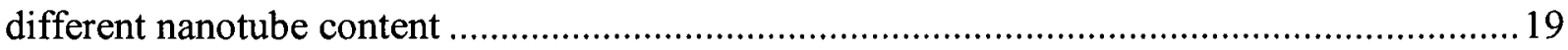

Fig. 14) Comparison of electrical resistance and thermal conductivity of some metallic,

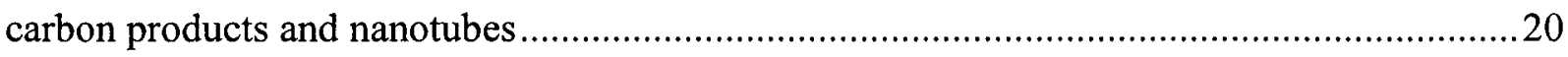

Fig. 15) Effect of carbon nanotubes on thermal conductivity ................................................2 20

Fig. 16) DC volume conductivity as a function of SWNT weight fraction of PMMA/SWNT

film (a): along the alignment of SWNT. (b): perpendicular to the alignment of SWNT .........21 
Fig. 17) Schematic of a three-roll mill and (b) region of high shear mixing between the feed and center rolls

Fig. 18) Transmission electron microscopy for (a) sonication of MWCNT in epoxy and (b) calendering of MWCNT in epoxy

Fig. 19) Schematic of functionalization of CNT 26

Fig. 20) Interface tailoring process and the resulting improvement in elastic modulus

Fig. 21) Schematic procedure of amino functionalization

Fig. 22) Different properties in epoxy matrix composites by using MWCNT and amino functionalized MWCNT in different amounts .28

Fig. 23) Load-displacement and resistance change for (a) unidirectional specimen with a cut in center ply for delamination launch, and (b) [0/90] s cross-ply specimen 30

Fig. 24) Three-points bend results for span-to-thickness ration of (a) 4 and (b) 8 30

Fig. 25) (a) Detection of fatigue crack growth by monitoring the notch tip, (b) resistance change vs. optically measured crack growth theoretically and experimentally 32

Fig. 26) Normalized change in surface resistance of (a) dry blended and (b) solution cast PMMA/MWNT at various MWNT loadings

Fig. 27) Sensitivity factors for PMMA/MWNT films 35

Fig. 28) Surface resistance of solution cast samples under cyclic tensile load with different MWNT wt $\%$. 35

Fig. 29) Stress and normalized surface resistance change vs. strain for PMMA/MWNT (10wt \%) films manufactured by (a) dry blending and (b) solution cast 36

Fig.30) Polymer/CNT nanocomposite strain sensors with different CNT content 37

Fig.31) Strain response of the SWCNT/PMMA composite sensor 37 
Fig.32) Strain and stress measurements (a) and reisitivity change measurements (b) during tensile loading cycles

Fig.33) Residual strain and irreversible resistance change subjected to cyclic tensile loadings39 Fig.34) TEM for purified multiwall carbon nanotubes (MWCNTs)

Fig.35) Chemical structure of Epon resin 862 42

Fig.36) Three-roll mill EXAKT (calendering machine) used to disperse the nanotubes within the epoxy resin .44

Fig.37) Sonicator 3000, MISONIX used as a dispersion technique

Fig.38) Agilent machine used for electrical measurements .46

Fig. 39) Three types of samples for monitoring the defect initiation in two regions during fatigue testing.

Fig.40) DSC results of the samples after curing 48

Fig.41) TGA result of the composite sample after curing .48

Fig. 42) Nanotube dispersion within epoxy by means of (A) acetone sonication and (B) calendering.

Fig.43) Scanning electron microscopy of the matrix including nanotubes. 50

Fig. 44) Change of resistance in tension for $1 \mathrm{wt} \%$ nanotube-glass fiber-epoxy composite....51 Fig.45) Change of resistance vs. strain by multi-point resistance measurement during tensile test (a) failure has occurred between points 2-3, and (b) points 1-2 .53

Fig. 46) Change of resistance vs. cycles under fatigue testing with maximum load of 6000 N55 Fig. 47) Change of resistance vs. cycles under fatigue testing with maximum load of 4000 comparing with $6000 \mathrm{~N}$ .55 
Fig. 48) Change of resistance vs. cycles with maximum applied loads of $6000,4000,3500$, 2500 , and $1500 \mathrm{~N}$ within 500 cycles

Fig. 49) (a) Residual change of resistance and (b) residual strain using strain gauge measured for 6 maximum loads in first 100 cycles.

Fig. 50) (a) Residual change of resistance and (b) residual strain vs. maximum applied cyclic loads .59

Fig. 51) Optical micrograph of fatigued samples after maximum cyclic loads of (A) $2500 \mathrm{~N}$, (B \& C) $4500 \mathrm{~N}(\mathrm{D} \& \mathrm{E}), 6000 \mathrm{~N}$ 60

Fig. 52a) Residual change of resistance and residual strain in two regions, after 100 fatigue cycles with maximum load of $6000 \mathrm{~N}$ (type I, sample 1)

Fig. 52b) Residual change of resistance and residual strain in two regions, after 100 fatigue cycles with maximum load of $4500 \mathrm{~N}$ (type I, sample 2) 64

Fig. 52c) Residual change of resistance and residual strain in two regions, after 100 fatigue cycles with maximum load of $4500 \mathrm{~N}$ (type I, sample 3). .66

Fig. 53a) Residual change of resistance and residual strain in two regions, after 100 fatigue cycles with maximum load of $2000 \mathrm{~N}$ (type II, sample 1)...... .68

Fig. 53b) Residual change of resistance and residual strain in two regions, after 100 fatigue cycles with maximum load of $3000 \mathrm{~N}$ (type II, sample 2)

Fig. 54a) Residual change of resistance and residual strain in two regions, after 150 fatigue cycles with maximum load of $6000 \mathrm{~N}$ (type III, sample 1) 70

Fig.54b) Residual change of resistance and residual strain in two regions, after 150 fatigue cycles with maximum load of $6000 \mathrm{~N}$ (type III, sample 2) 


\section{List of Tables}

Table 1) Flexural modulus and strength for different amounts of amino-functionalized MWCNT

Table 2) Surface resistance of PMMA/MWCNT fabricated by two methods with different nanotube weight fractions 33

Table 3) Sensitivity factors for PMMA/MWNT films for different MWNT contents 34

Table 4) Number of passes through three-roll mill machine with different gap distances .44 


\section{CHAPTER 1: Introduction}

Carbon nanotubes (CNT) are known as the stiffest and strongest materials in the world [1-3]. They were discovered in the early 1990 s and researchers started to focus on these new materials due to their considerable physical and mechanical properties. Their remarkable mechanical properties such as high stiffness and strength, exceptional resilience, low density, fiber-like structure with high aspect ratio (length/diameter), as well as high electrical and thermal conductivity render Carbon Nanotubes (CNTs) potential as nanoscale reinforcement to achieve improved electrical properties [4-9]. Recently, researchers have utilized them as strain sensors by embedding them in polymer matrix composites (PMCs) and monitoring damage and subsequently failure, by direct measurement of current in the composite [10-13]. Damage monitoring using electrical techniques has been of interest to researchers for some time and began with the use of carbon fibers as the conductive reinforcement, so that fracture of the fibers would result in a change of electrical resistance [14-16]. Since matrix-dominated fracture mechanisms can not be monitored utilizing these conductive fibers and this also places a restriction on only using conductive fibers such as carbon fibers, using a dispersed conductive reinforcement in the matrix has become the main consideration for damage monitoring. The high aspect ratio of carbon nanotubes has been considered as crucial to the formation of a conductive percolating network through the polymer matrix composite at relatively low CNT concentrations: such a network is highly sensitive to the onset of damage in 
matrix-dominated fractures [10]. This exceptional sensitivity causes an increase in electrical resistance along embedded carbon nanotubes in PMCs under even a low mechanical load [17]. In comparison with resistance-type strain gauges, which provide a conventional way for measuring strain, using conductive CNT may not have the same limitations, such as measuring strain at only specific locations and a lack of versatility and flexibility [18]. In Thostenson and Chou's study, [10] unidirectional glass fiberepoxy composites with dispersed multiwall carbon nanotubes within the epoxy have been utilized to evaluate the damage and percolation threshold in tensile and flexural tests as an in situ sensor.

When considering non-static loads such as fatigue, which is one of the most crucial factors for failure in many structural components, the long term durability of polymer matrix composites is highly dependent on the polymer matrix and the fiber-matrix interface [19]. In other words, fatigue life and damage tolerance are strongly affected by matrix cracks, like micro cracks appearing between fiber reinforcements, or ply delamination between layers [10]. Carbon nanotubes as additives can play a significant role as distributed sensors to monitor damage and to determine the extent and defect propagation created by cyclic loads [20, 21]. In another study, Böger et. al. [22] worked on stress/strain and damage monitoring of glass fiber-epoxy using carbon nanotubes and carbon black during tensile, fatigue, and interlaminar shear strength testing. The composite specimens were tested in tensile loading cycles while unloading every one cycle. The residual strain after unloading was recorded every one cycle due to the plastic deformation and simultaneously, resistance was changed as well, which is due to some permanent damage such as cracks in the matrix. By continuing tensile loading and 
unloading every one cycle, it was observed that the residual strain and irreversible resistance changes increase gradually, which shows the capability of nanotubes in following the damage accumulation as well as the strain gauge records.

Crack and failure zone detection while tension and fatigue loadings are investigated in this work by using nanotube network of sensors and strain gauge. The sensitivity of nanotube networks versus strain gauge is also explored during damage accumulation and failure under loadings. 


\section{CHAPTER 2: LITERATURE REVIEW}

\subsection{Composite Materials}

A composite material can be defined as a combination of two or more different phases, with a distinct interface between them and significant portions of each phase.

Typically, composites consist of two distinct phases in which the interface plays a major role. These two phases are:

1- Matrix

The matrix mostly plays the role of a binder, to give a definite shape and preferred orientation or location to the reinforcement. In the case of enhancing mechanical properties, it is very significant in transferring the load to the reinforcement through the matrix-reinforcement interface. Protection from environmental damage is another function of matrices.

2- Reinforcement

To enhance mechanical or/and physical properties of the composites, reinforcements are utilized and play the role of prime load-carrying member.

\subsubsection{Classification of composites}

Based on the matrix and reinforcement, different classifications of composites can be defined: 
(a) Based on matrix:

1- Ceramic matrix composites (CMCs)

2- Metal matrix composites (MMCs)

3- Polymer matrix composites (PMCs)

(b) Based on reinforcement form:

1- Particle reinforced composites

2- Fiber reinforced composites

Matrix-based classification is the one most used for composites.

\subsection{Polymer matrix composites (PMCs)}

Different types of reinforcements can be used within the polymer matrix. The polymer itself can be either thermoplastic or thermoset. Due to their ease of fabrication, light weight, and low cost, PMCs are used in large diversity and quantity for composite applications.

In the case of reinforcements, fibers like glass fibers, carbon fibers, and Kevlar are the most used. According to the service temperature, thermoset or thermoplastic polymers can be used as the matrix. Due to their low melting and degradation temperature, the matrix defines the service temperature of the composite. The most widely used and least expensive matrices are polyesters and vinyl esters (thermoset) which are mostly used with glass fiber reinforcements. Epoxy thermoset resins are the other type of polymer matrice widely used in aerospace applications. They have better mechanical properties and moisture resistance than polyesters and vinyl esters. Polyimide is a type of thermoset resin which is utilized for high temperatures. High temperature thermoplastic polymers 
like polyetheretherketone (PEEK), poly (phenylene sulfide) (PPS), and polyetherimide (PEI) are future significant options for aerospace applications.

\subsubsection{Polymer nanocomposites}

These composites consist of a polymer matrix and nano-sized particles dispersed in the polymer for enhancing the mechanical and/or physical properties. According to their shape, three main types of nano-particles are used in polymer nanocomposites:

a) Lamellar (Nanolayered silicates )

b) Shell-like (carbon nanotubes CNT)

c) Fibrillar (carbon nanofibers CNF, cellulose nanowhiskers)

A small amount of nanoparticles generates a very large improvement in mechanical and/or physical properties of the composites mainly due to their high aspect ratio [23-25].

\subsubsection{General fabrication processes for polymer matrix composites}

The most common manufacturing methods for fiber reinforced polymeric (FRP) composites are:

1- Hand Lay-up

2- Spray-up

3-Compression moulding

4- Resin Transfer Moulding (RTM)

5- Pultrusion

6- Filament Winding 


\subsubsection{Hand Lay-up}

In hand lay-up, the reinforcement is put down to line a mould previously treated with a release agent to prevent sticking and perhaps a gel coat to give a protective surface.

There are two main methods of Hand Lay-up: wet lay-up and dry lay-up.

\section{Wet Lay-up}

In this method the dry reinforcement is first applied to the mould and then is saturated with liquid resin. The wet lay-up technique is described in Figure 1.

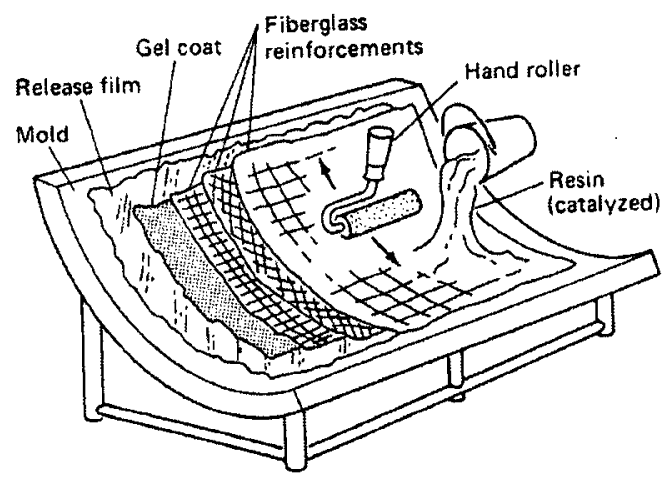

Fig 1) Wet Lay-up Technique [26]

\section{Dry Lay-up}

In this method the reinforcement and the thermoset resin are applied simultaneously as a pre-impregnated fiber tape (prepreg)--the resin in the prepreg sheets is ' $\mathrm{B}$ ' staged. Stage ' $\mathrm{B}$ ' is solidified and tacky but only partially cured. 


\subsubsection{Spray-up Method}

In this method chopped fibers and resin are fed into a gun and then these guns spray the mixture on to a mould prepared with release agent and gel coat. Then the sprayed composite has to be rolled to remove entrapped air and to give a smooth surface finish.

\subsubsection{Resin Transfer Moulding (RTM)}

In this method, the low viscosity resin is injected into the closed mould which contains a fiber perform using a low pressure and subsequently cured. The process allows simple fabricating of low performance to complex, high- performance articles in varied sizes. The main potential advantages of RTM can be summarized as the capability of rapid manufacture of large, complex, high-performance structures with good surface finish on both sides. In resin transfer moulding, high glass ratios can not be achieved and improperly placed reinforcement can cause dry spots or resin pools. Thus, it is not recommended for a part that will be highly stressed.

In the 1980s, a new technique was introduced which has the most important role in the fabrication of marine structures. Vacuum-assisted resin transfer moulding (VARTM) is now gradually replacing the hand lay-up process in making large components.

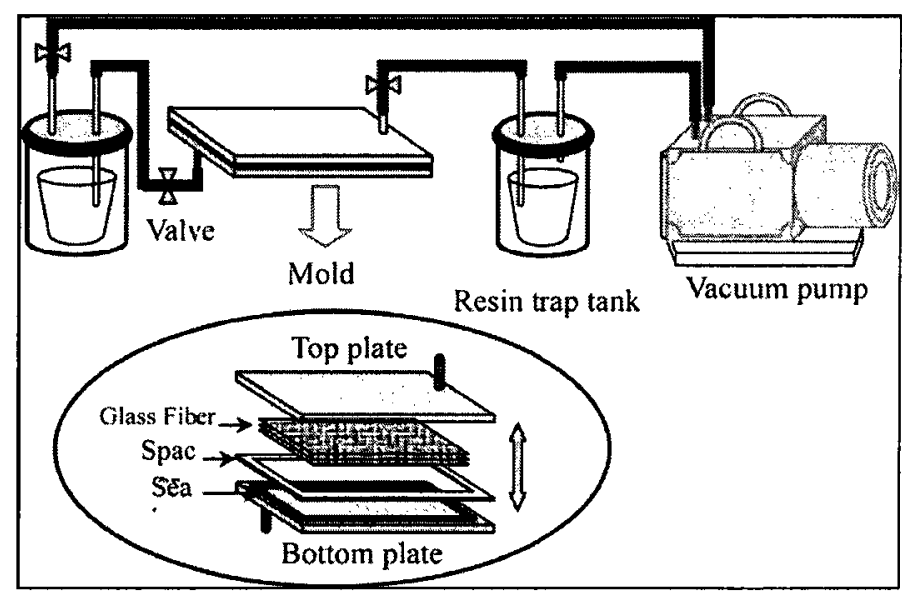

Fig. 2) VARTM process for nano-clay/glass fiber/epoxy composite[27] 
Plate panels up to $10 \mathrm{~m} \times 10 \mathrm{~m}$ in size and $18 \mathrm{~mm}$ thickness have been manufactured successfully by this method. Also, hull and superstructure mouldings up to $30 \mathrm{~m}$ long have been produced using VARTM. A schematic of the VARTM technique is shown in Figure 2.

\subsubsection{Pultrusion Method}

In this method, rods of uniform cross-section can be produced in long lengths. Continuous rovings of the reinforcement are impregnated with resin by being passed through a bath of resin. Dry fiber rovings (strands) are continuously pulled through the resin bath and forced through dies to form various cross-section shapes; often the surface is reinforced with cross-ply cloth/veils to prevent matrix cracking (splitting) along the fiber direction. The polymer phase is cured continuously at elevated temperatures (specialized fast curing resins) and sections are automatically cut at required lengths (can produce long sections).

\subsubsection{Filament Winding}

Filament winding is a semi-automatic manufacturing method in which a continuous strand of impregnated fibers, or tape, is wound on to a mandrel. The mandrel can be cylindrical, round or of any shape that does not have a reverse curvature. The technique has the capacity to vary the winding tension, winding angle, or resin content in each layer of reinforcement until the desired thickness or resin content of the composite are obtained with the required strength. Filament wound components include pipe work, pressure vessels, storage tanks and aerospace parts. There are two main methods of filament winding: wet winding and dry winding [28]. 


\subsection{Carbon nanotubes and their composites}

Carbon Nanotubes (CNTs) are known as the stiffest and strongest materials in the world [1-3]. They were discovered in the early 1990 s and researchers started to focus on these new materials due to their considerable physical and mechanical properties. Their remarkable mechanical properties such as high stiffness near 1TPa (1000GPa) which is much bigger than that of diamond (441GPa), and high strength means that they can be deformed to relatively large strains without any permanent deformation or failure. Their high strength in the range of $30 \mathrm{GPa}$, exceptional resilience, low density, fiber-like structure, and high aspect ratio (length/diameter), as well as exceptionally high electrical and thermal conductivity, mean that carbon nanotubes can be used to improve mechanical properties of composite materials as a nanoscale reinforcement or to achieve high electrical properties or some other indirect use of the above mentioned properties [49, 29-33].

The morphology of a carbon nanotube is defined as single sheet of graphite which has a hexagonal structure with covalent bond between carbon atoms and is rolled into a tube in which both ends are capped with a C60 structure (Figure 3) [34, 25]. This type of wrapped sheet of graphite is called a Single Wall Carbon Nanotube (SWCNT) and can be in two different types, armchair and zigzag. The difference between these two types is shown in Figure $4[30,35]$. The density of SWCNT is about $1.33-1.40 \mathrm{~g} / \mathrm{cm}^{3}$, which is almost half the density of aluminum. The mechanical properties of these nanotubes are mentioned above and their electrical behaviors are as below:

The electric current carrying capability is estimated to be $1 * 10^{9} \mathrm{amp} / \mathrm{cm}^{2}$, (copper wires burn out at about $1 * 10^{6} \mathrm{amp} / \mathrm{cm}^{2}$ ). The thermal conductivity is predicted to be $6000 \mathrm{~W} /$ 
$\mathrm{m} \mathrm{K}$ at room temperature which is almost twice the thermal conductivity of diamond $(3320 \mathrm{~W} / \mathrm{m} \mathrm{K})$. They are stable up to $2800{ }^{\circ} \mathrm{C}$ in vacuum and $750{ }^{\circ} \mathrm{C}$ in air, whereas metal wires would typically melt at $600-1000{ }^{\circ} \mathrm{C}$ [33].

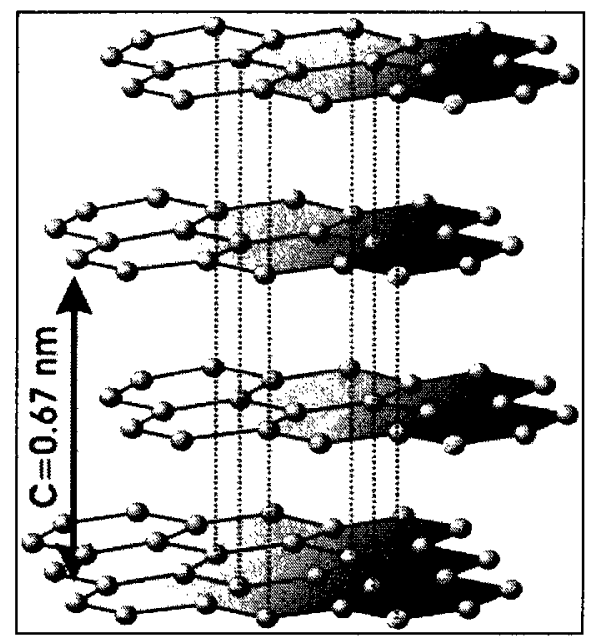

Fig.3) Crystal structure of graphite [34]

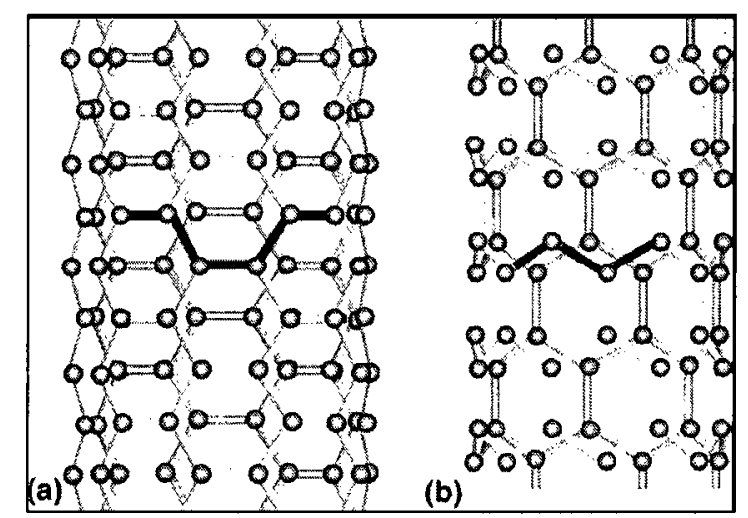

Fig. 4) (a) armchair and (b) zig-zag structures of carbon nanotubes [30]

\subsubsection{SWCNT and MWCNT}

Carbon nanotubes can be in the form of Single Wall (discovered in 1993), Double Wall, and Multi Wall (discovered in 1991) [35-37]. The single wall structure was explained in Figure 4, and a double wall or multiwall, is simply formed of concentric single-walled nanotubes in which the interlayer space is comparable with the interlayer space of 
graphite which is shown in Figure 3. In each concentric layer, like each layer of graphite, the bonding is covalent, but the bonding between the walls of the nanotubes is a Van der Waals interaction, similar to the Van der Waals bonding between graphite layers. Due to this weaker interlayer, (Van der Waals bonding) minimum load transfer would be expected within these layers and consequently in multiwall nanotubes the main load would be carried by the outer layer between the matrix and nanotube in nanocomposites [38].

In CNTs the main variability in morphology has been related mostly to MWCNTs rather than SWCNTs, since they are like concentric SWCNTs which are different in inner and outer diameter. Figure 5 shows a TEM micrograph of a MWCNT in which the outer and inner diameters are clarified [33].

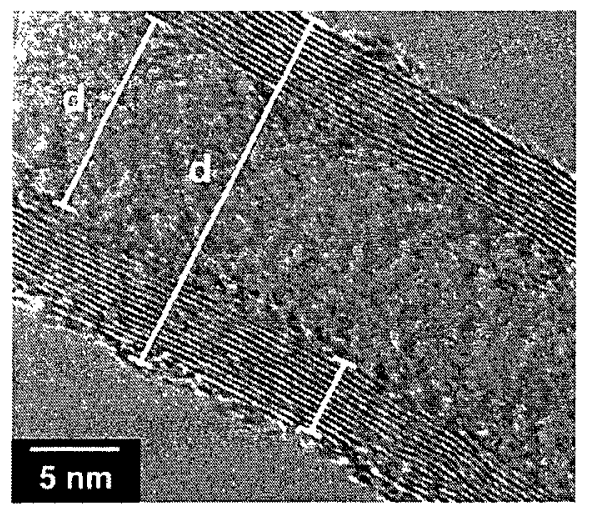

Fig 5) TEM micrograph of a MWCNT, indicating the outer (d) and inner (di) diameter [39]

Due to the difference in wall thickness of MWCNTs compared to SWCNTs, MWCNTs are less effective for elastic modulus improvement since the interlayer bonding is not strong enough for significant load transfer in the nanotube. Therefore, the higher is the wall thickness, the lower would be the stiffness and consequently SWCNTs have the highest stiffness among CNTs. But, the reason that MWCNTs are more popular than 
SWCNTs is due to their combination of mechanical and physical properties and the possibility of their manufacture by various methods and sources, which also results in much lower cost in comparison with single wall carbon nanotubes. Consequently, they are the nanotubes mostly used in novel sciences such as Polymer Nanocomposites [4048].

Figure 6 shows some comparable properties between MWCNT, SWCNT, and CF.
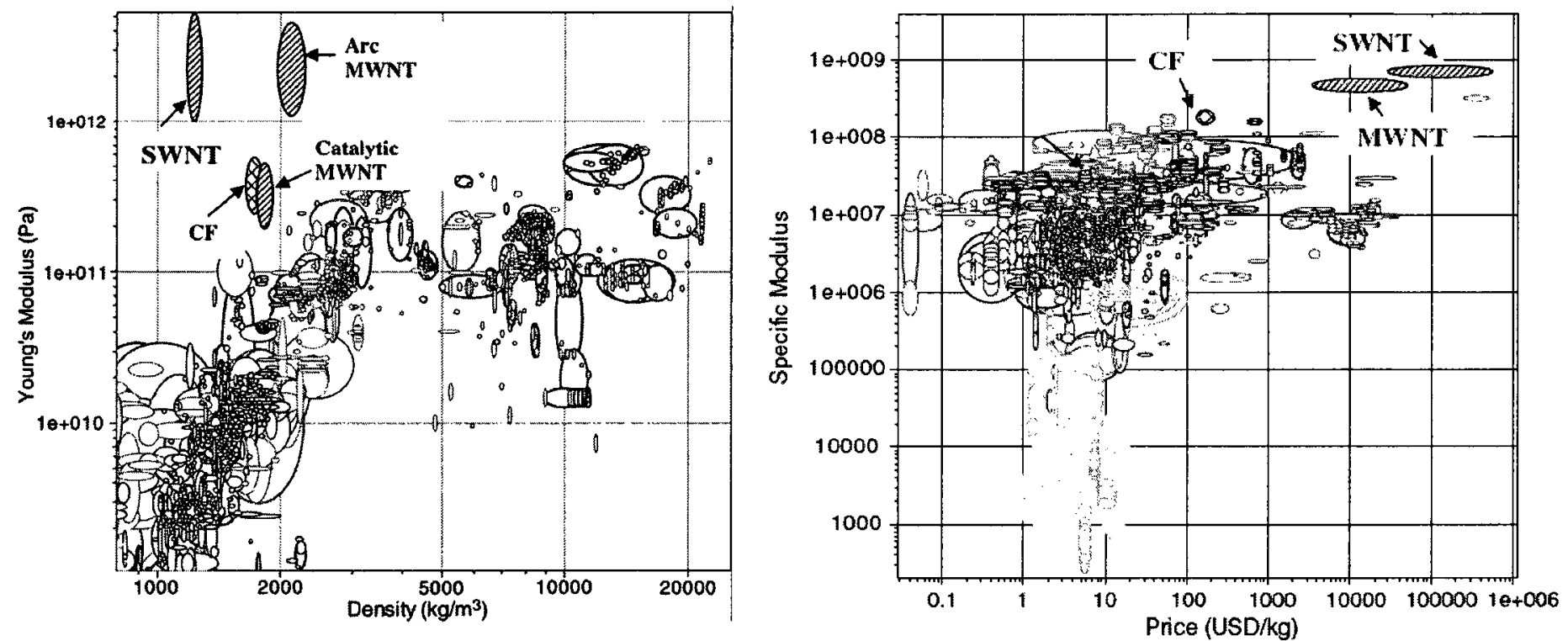

Fig. 6) Modulus vs. density and modulus-to-weight ratio vs. price for different materials [49]

\subsubsection{Processing of carbon nanotubes}

After the discovery of CNTs in the early 1990s, the variety of techniques for their manufacture increased significantly. The different methods for SWCNTs and MWCNTs manufacture can be categorized as below:

1- Arc discharge [50].

2- Laser ablation [51].

3- Gas phase catalytic growth from carbon monoxide [52] 
4- Chemical Vapor Deposition on a substrate (CVD) from hydrocarbons [53].

The first method that resulted in the discovery of nanotubes in the early 1990s was the arc discharging done by lijima (Figure 7).

Since for applications in composites materials, large volumes of nanotubes are needed, and also the purity of these carbon nanotubes is essential, the first methods are not sufficient for processing CNTs for composite applications. The first two methods, arc discharge and laser ablation, are very costly and are also slow processes which are not beneficial for composites. Also, lots of impurities such as catalyst particles, amorphous carbon or non-tubular fullerenes can be found, within CNTs, which are not appropriate for composite purposes, since a purification step would be necessary.

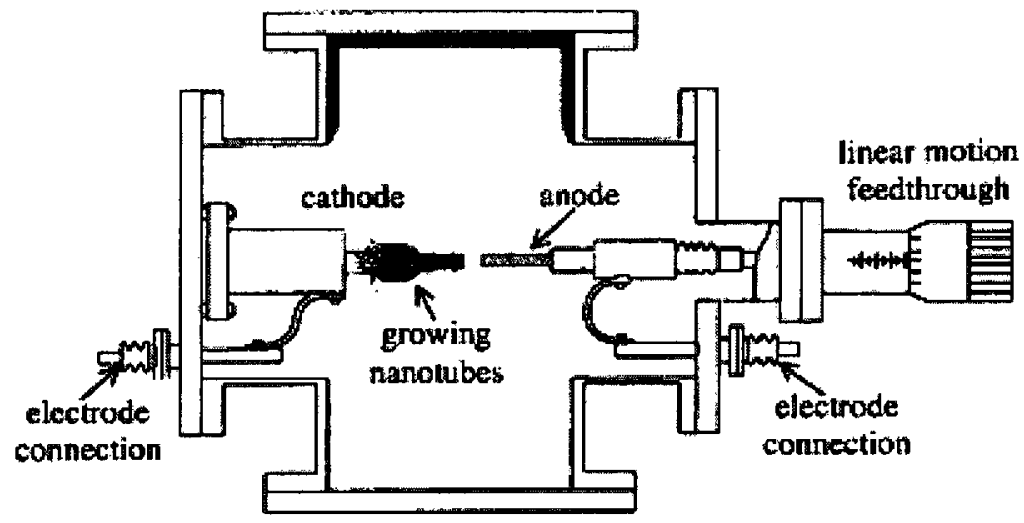

Fig. 7) Schematic arc-discharge technique during the time that nanotubes was first discovered by lijima [35]

It is concluded that gas phase growth such as chemical vapor deposition is the most suitable method to produce nanotubes in large amounts and also in high purity. By having carbon monoxide as the carbon source, it would be feasible to deposit only single wall carbon nanotubes, in a high temperature and pressure atmosphere $\left(1200^{\circ} \mathrm{C}, 10 \mathrm{~atm}\right) \mathrm{but}$ the deposition from hydrocarbon gases would produce both single and multiwall nanotubes with impurities and amorphous carbon, but in a more lenient atmosphere than 
monoxide gas $\left(600-700^{\circ} \mathbb{C}\right)$. One of the unique advantages of the CVD technique over gas phase catalytic growth from carbon monoxide, is synthesizing aligned nanotubes and having a control on nanotubes length and diameter, which is due to adjustment of the catalyst layer (such as Nickel) thickness coated on the substrate using plasma, excited by a DC or microwave source CVD (Plasma-Enhanced CVD). This is also 40 times faster than thermal CVD, however conventional CVD is a good choice for producing large quantities of nanotubes rather than PECVD. The straightness, diameter, and length of tubes, which are controlled by changing the growth time and temperature, achieved by this method are shown in Figures 8 and 9.

In the case of plasma-enhanced CVD, ammonia is used as a catalyst gas and acetylene as a carbon source and the required plasma is created by direct current power having highly carbonized tungsten filament assisting the gas combustion [50-54, 30].

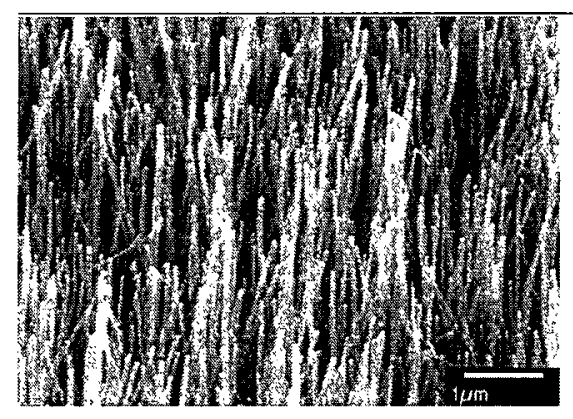

(a)

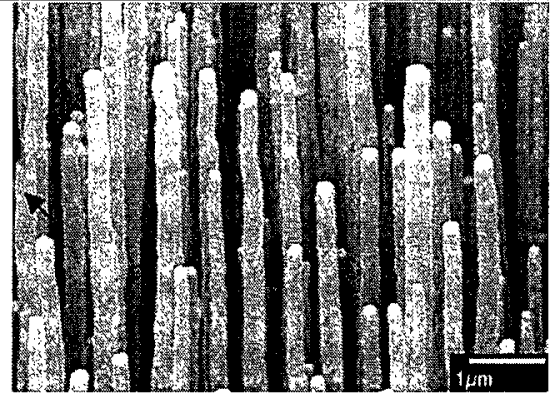

(b)

Fig. 8) SEM Photos depicting the nanotube diameter through Plasma Enhanced CVD (a) 40-50 $\mathrm{nm}$ and (b) 200-300 $\mathrm{nm}$ aligned carbon nanotubes [54]

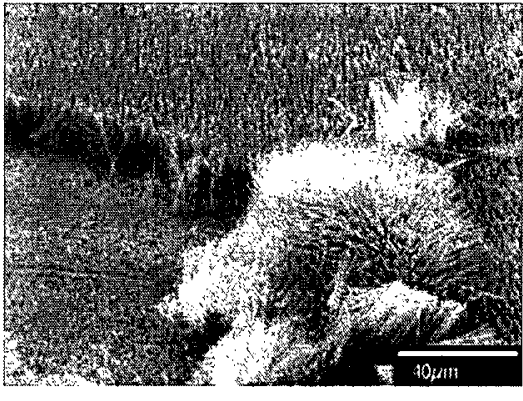

(a)

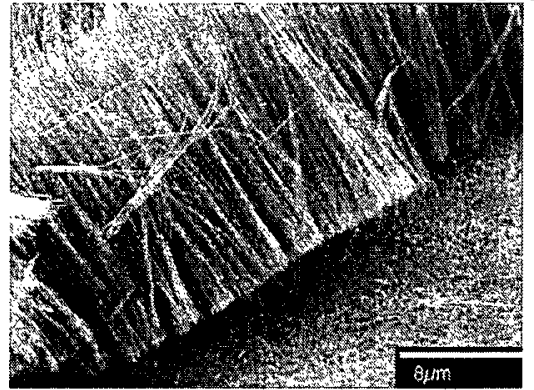

(b)

Fig.9) Straightness of MWCNTs through Plasma Enhanced CVD [54] 


\subsubsection{Carbon nanotubes used in polymer matrix composites and their}

\section{properties}

Due to the exceptional mechanical and other properties of CNTs, they are largely used in composites and especially in polymer matrix composites. Below is a review of different mechanical and electrical behavior of the nanotubes in polymers.

\subsubsection{Mechanical Properties}

\subsection{Stiffness}

The elastic modulus of nanotube composites is greatly dependent on two main factors.

The first is the diameter of the nanotubes. The bigger diameter we have, the lower will be the composite Young's modulus, since if the diameter is higher, the empty volume fraction that it occupies affects the rule of mixtures (formula 1), and thus the elastic modulus of the composite would decrease:

$E_{c}=E_{f} V_{f}+E_{m} V_{m} \quad$ (Formula 1, rule of mixtures)

where $E_{c}, E_{f}$, and $E_{m}$ are respectively; the elastic modulus of the composite, reinforcement, and matrix, and $\mathrm{V}_{\mathrm{f}}$ and $\mathrm{V}_{\mathrm{m}}$ are volume fractions of the reinforcement and matrix.

By increasing the nanotube diameter, it's Young's modulus would approach that of graphite.

The second factor affecting the elastic modulus is whether the CNT is SWCNT or MWCNT, and if it is MWCNT, how many interlayers we have. Since the bonding between the interlayers of the MWCNTs are weak Van der Waals, only the outer layer of 
the nanotube would carry the main load, therefore the higher is the amount of layers, the lower would be the stiffness. Consequently, single wall nanotubes have higher stiffness than multiwall nanotubes, but because multi-walled carbon nanotubes can be produced in lower cost than single-walled carbon nanotubes, they are more interesting as multifunctional reinforcement $[39-40,23-24,7]$.

Generally the use of CNTs causes a higher stiffness in the polymer matrix composites by having a high dispersion and good interface between reinforcement and polymer matrix. Figures 10 and 11 show the relation between carbon nanotube content in the polymer matrix composite, and the obtained elastic modulus.

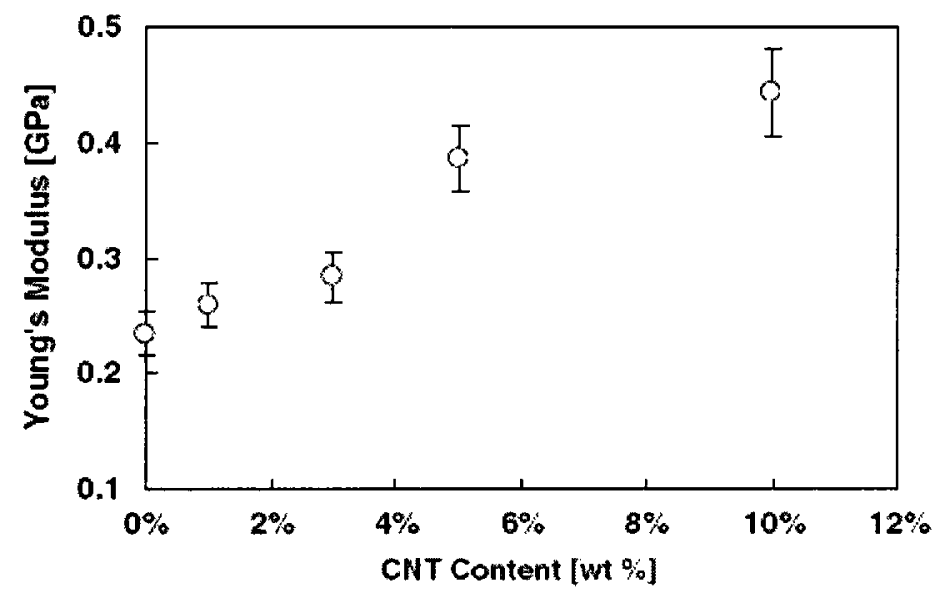

Fig. 10) Stiffness of a polymer composite versus amount of MWNT [55]

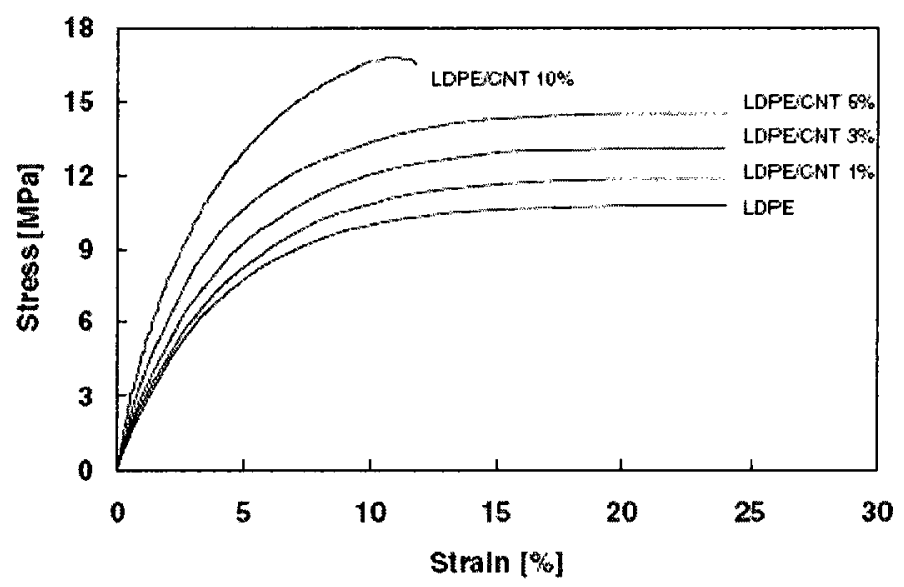

Fig. 11) Mechanical properties of a LDPE/ CNT composite as a function of MWNT content [55]. 


\subsection{Flexural stiffness}

As mentioned, the effect of more carbon tubes as internal layers in MWCNTs results in lower stiffness in tension, since the main load carrying member is the outer layer of the nanotubes, but when the nanotube is under flexural loading, all the layers are going to play an important role, therefore, the more layers and the larger the diameter of the tube, the higher would be the flexural stiffness, flexural strength and the resistance to buckling [56]. Figure 12 shows the exceptional flexural resilience of the nanotube theoretically and experimentally, especially MWCNT, at high strain [9].

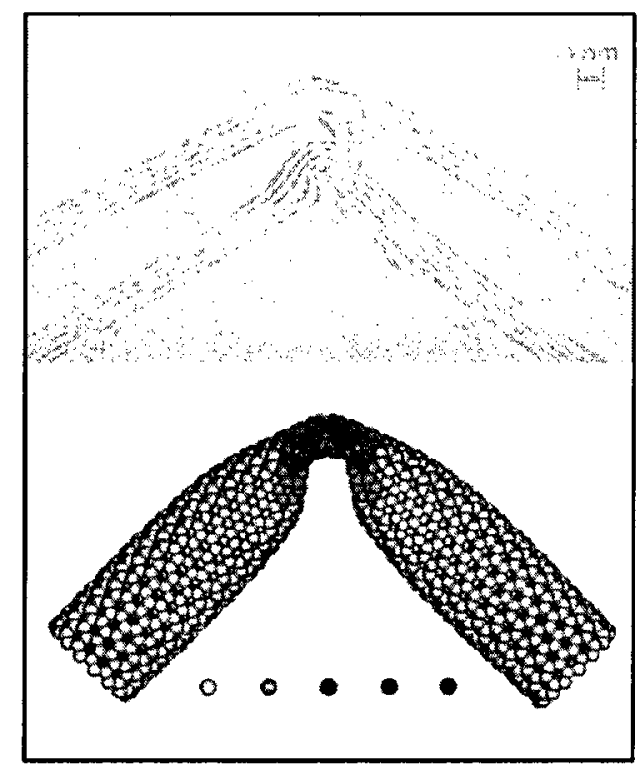

Fig. 12) TEM micrograph compared to computer simulation of a nanotube subjected to buckling [9]

As shown in Figure 13 and Table 1, the flexural strength and stiffness are increased by additional amino-functionalizing of the MWCNT. By amino-functionalizing it was demonstrated that the interface between the reinforcement and the matrix would be significantly increased [57]. 


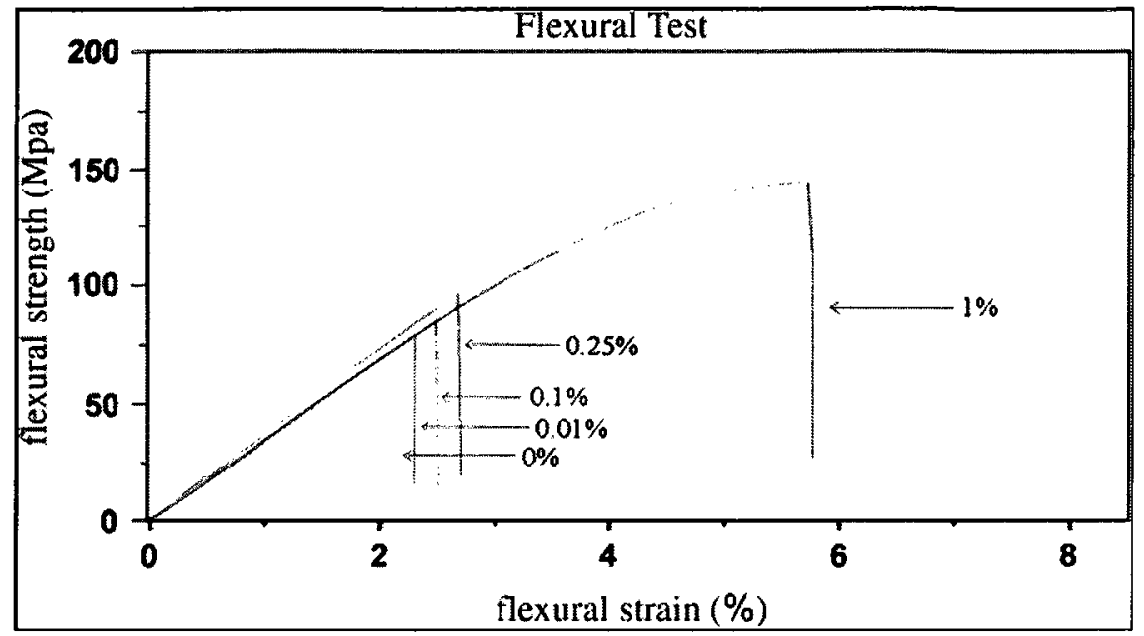

Fig. 13) Flexural stress-strain curve of amino-functionalized composites with different nanotube contents [57]

Table 1) Flexural modulus and strength for different amounts of aminofunctionalized MWCNT [57]

\begin{tabular}{|lll|}
\hline \multicolumn{3}{l|}{ Results of flexural test of amino-functionalized composites } \\
\hline Amino-functionatized & Flexural modulus & Flexurat strength \\
MWNTs w\% & (GPa) & (MPa) \\
\hline 0 & 2.85 & 71.6 \\
0.01 & 2.96 & 80.1 \\
0.1 & 3.06 & 84.1 \\
0.25 & 3.39 & 90.4 \\
1 & 2.80 & 144.3 \\
\hline
\end{tabular}

\subsubsection{Physical properties:}

Here we mostly discuss the exceptional electrical and thermal properties of the nanotubes. The comparison of electrical resistance and thermal conductivity for nanotubes and some other materials are shown in Figure 14 (bulk metallic materials $(\mathrm{Cu}$, $\mathrm{Al}, \mathrm{Mg}$, brass, bronze, and $\mathrm{Ti}$ ) as well as pitch carbon fibers (ranging from $\mathrm{P}-25$ to $\mathrm{P}-$ 140), PAN carbon fibers (T-300), and highly oriented pyrolytic graphite (HOPG), and for SWCNTs - shown as the rectangular area) [58-61]. 


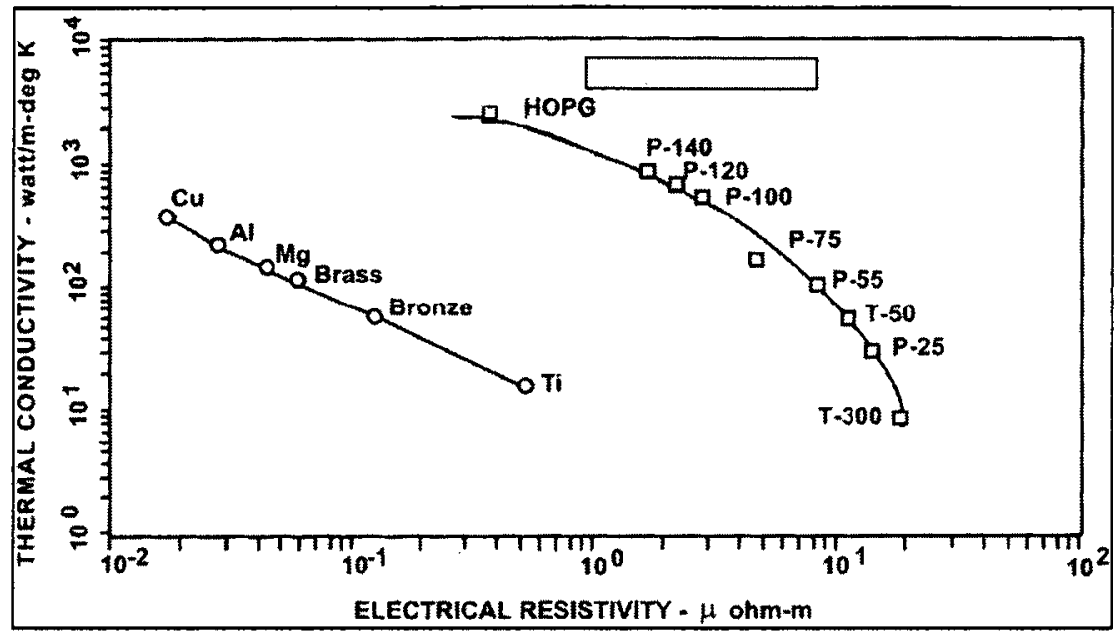

Fig. 14) Electrical resistance and thermal conductivity of some metallic, carbon products and nanotubes [58-61]

In other research, following ASTM D257 [62], the DC volume resistance has been measured for epoxy-nanotube composite samples (the measurements were performed with a highly sensitive sourcemeter, Keithly 6430 Sub Femtoamp Remote Sourcemeter). Also, a flash diffusivity technique was used to measure the thermal conductivity of the composites at $25^{\circ} \mathrm{C}$. Regarding the thermal conductivity measurements, a graphite coat was applied to the samples prior to measurements [23].

Figure 15 shows the results of thermal conductivity vs. different CNT loadings from these measurements.

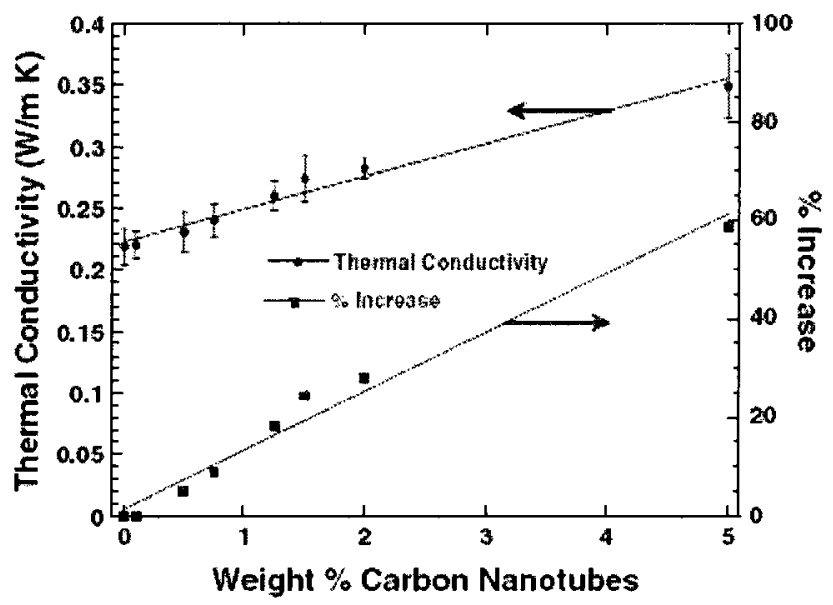

Fig. 15) Effect of carbon nanotubes on thermal conductivity [23] 
As shown in Figure 15, in epoxy/carbon nanotube composites the volume resistance decreases by having more weight fraction of nanotubes.

Another way to investigate the effect of the carbon nanotubes on electrical and thermal conductivity is measuring the electrical conductivity in the aligned direction of the nanotubes and perpendicular to their direction, where the values along the nanotubes are expected to be higher. Figure 16 shows the effect of the alignment of the carbon nanotubes on the volume conductivity in a composite.

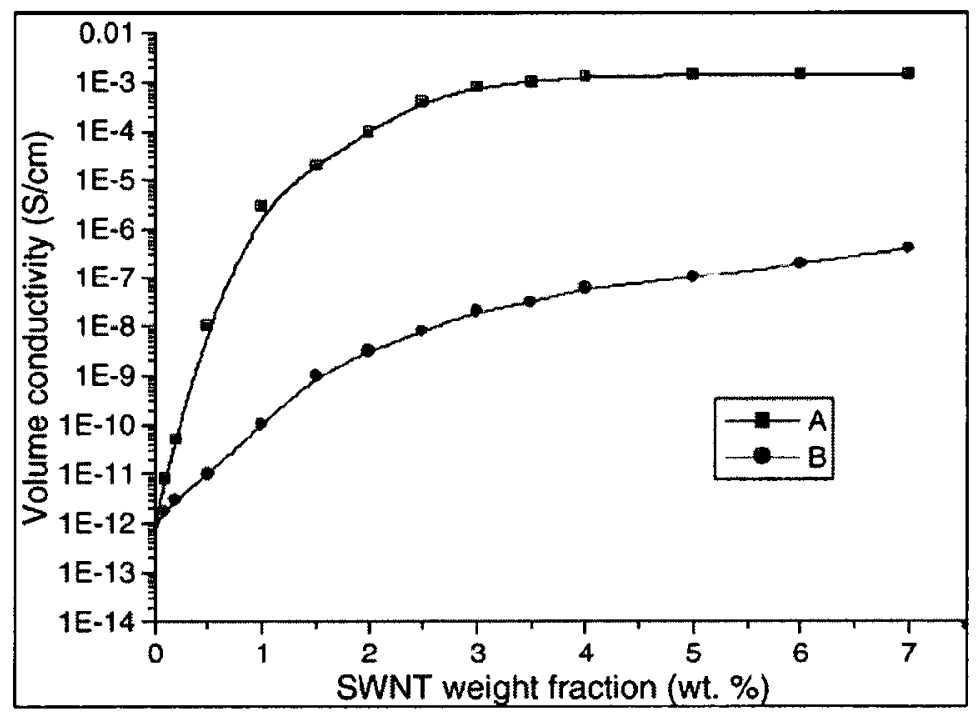

Fig. 16) Conductivity results (a) along the SWNT alignment and (b) perpendicular as a function of SWNT weight fraction of PMMA/SWNT film [63]

\subsubsection{Processing of carbon nanotube polymer composites}

The two most important processing parameters in carbon nanotubes polymer composites are the degree of dispersion of the nanotubes within the polymer, and the interface between the nanotubes and the polymer, which is related to the wetting and adhesion. For instance, by improving the dispersion and the interface bonding in nanotube epoxy 
composites, the elastic modulus can be improved by $30 \%$ [57, 63]. More details of these two important issues are discussed below.

\subsubsection{Dispersion of nanotubes in the matrix}

As mentioned, uniform dispersion (and sometimes orientation) within the matrix are very necessary to achieve proper mechanical and/or physical properties. The agglomeration of carbon nanotubes is mostly formed due to Van der Waals interaction between tubes and causes a reduction in the measured properties compared to those expected theoretically. Therefore, nanotubes that are partially bonded together and are not well bonded to the matrix, reduce the performance of the whole composite. Especially for MWCNTs, it is very difficult to disperse them uniformly in the polymers due to the high amount of Van der Waals interactions between the tubes that can cause agglomeration [64]. Due to various strategies, dispersed nanotube reinforced composites can be achieved nowadays by various methods [65]. For nanotubes manufactured by CVD-growth (the mostly-used nanotubes for composites), agglomeration is significant, since the entanglement of the tubes occurs during their growth. One of the usual ways to disperse these nanotubes in the epoxy matrix is repeated stirring at $2000 \mathrm{rpm}$ before and after adding the curing agent [66]. For all other nanotube types, the usual amount of nanotubes added to the matrix is almost $1 \mathrm{wt} \%$ : in this case the method used for the dispersion, is usually sonication for 5 minutes using a high power sonic tip, followed by another 2 hours of mild sonication, and finally another high power sonication for 5 minutes [67].

For thermoset polymer composites reinforced with nanotubes, the most used approaches are high speed mixing, high energy sonication, and functionalization of nanotubes within 
the thermoset polymer. Also, for thermoplastic composites (for which viscosity decreases with increasing temperature) solvent-assisted dispersion while melting the thermoplastic, is one of the most used dispersing techniques [68-72]. For thermoset polymer composites, calendering (three-roll mill) is one of the new dispersing methods used for nanotubes. Figure 17 shows a schematic of a calendering dispersing machine.

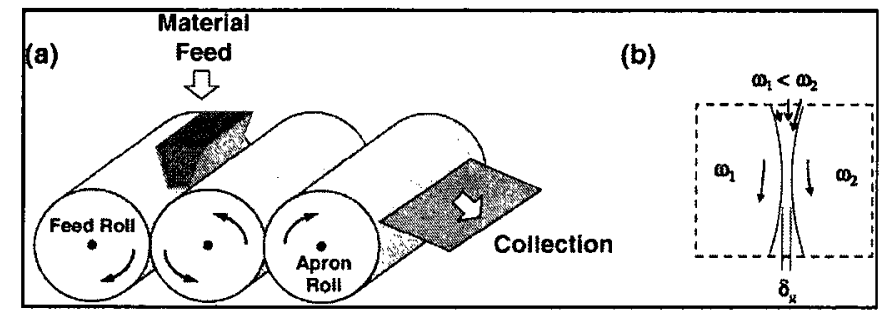

Fig. 17) Schematic of a three-roll mill and high shear between the rolls and the material [23]

Generally the most used methods for nanotube dispersion in varous thermoset polymers are explained below:

\section{Stirring.}

Stirring is used to disperse different particles such as nanotubes in low viscosity systems. The dispersion can be controlled by the mixing speed. Stirring can be used for MWCNTs in polymer resins to achieve a good dispersion. This method is much better for SWCNTs and DWCNTs than MWCNTs, though they tend to re-agglomerate after mixing [73].

\section{Sonication.}

Although a high energy exists in ultrasonic devices, the shear force portion is very low. Consequently, ultrasonic devices are more suitable for low viscosity polymer resins and of course at low volume fractions. On the other hand, the energy produced in this method can cause some damage in CNTs, such as reduction in overall aspect ratio [43]. The best way of producing CNT-polymer composites is dispersing them by the sonication 
technique in the presence of a proper solvent such as acetone. By using a solvent, nanotubes start to be separated from agglomerates. Then, the suspension can be mixed with the resin after which the solvent can be heated up and evaporated [73].

\section{Calendering.}

This method has become a very promising way to disperse carbon nanotubes or other nano-particles with polymer resins. Basically, calendering was established to disperse micro-particles such as color pigments or lacquers, in different polymer resins. In addition to the dispersion advantage of this method, the other benefit of using the calendering technique is for manufacturing large volumes of nanocomposites. The gap between the rolls can be reduced down to $5 \mu \mathrm{m}$ and speeds of 20,60 , and $180 \mathrm{rpm}$, for the first, second, and third roll, respectively can be utilized. Also, since the manufacturing time through this technique is in the range of minutes, calendering is one of the most rapid methods [73].

Figure 18 shows transmission electron micrographs of MWCNT dispersed in epoxy by sonication and calendering methods.
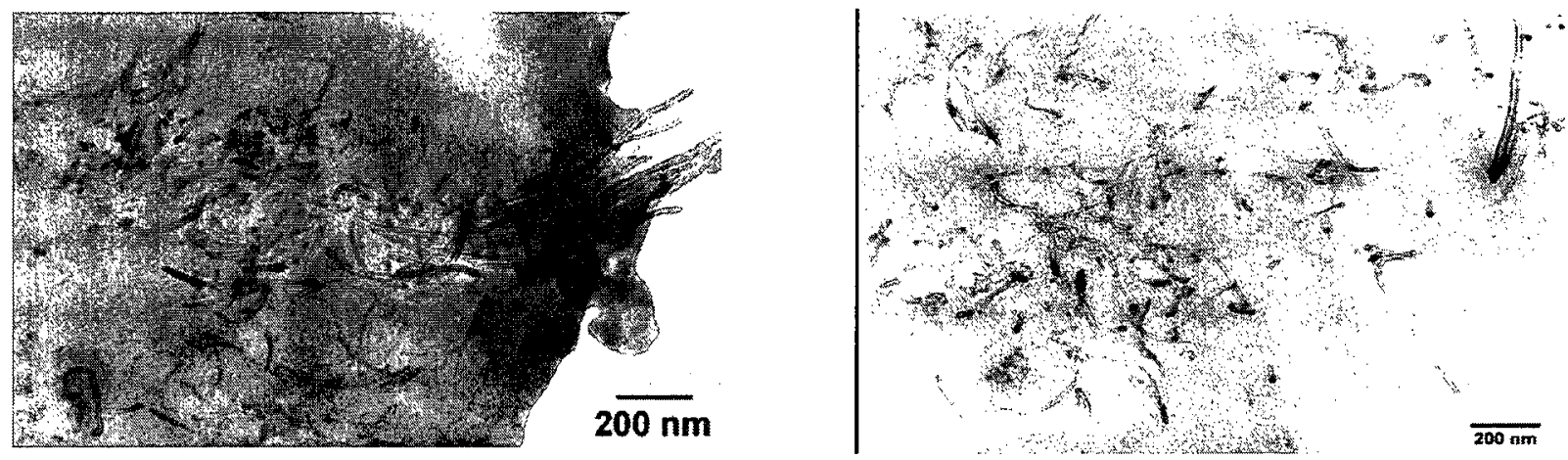

Fig. 18) Transmission electron microscopy for (a) sonication of MWCNT in epoxy and (b) calendering of MWCNT in epoxy [73] 


\subsubsection{Interface between the nanotubes and the matrix}

To increase the efficiency of load transfer or physical properties like conductivity between the reinforcement and the matrix, a strong interface is needed. Interface strength is also defined by the type of bonds between the matrix and reinforcements. In polymer matrix composites covalent bonds are the strongest bonds between these two ingredients in contrast to the weak Van der Waals bond. To achieve covalent bonds, much effort is devoted to functionalization of CNTs to facilitate covalent bonding instead of weak secondary bonding [65].

Generally for maximizing the contact area, carbon nanotubes need to be separated from the bundles and uniformly spread within the polymer matrix however at the same time, the interface should be strong enough to achieve the main aims of the composite. As mentioned earlier, the higher shear strength that can be achieved by covalent bonding across the interface is unlikely to occur just by dispersing the reinforcement within the polymer matrix and some modification to the CNT surface is often performed. A complete review of chemical modification of carbon nanotubes to get strong chemical bonds between the two ingredients in composite has been made by Sinnot [74-75].

In Figure 19, a schematic of the functionalization process of CNTs shows the cycle from the oxidation to the composite manufacturing. An improved matrix/nanotube interaction can be achieved via an equivalent bonding between the functional groups on the nanotube surfaces and the epoxy. In the first step the nanotubes are oxidized (1) then functionalized (2) and finally processed into nanocomposites (3) [76]. 


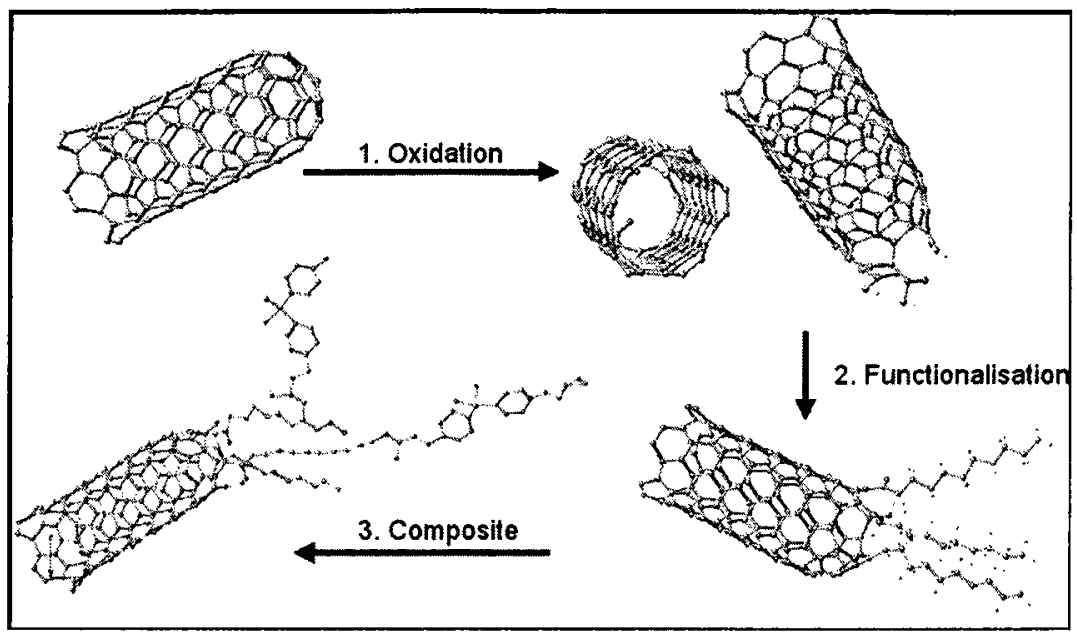

Fig. 19) Functionalization schematic for a carbon nanotube [76]

One functionalization that has been done by Liu on SWCNT, involves sonication of purified single wall carbon nanotubes in a mixture of concentrated sulfuric and nitric acid which results in carboxylic acid (-COOH) groups covalently attached to the CNTs [77]. Another way of functionalization (Sen and Hamon) is ester functionalization on SWCNT giving SWCNT-COO $(\mathrm{CH} 2) 11 \mathrm{CH} 3$ in polyurethane matrix which causes a good interaction with the matrix [78-79]. Figure 20 shows a modification process of MWCNT/ polymer composites in which carboxylic acid is attached firstly to the tube surface and subsequently connected with di-glycidyl ether of bisphenol-A-based epoxide resin [80]. Functionalizing the nanotubes with amino acids by heating oxidized nanotubes with excess triethylenatetramine is another way of surface modification which was done by Gojny for epoxy-based matrices $[76,81]$. 


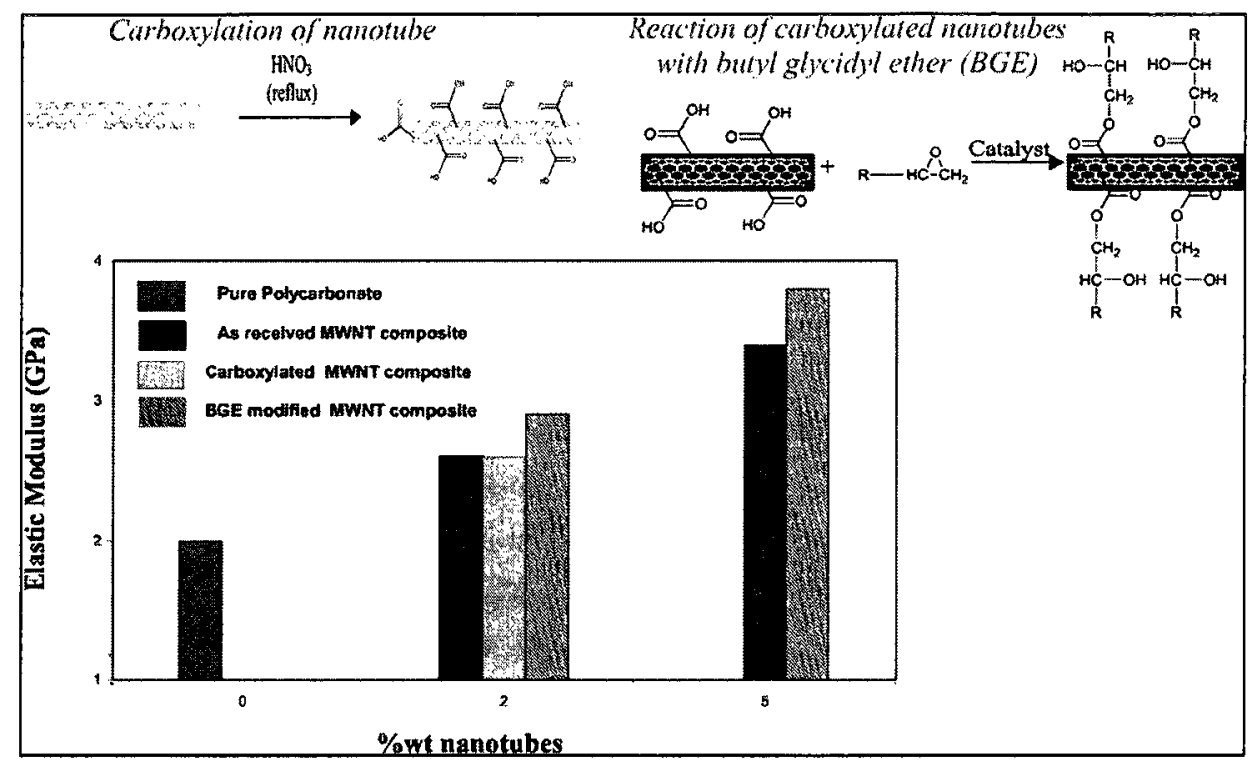

Fig. 20) Elastic modulus dependency on interface improvement [80]

Figure 21 shows the schematic of this functionalization procedure [57]. Another way for functionalizing carbon nanotubes is electron irradiation [82].

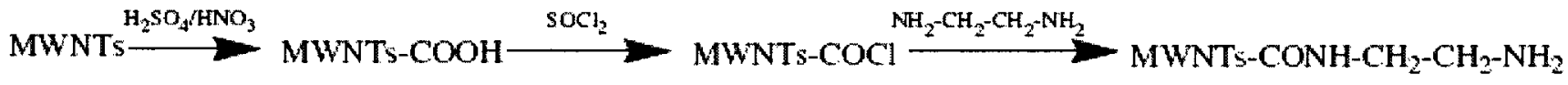

Fig. 21) Schematic procedure of amino functionalization [57]

The effect of amino-functionalized CNTs on mechanical properties of a carbon nanotube composite is shown in Figure 22. The differences show how effective is the chemical bond between the matrix and the reinforcement [83].

Silanization reaction is another newly developed method to chemically functionalize carbon nanotubes for polymer matrix composites [80]. 

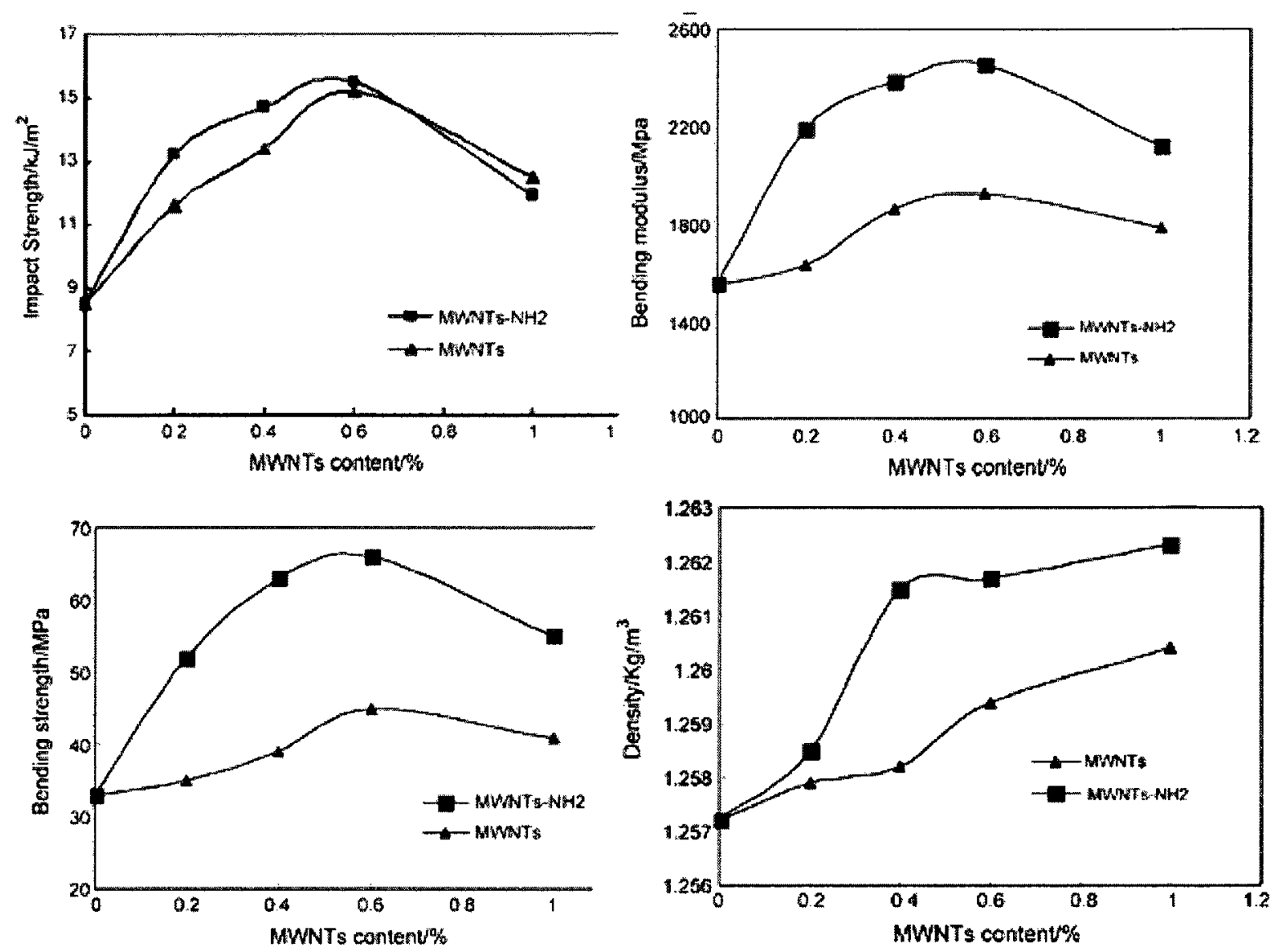

Fig. 22) Different properties in epoxy matrix composites by using MWCNT and amino functionalized MWCNT in different amounts [84]

\subsubsection{Carbon nanotubes as a percolation network of sensors}

Recently, carbon nanotubes (CNTs) have been utilized as strain sensors by embedding them in polymer matrix composites (PMCs) and monitoring damage and subsequently failure by direct measurement of current in the composite. This is due to their exceptionally high electrical conductivity and the percolation network which they form [10-13]. Damage monitoring using electrical techniques is a long term interest of researchers which started with the use of carbon fibers as the conductive reinforcement, 
so that fracture of the fibers would result in a change of electrical resistance [14-16]. Since matrix-dominated fracture mechanisms can not be monitored utilizing conductive fibers, and this also places a restriction on using only conductive carbon fibers, using a dispersed conductive reinforcement in the matrix has become the main consideration for damage monitoring. The high aspect ratio of carbon nanotubes has been used to form a conductive percolating network through the polymer matrix composite at relatively low CNTs concentrations: a network is highly sensitive to the onset of damage in matrixdominated fractures [88]. This exceptional sensitivity causes an increase in electrical resistance along embedded carbon nanotubes in PMCs for even a low mechanical load such as an applied tensile stress [17]. In comparison with resistance-type strain gauges, which is a conventional way for measuring strain, using conductive CNTs does not have the same limitations, such as measuring strain at only specific locations and a lack of versatility and flexibility [18]. In Thostenson and Chou's study, unidirectional glassfiber/epoxy composites with dispersed multiwall carbon nanotubes within the epoxy have been utilized to evaluate the damage and percolation threshold in tensile and flexural tests as an in situ sensor.

These tests have been carried out for two different types of specimens.

I) A five-ply unidirectional composite with a cut in the middle of the center ply of the laminate to impose an artificial defect and achieve ply delamination.

II) A $[0 / 90]_{s}$ cross-ply specimen to investigate transverse microcracks.

Figure 23 shows the results of tensile tests for these two types and a linear increase of resistance change during the initial load, due to initial micro cracks and initial tension. Then a sharp increase of resistance change occurs at ply delamination launch in the 
unidirectional specimen and by micro-crack formation in the $90^{\circ}$ plies. Propagation of delamination while load increase, causes a large increase of resistance change. This is due to disconnection of the nanotube percolation network.
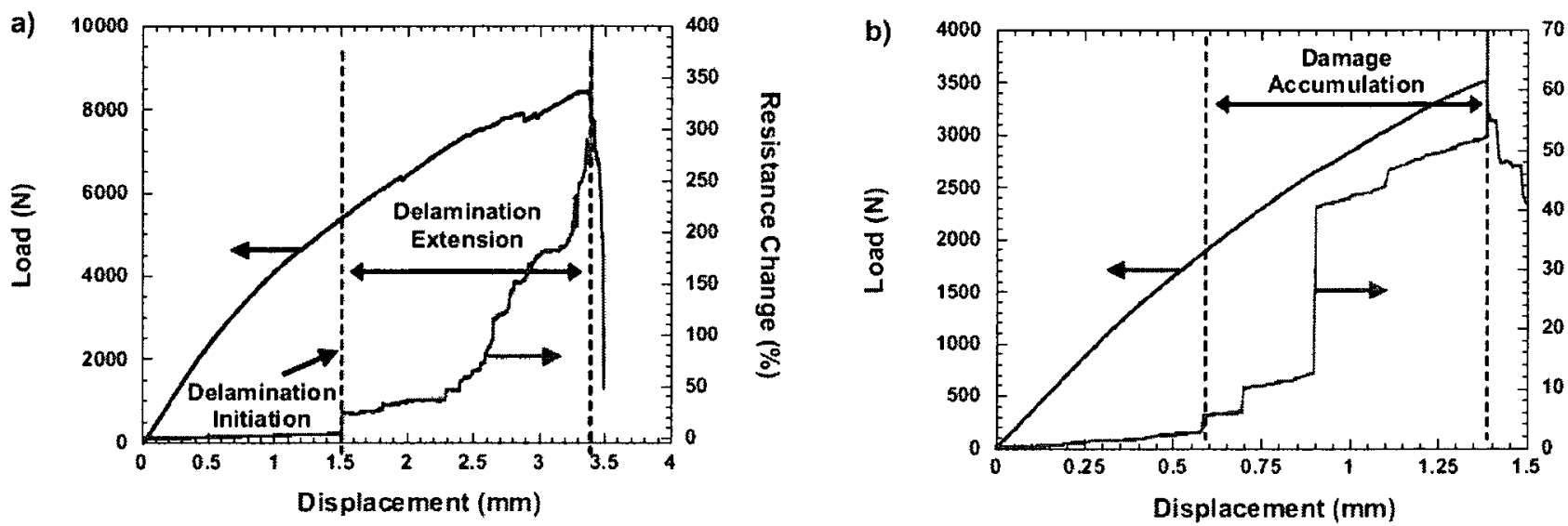

Fig. 23) Load-displacement and resistance change for (a) unidirectional specimen with a cut in center ply for delamination launch, and (b) [0/90] s cross-ply specimen [88]

Also, flexural tests have been conducted in three-point bending to investigate the capability of nanotube percolation network sensors to monitor the through-thickness fracture of plies in unidirectional specimens with two span-to-thickness ratios, to achieve two different types of fracture (Figure 24).

a)

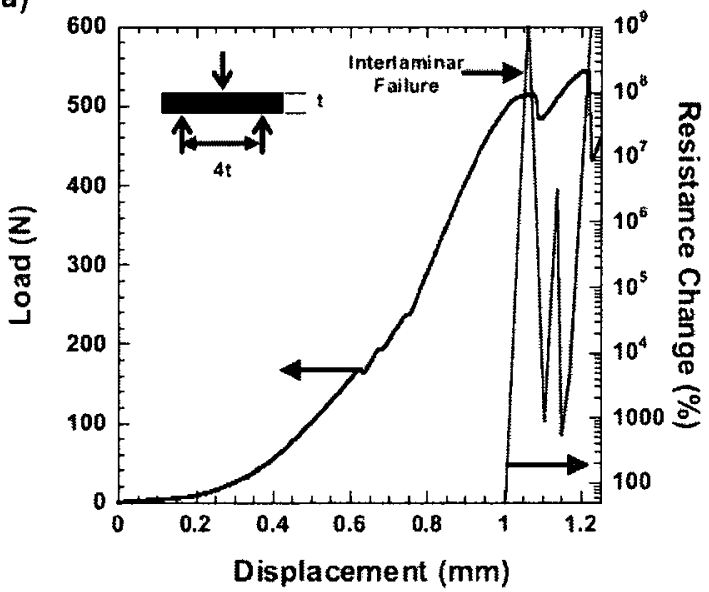

b)

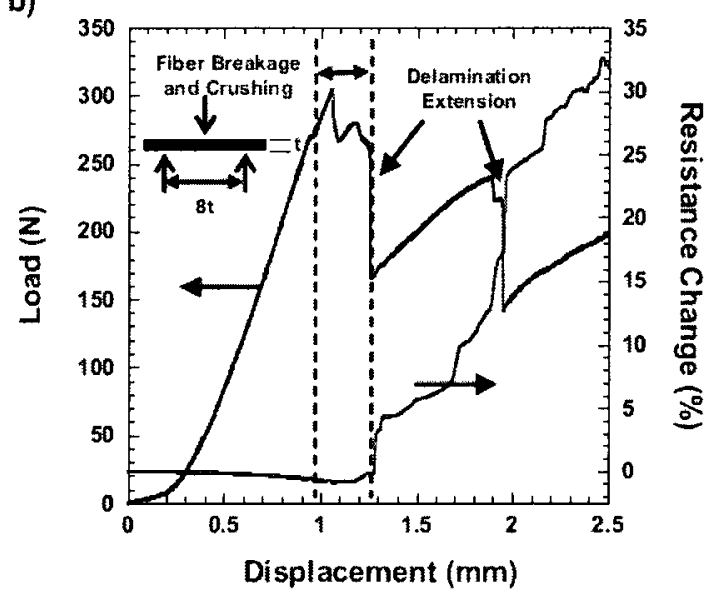

Fig. 24) Three-points bend results for span-to-thickness ration of (a) 4 and (b) 8 [10]. 
On initial loading, a decrease in resistance is observed due to deformation of the beam in tension and compression causing new electrical contacts. A sharp increasing of resistance occurs in the shorter span as a result of complete delamination and in the longer span, resistance is increasing at a higher rate, but not as sharply, due to matrix cracking and their accumulation to cause local delamination [88].

When considering non-static loads such as fatigue, which is one of the most crucial factors for failure in many structural components, the long term durability of polymer matrix composites is highly dependent on the polymer matrix and the fiber-matrix interface [19]. In other words, fatigue life and damage tolerance are strongly affected by matrix cracks, such as microcracks appearing between fiber reinforcements, or ply delamination between layers [10]. Carbon nanotubes as an additive can play a significant role as distributed sensors to monitor this damage and to determine the extent and defect propagation created by cyclic loads $[20,21]$. In Zhang's and colleague's work, carbon nanotubes dispersed in epoxy within twill-weaved graphite fiber cloth were used to detect fatigue crack growth by using compact tension samples with a notch-shaped pre-crack in which the applied fatigue load was perpendicular to the pre-crack. Figure 25 shows the crack growth in cyclic loading, as well as the average resistance change as a function of crack growth. This change of resistance has also been calculated theoretically by using the classical volume resistance model $(\mathrm{R}=\mathrm{pl} / \mathrm{A})$ and the differential form of that $(\mathrm{dR} / \mathrm{R}=$ dl/l-dA/A [20]. 


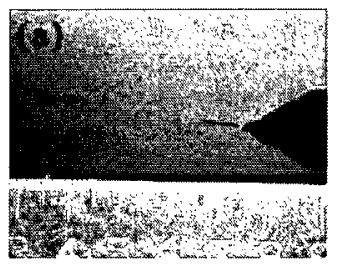

1st cycte

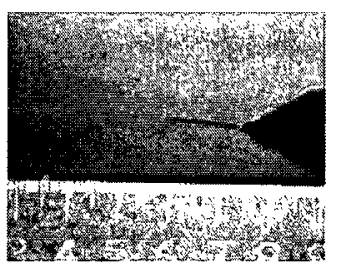

120 th crots

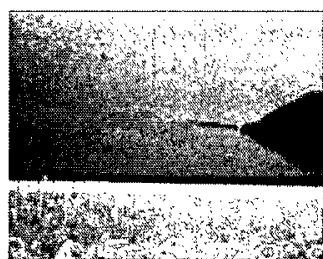

40th cycle

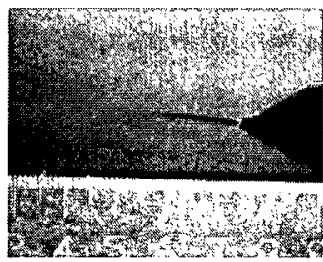

160th cycle

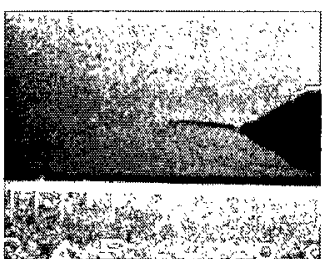

goth cycle

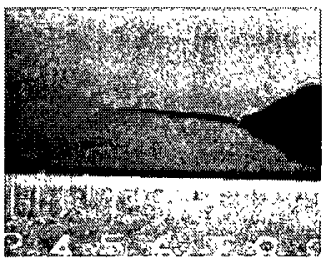

195 th cycle

(b)

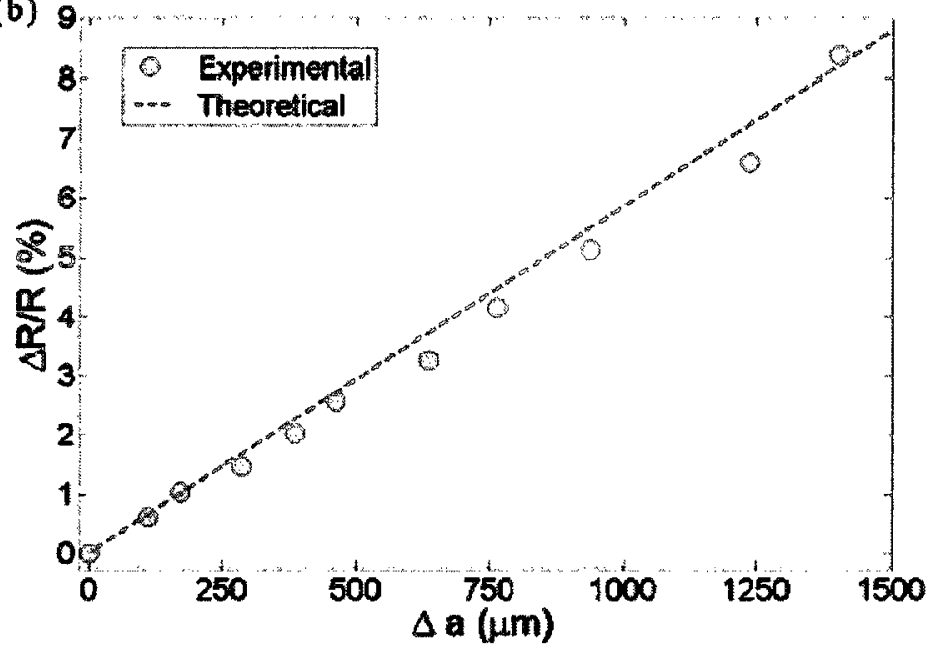

Fig. 25) (a) Detection of fatigue crack growth by monitoring the notch tip, (b) resistance change vs. optically measured crack growth theoretically and experimentally [20].

In another work, PMMA thermoplastic/ MWCNT films have been fabricated by a simple melt-based process (dry blending of polymer powder and MWCNT and hot pressed), and a solvent-based method (dispersion has been done ultrasonically). Surface resistance has been measured for the specimens fabricated via these two methods and the results are shown in Table 2. As a consequence, the results of solution-based manufacturing show lower resistance, which means higher electrical conductivity, which in turn indicates that 
nanotubes are better dispersed using ultrasonic rather than dry-blending. Tensile testing was carried out for the aforementioned samples.

Table 2) Surface resistance of PMMA/MWCNT fabricated by two methods with different nanotube weight fractions [21]

Surface resistivity $\rho$ ( $\Omega /$ square) of PMMN/MWNT films at different MWNT loadings

\begin{tabular}{|c|c|c|c|c|c|c|c|c|}
\hline MWNT wt.\% & $1 \mathrm{wr} \%$ & 2 wt $\%$ & 3 wt. $\%$ & $4 w \mathrm{t} \%$ & $5 w t \%$ & 6 wL $\%$ & $8 w L \%$ & 10 wto \\
\hline Dry blended & $N / \Lambda$ & $210^{9}$ & $\mathrm{~N} / \mathrm{A}$ & $\sim 10^{8}$ & $\mathrm{~N} / \mathrm{A}$ & $\sim 5.7 \times 10^{6}$ & $\sim 4.4 \times 10^{6}$ & $\sim 1.1 \times 10^{6}$ \\
\hline Solution based & $\sim 1.6 \times 10^{7}$ & $N / A$ & $\sim 68 \times 10^{3}$ & $\mathrm{~N} / \mathrm{\Lambda}$ & $-1.6 \times 10^{3}$ & $\sim 9.7 \times 10^{2}$ & $29.3 \times 10^{2}$ & $\sim 7.6 \times 10^{2}$ \\
\hline
\end{tabular}

In the nanotube percolation network, it is apparent that the achieved conductivity is a consequence of the number of contacts between tubes and the distance between them [85, 87]. Figure 26 shows the normalized changes in surface resistance of PMMA/MWNT films vs. applied strain for various weight fractions of nanotubes for the two mentioned manufacturing methods. It is apparent that surface resistance increases proportionally with tensile strain. As shown, the slope of the curves is increasing as the MWCNT weight percentage decreases to $1 \mathrm{wt} \%$. This shows higher sensitivity, at lower nanotube amount in this system. In this work, sensitivity factor $(\mathrm{SF}=\Delta \mathrm{R} / \mathrm{R} \varepsilon)$ is calculated in order to identify the sensitivity of different MWCNTs loadings. For the sensitivity factor equation mentioned above, a strain gage was used to measure the strain $(\varepsilon)$. Table 3 and Figure 27 show the sensitivity factor of samples with different nanotubes loading and depict higher electrical sensitivity at lower nanotube content [21]. 

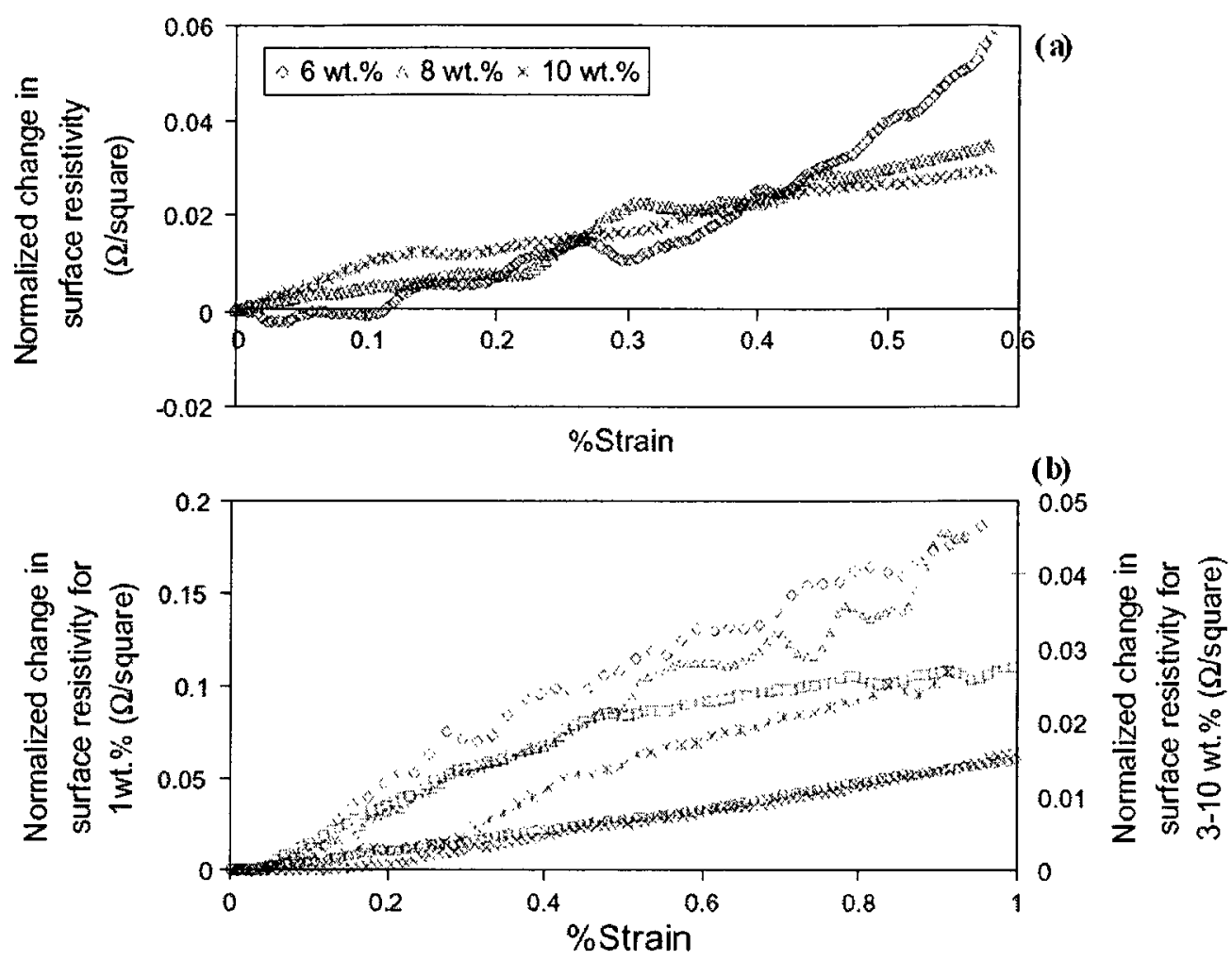

Fig. 26) Normalized change in surface resistance of (a) dry blended and (b) solution cast $P M M A / M W N T$ at various MWNT loadings [21]

Table 3) PMMA/MWNTs sensitivity factors in different $M W N T$ content [21].

Sensitivity factors of PMMAMWNT films at different MWNT concentrations

\begin{tabular}{|c|c|c|c|c|c|c|}
\hline MWNT wt & $1 \mathrm{wt} * / \mathrm{t}$ & $3 \mathrm{wt} \%$ & $5 \mathrm{wt} . \%$ & 6 wt: & 8 wt.\% & $10 \mathrm{wt} \%$ \\
\hline Dry blended & $N / A$ & $\mathrm{~N} / \mathrm{A}$ & $N / \Lambda$ & 8.44 & 7.45 & 5.66 \\
\hline Solution batsed & 15.32 & 4.59 & 4.26 & 3.27 & 1.90 & 1.44 \\
\hline
\end{tabular}

This strain sensing has been repeated for the samples in cyclic tensile loading (over 3-4 cycles until $1 \%$ strain to stay within the elastic region at different nanotube content).

Figure 28 shows these cyclic loadings results with reversible resistance [21]. It can be seen that again at lower content of nanotubes, more sensitivity can be achieved. 


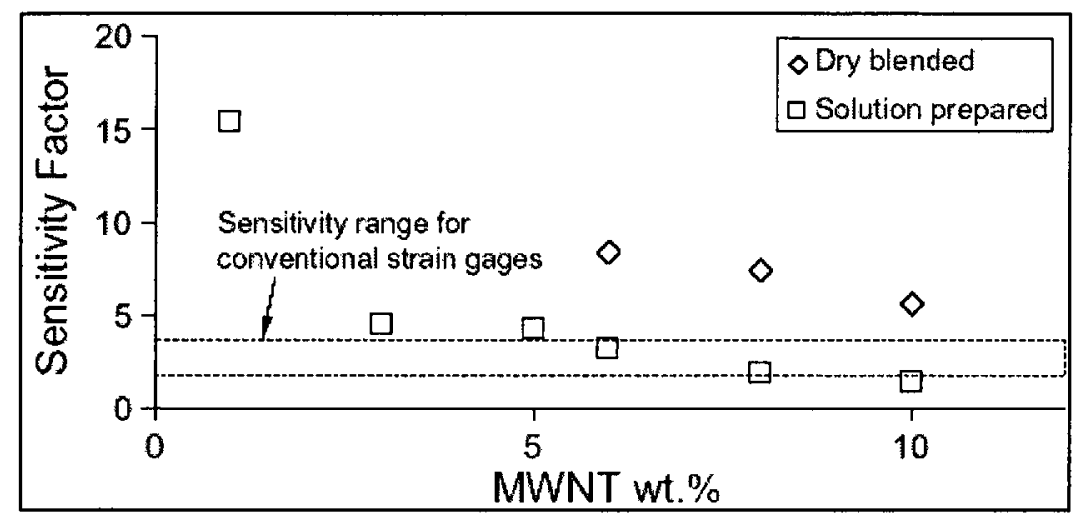

Fig. 27) Sensitivity factors for PMMA/MWNT films [21]

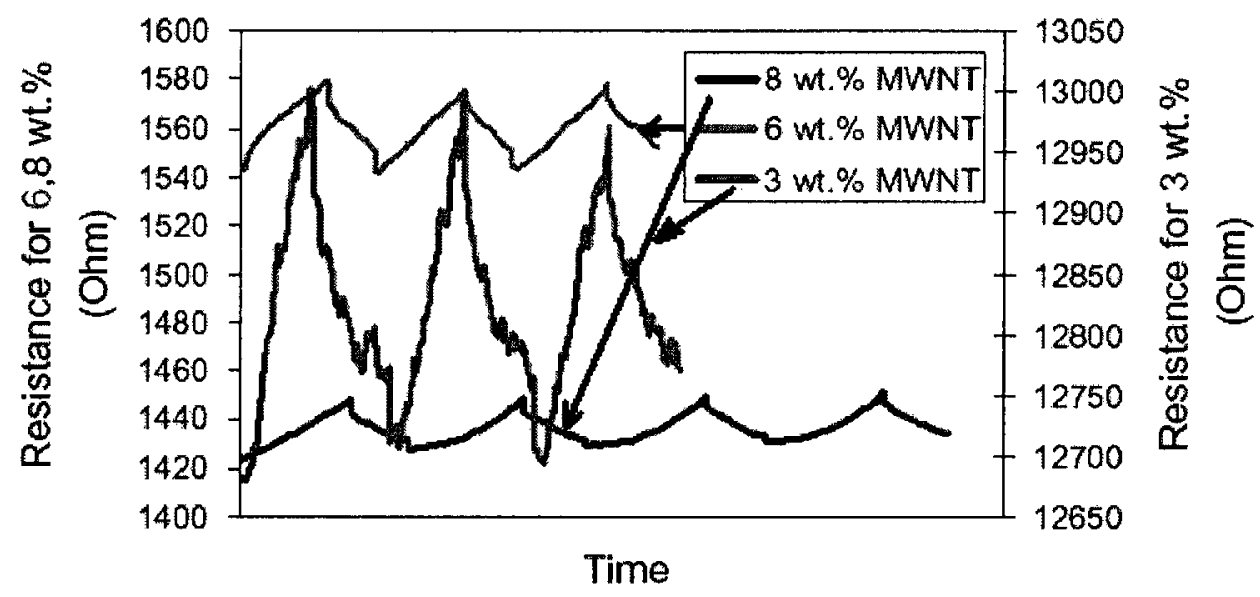

Fig. 28) The results of surface resistance for solution cast samples with different MWNT wt\% under cyclic tensile load [21]

Also according to the stress strain curve of these two types of composites, it is shown in Figure 29 that the dry-blended sample initially has a higher young modulus compared with the solution cast one, while the solution cast has higher tensile strength and ductility. The surface resistance change has also shown higher values for the dry blended films at $10 \mathrm{wt} \%$ of nanotubes [21]. 

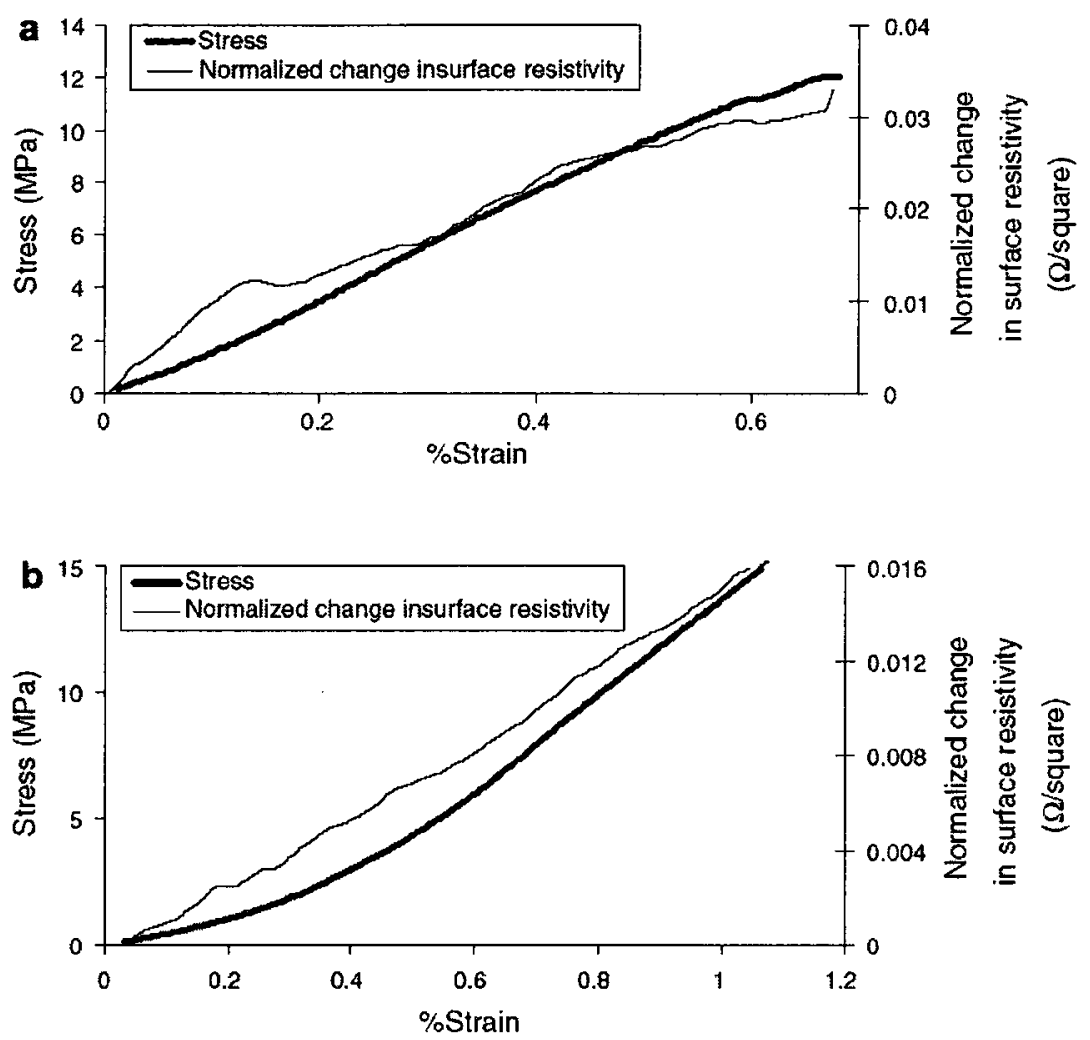

Fig. 29) Stress and resistance change vs. strain for PMMA/MWNT (10wt \%) films manufactured by (a) dry blending and (b) solution cast [21].

The resistance change versus strain (under small strain) for different carbon nanotube loadings in epoxy/CNT composites is investigated in the work of $\mathrm{N}$. Hu et al using a three dimensional statistical resistor network model (Figure 30). Again it can be seen that the lower is the content of nanotubes (close to the percolation threshold), the higher will be the sensitivity of the nanotube network due to the tunneling effect at small strains [89]. The same effect has been investigated by I. Kang et al [90] who show the higher sensitivity of nanotubes at low contents of SWCNTs dispersed in PMMA polymer (Figure 31). 


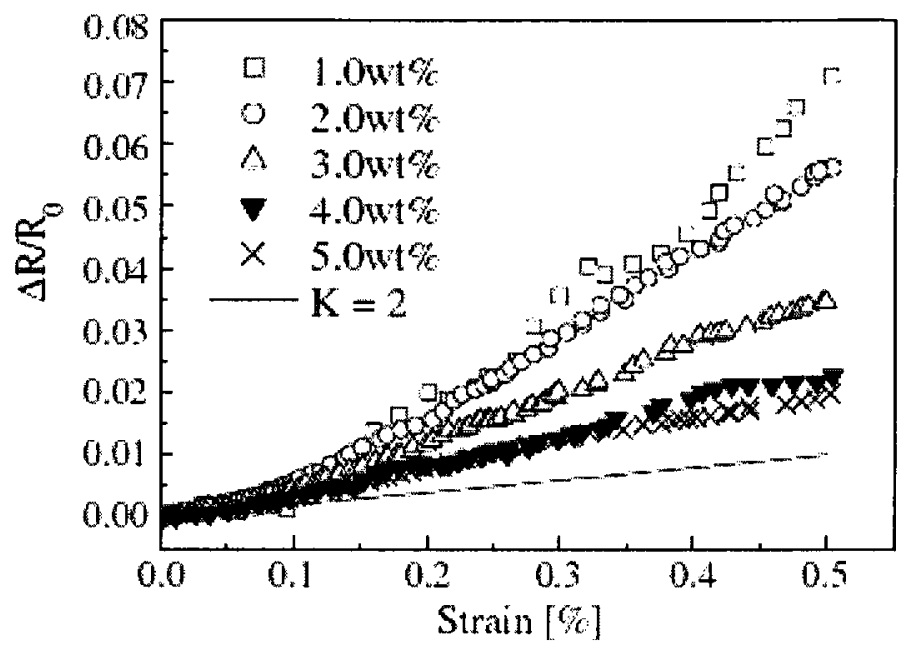

Fig.30) Strain sensing in polymer/CNT nano-composite in different CNT content [89]

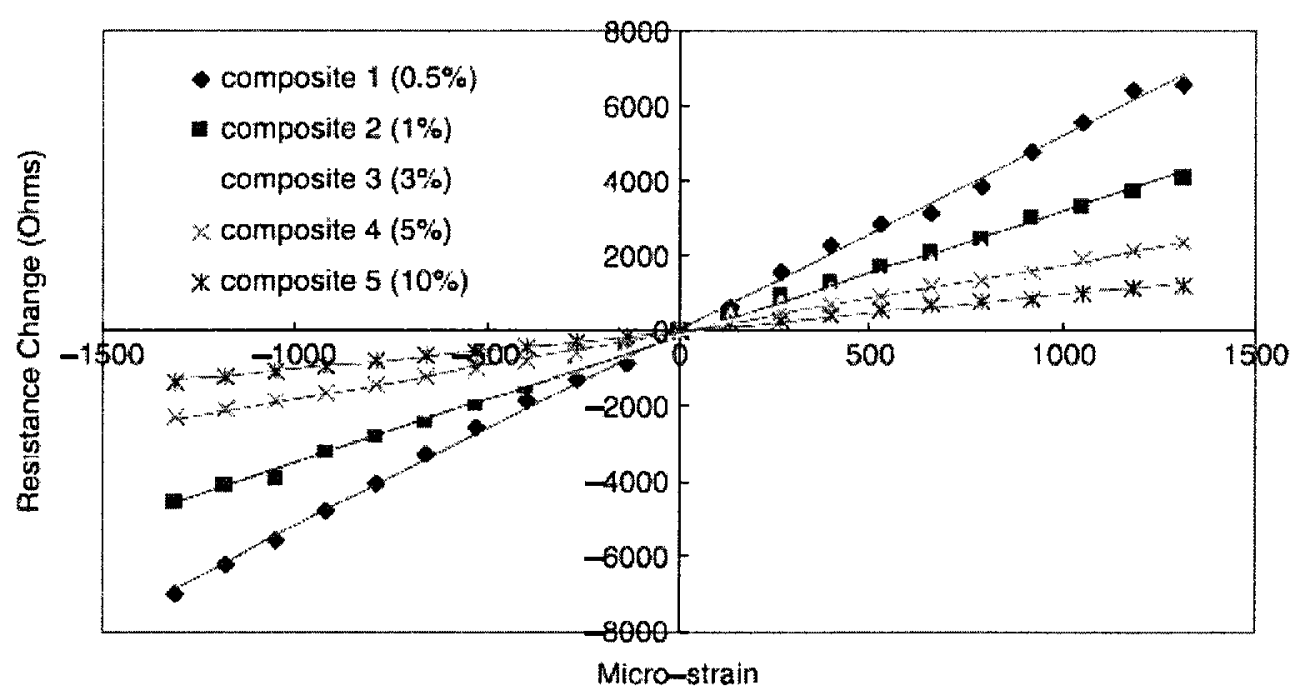

Fig.31) Strain behavior in SWCNT/PMMA composite sensor [90]

In another work, epoxy/glass-fiber/carbon nanotubes were processed to achieve an electrically conductive polymer composite. These composite samples were used to monitor the damage initiation and assess the potential for stress-strain monitoring in 
incremental tensile and fatigue test. The specimens were tested in tensile loading cycles, which were unloaded every 1 cycle.

Figure 32a shows that there is some residual strain after 5 cycles when the sample is unloaded to $0 \mathrm{~N}$. After each cycle, due to the plastic deformation of the matrix and damage such as cracks in the matrix, the residual strain increases. Resistance change also correlates well with increasing tensile load (Figure 32b). Some irreversible resistance change or residual resistance change can be observed after 5 cycles due to the permanent damage mentioned earlier. Figure 33 shows the correlation of residual strain and irreversible resistance change during the test. In this Figure, a very small residual strain (almost $0.05 \%$ ) can be seen at 5 cycles and at the same time the irreversible resistance change shows a value of $0.02 \%$ at the same point. After 11 cycles, it can be seen that a residual strain of $0.52 \%$ has been recorded while for irreversible resistance change the value of $1.4 \%$ has been achieved. This shows that the nanotubes have the capability of following the damage accumulation as well as strain gauge measurements. In this work, the samples were loaded in tensile loading cycles and investigated in a few cycles and residual strain and resistance were measured [22].

In this thesis, crack detection was explored according to different resistance changes in different zones of a sample, while subjected to tensile and fatigue loadings. These results were compared with that of strain gauges to investigate each method's sensitivity to crack detection. 


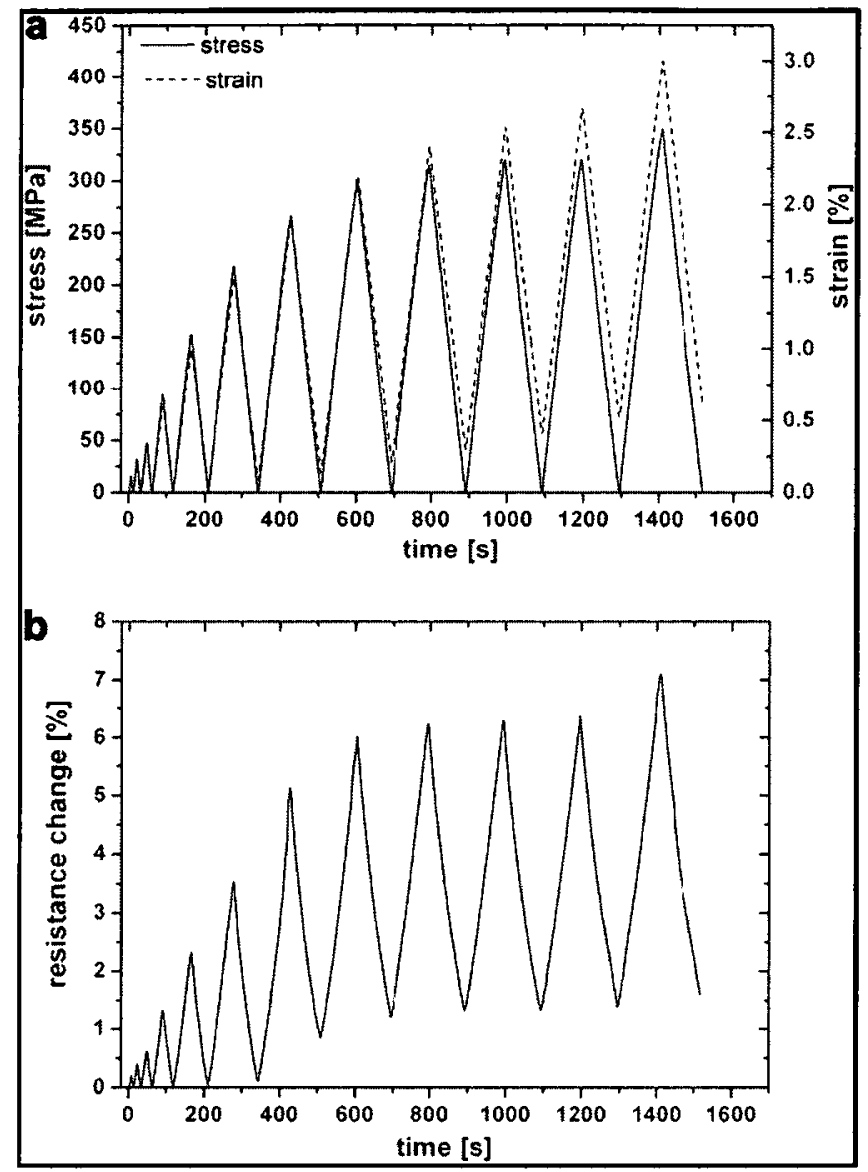

Fig.32) Strain and stress measurements (a) and resistance change measurements (b) during tensile loading cycles [22]

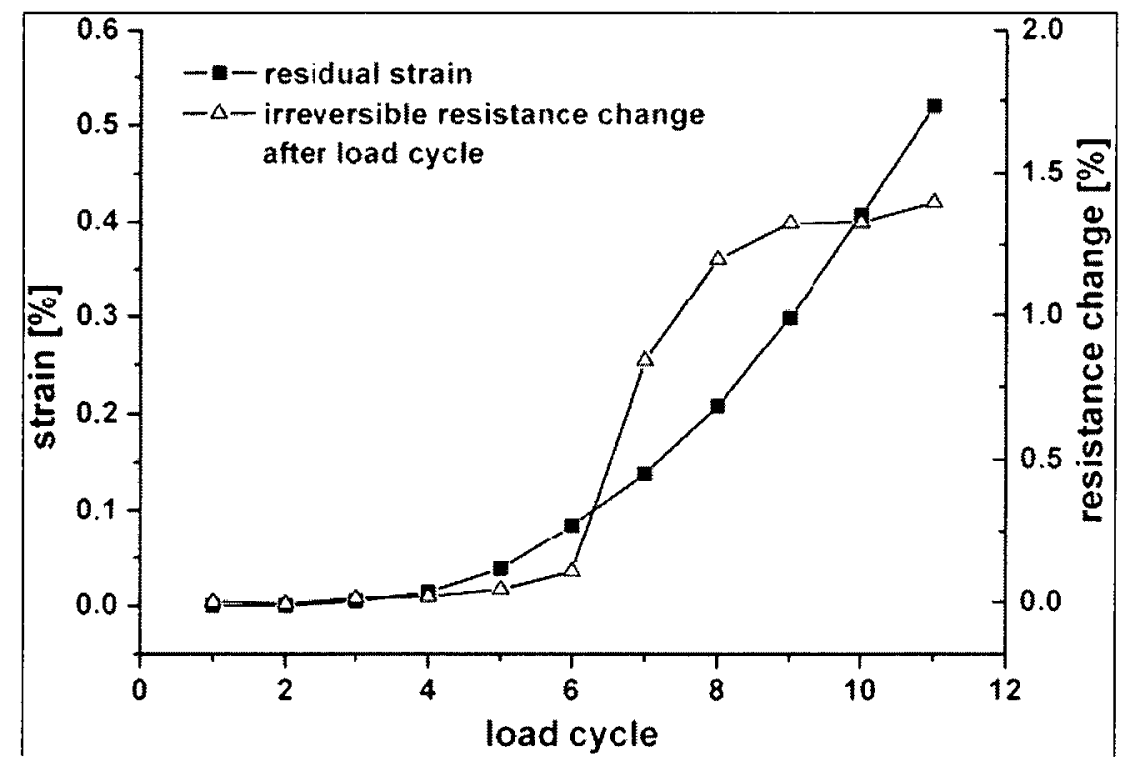

Fig.33) Residual strain and irreversible resistance change subjected to cyclic tensile loadings [22] 


\section{CHAPTER 3: ObJectives OF THE Present Work}

The main aim of this work is to use multiwall carbon nanotubes as a network of sensors to follow the crack detection and failure zone within a polymer matrix composite, reinforced with glass fiber. Due to the high sensitivity of nanotubes to electrical current flow, the occurrence of any crack or delamination or damage will increase the electrical resistance.

In this study, tensile and fatigue testing have been conducted to monitor the mechanical degradation and to localize the failure zone by measuring the electrical resistance and strain change under these loadings.

This health monitoring of the damage formation and subsequently the failure has been compared with the conventional way of using strain gauges. The sensitivity of this health monitoring using a carbon nanotube network versus strain gauge for strain and failure monitoring has been explained in this work. 


\section{CHAPTER 4: Experimental Procedure}

\subsection{Primary materials}

\subsubsection{Multiwall carbon nanotubes (MWCNTs)}

Multiwall carbon nanotubes grown by the chemical vapor deposition technique (more than $95 \%$ purity) have been used in this work (Cheap Tubes). They have outer diameters in the order of $10-20 \mathrm{~nm}$ and lengths of $10-30 \mu \mathrm{m}$. The other specifications of carbon nanotubes used in this work are as below. Figure 34 shows the transmission electron micrograph of these nanotubes.

1) Inside Diameter: $3-5 \mathrm{~nm}$

2) Ash: $<1.5 w t \%$

3) Purity: $>95 w t \%$

4) Length: 10-30um

5) Specific Surface Area: $233 \mathrm{~m}^{2} / \mathrm{g}$

6) Electrical Conductivity: $>10^{-2} \mathrm{~S} / \mathrm{cm}$ 


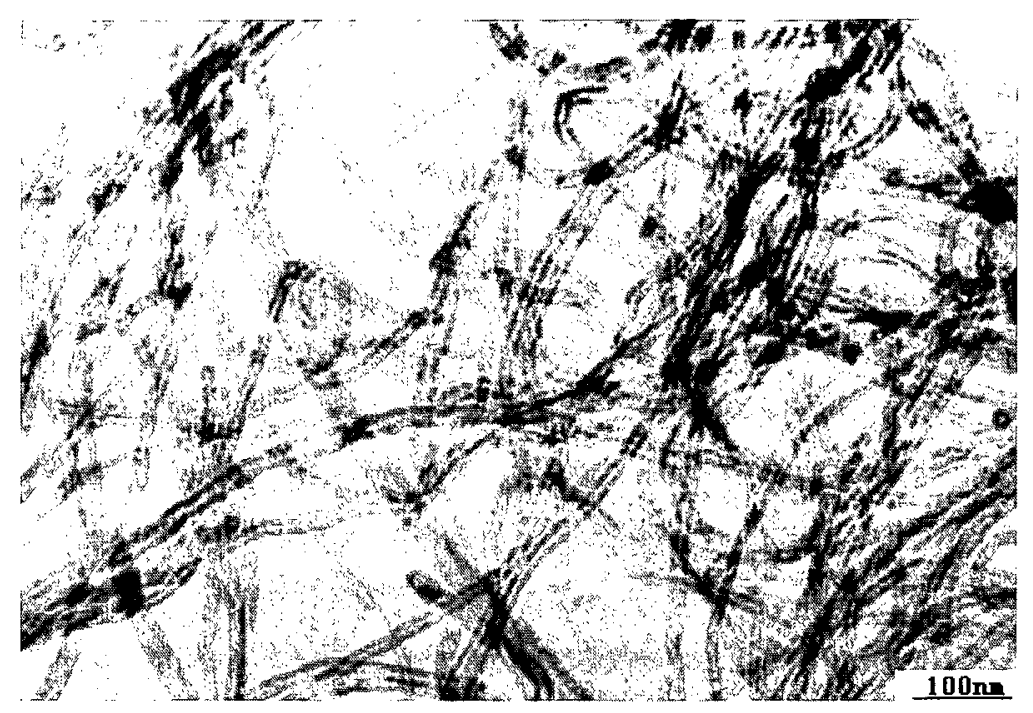

Fig.34) TEM for purified multiwall carbon nanotubes (MWCNTS)

\subsubsection{Epoxy and curing agent}

The epoxy polymer and curing agent are bisphenol-F epoxy, EPIKOTE Resin 862, and EPIKURE W (an aromatic amine curing agent), respectively (Hexion specialty chemicals).

Some properties of the epoxy resin 862 are mentioned below:

Viscosity at $25^{\circ} \mathrm{C}: 25-45$ Poise

Viscosity at $50^{\circ} \mathrm{C}: 2$ Poise

Density at $25^{\circ} \mathrm{C}: 1.186 \mathrm{~g} / \mathrm{cm}^{3}$

The ideal chemical structure of Epon resin 862 is shown in Figure 35.

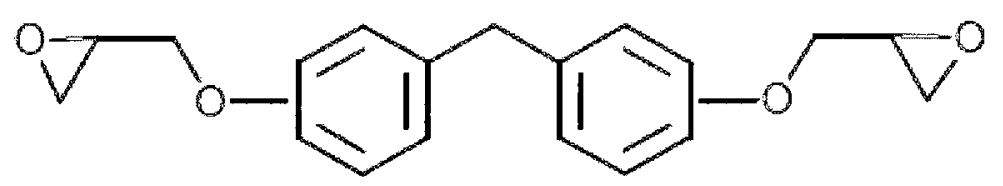

Fig.35) Chemical structure of Epon resin 862 [92]

Also some physical properties of Epicure W are mentioned below: 
Boiling point: $308^{\circ} \mathrm{C}$

Density at $25^{\circ} \mathrm{C}: 1.02 \mathrm{~g} / \mathrm{cm}^{3}$

Slightly soluble in water

Viscosity: $500-2000 \mathrm{cP}$

Density: $6.2 \mathrm{~g} / \mathrm{cm}^{3}$

\subsubsection{Glass fibers}

Bidirectional woven glass fibers have been utilized as the mechanical reinforcement. (The density value of this E-glass fiber is $2.53 \mathrm{~g} / \mathrm{cm}^{3}$ )

\subsection{Fabrication of nanotube-glass fiber-epoxy composites}

By measuring the weight of the nanotubes and epoxy resin and knowing the ratio of curing agent (the ratio of 26.4:100 of curing agent to epoxy resin), one weight percent of multiwall carbon nanotubes was mixed within the epoxy resin (this amount was selected due to conductivities achieved in other works [91]).

Due to agglomeration of the nanotubes, in order to untangle and disperse them within the epoxy to make the network of connection and achieve high electrical conductivity, a calendering machine (Three-Roll Mill EXAKT) has been used to produce high shear force mixing while passing the resin/nanotubes mixture through the rolls. The minimum agglomeration was seen after gradually reducing the gap setting from $50 \mu \mathrm{m}$ to $5 \mu \mathrm{m}$.

The mix of carbon nanotubes and epoxy resin was first manually stirred and then passed through the three-roll mill machine as follows in Table 4:

Figure 36 shows the calendering machine used for nanotube dispersion. 
Table 4) Number of passes through three-roll mill machine with different gap distance

\begin{tabular}{|c|c|}
\hline RoIn gap distance (num) & Number or passes \\
\hline 50 & $\mathbb{1}$ \\
\hline 30 & $\mathbb{1}$ \\
\hline 20 & 2 \\
\hline 10 & 3 \\
\hline 5 & 8 \\
\hline
\end{tabular}

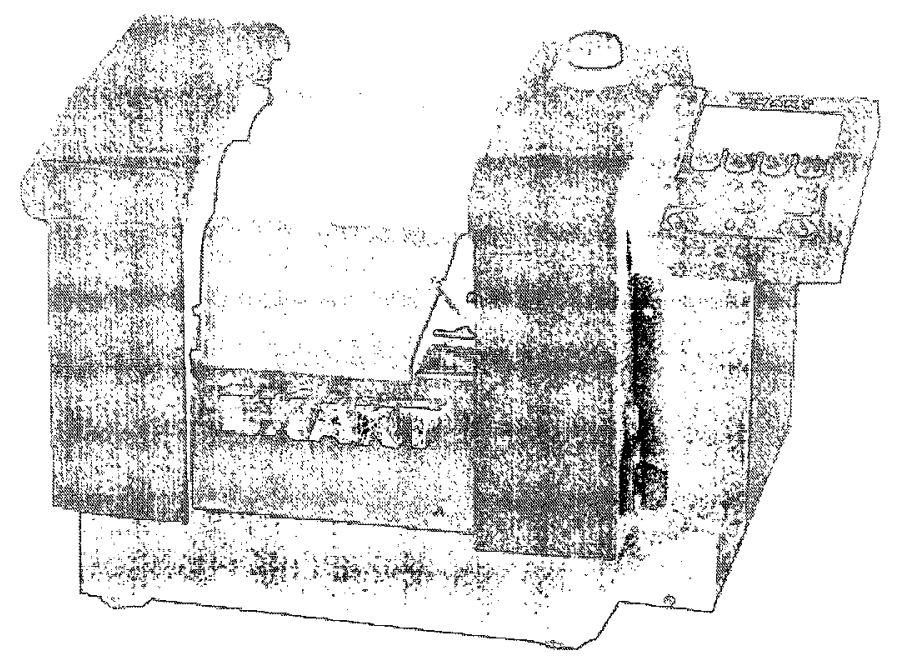

[F.g.36) Three-roll mill EXAKT (calendering machine) used to disperse the nanotubes within the epoxy resin [93]

Also am ultrasonicator (Sonicator 3000, MISONIX) was used to try and disperse the nanotubes within the epoxy (dispersing was performed by sonication method in presence of acetone). By using a solvent, nanotubes start to be separated from the agglomerates. Then, the suspension can be mixed with the resin while the solvent can be heated up and evaporated. But, due to higher agglomeration, and lower electrical conductivity compared 
to that from the three-roll mill machine, ultrasonication alone was not used as a dispersion technique for the final samples. Figure 37 shows the Sonicator machine used as one of the dispersion techniques.

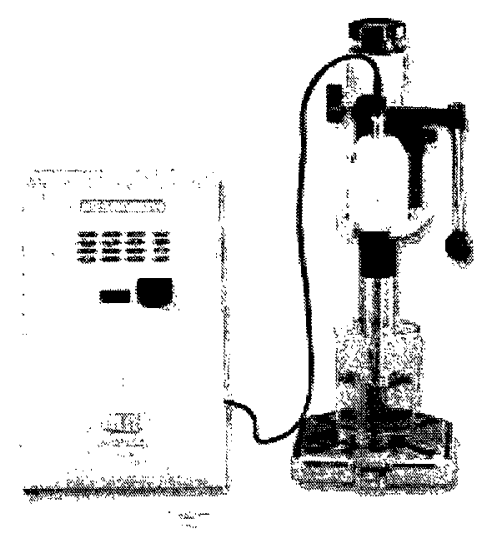

Fig.37) Sonicator 3000, MISONIX used as a dispersion technique [94]

The mix of dispersed carbon nanotubes within epoxy resin was heated up to $50^{\circ} \mathrm{C}$ to reduce the viscosity and the curing agent (in the ratio of 26.4:100) was added to the epoxy/nanotube mix. After stirring for 5 minutes, the mixture was heated up to $70^{\circ} \mathrm{C}$ for 20 minutes in a vacuum oven in order to degas and remove the bubbles. The final resin obtained was applied to two layers of bidirectional woven glass fibers by hand lay-up followed by two hours of vacuum bagging. The fabricated polymer matrix composite was cured in an oven for $6 \mathrm{hrs}$ at $130^{\circ} \mathrm{C}$. The degree of cure and glass fiber volume fraction and degradation temperature was determined by DSC (TA instruments Q10) (Differential Scanning Calorimetry) and TGA (TA instruments Q50) (Thermo Gravimetric Analysis), respectively. 


\subsection{Electrical measurements under mechanical loads (tensile and fatigue)}

Samples were cut out of the cured composite plate, according to ASTM D 3039 for mechanical testing. To improve gripping of the end-tabs of the samples, screen sandpaper was bonded onto the tabs. Silver epoxy-based glue was used as the contact for the conductive probes for electrical resistance measurement. The measurements were made using a high resistance meter (Agilent machine 4339B) (Figure 38).

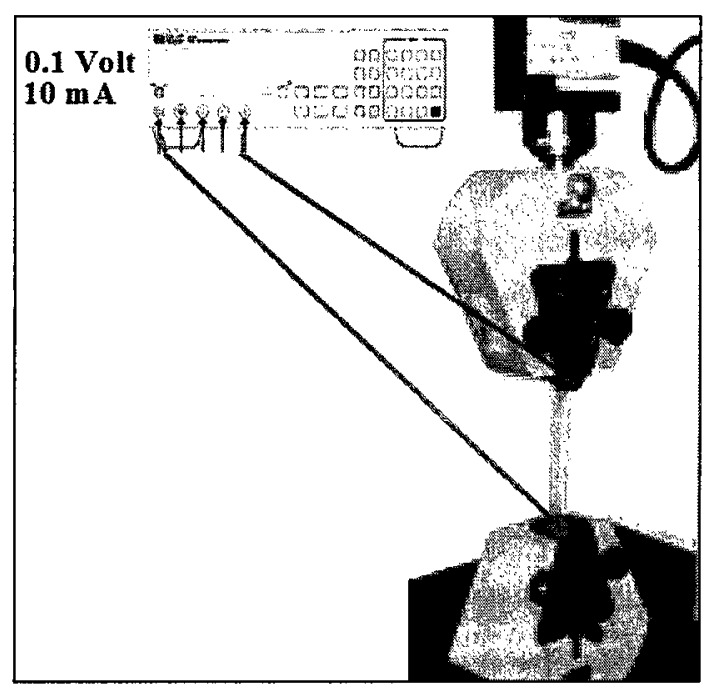

Fig.38) Electrical measurements by Agilent machine while conducting tensile and fatigue testing.

Tensile and fatigue tests were carried out on an MTS $100 \mathrm{KN}$ universal testing machine and at the same time, a constant source voltage was applied to the samples and the electrical current was measured in order to calculate the electrical resistance change. Tensile tests were performed at a rate of $1.27 \mathrm{~mm} / \mathrm{min}$ while measuring the resistance change. In the tensile and fatigue conductivity tests, electrical resistance change is defined as $\left(\mathrm{R}_{\mathrm{i}}-\mathrm{R}_{0} / \mathrm{R}_{0}\right) \times 100$ where $\mathrm{R}_{0}$ is the electrical resistance of the measured region before loading, and $R_{i}$ is the resistance while loading. Also for a few samples, residual resistance change has been measured which has the same definition as resistance change except $R_{i}$ is the resistance when the sample is unloaded. For a few tensile samples, two 
other electrical probes were bonded on the sample surface equally spaced apart between both ends to measure the resistance changes along the sample in three different zones. Also for a few fatigue test samples one more electrical probe was attached in the middle of the sample in order the measure the electrical resistance change in two regions. Fatigue samples prepared in three different ways are shown in Figure 39:

Type I) Samples with two regions with strain gauges placed at the center of each region.

Type II) Samples with two regions with a deliberate cut made in the lower region of the cured samples: The first strain gauge is attached at the center of the top region and the other one in the bottom region, nearer to the top region to allow some distance from the defect. This is due to the fact that the strain gauge is surface mounted and the deliberate defect may affect the strain around the strain gauge.

Type III) Samples with three layers of glass fiber rather than two: The mid layer has a cut in the bottom region. After manufacturing of the composite, the defective part of the sample was marked in order to identify the artificial crack made in the mid layer. Strain gauges were positioned at the center of each region. The defect here is in fact below the surface of the sample and thus should not diminish the stress field around the strain gauge.
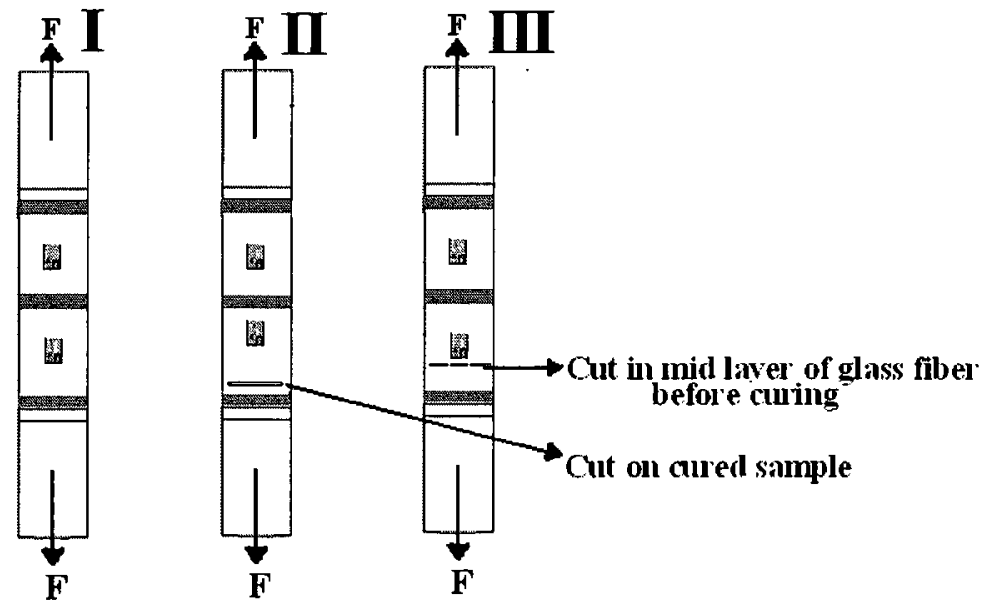

Fig. 39) Three types of samples for monitoring the defect initiation in two regions during fatigue testing. 


\section{CHAPTER 5: RESULTS AND DISCUSSION}

After curing the composite samples, DSC (Differential Scanning Calorimetry) and TGA (Thermo Gravimetric Analysis) tests were conducted to see whether the composite was properly cured or not, and also to know the volume fraction of fibers. Figures 40 and 41 show the results of these two tests.

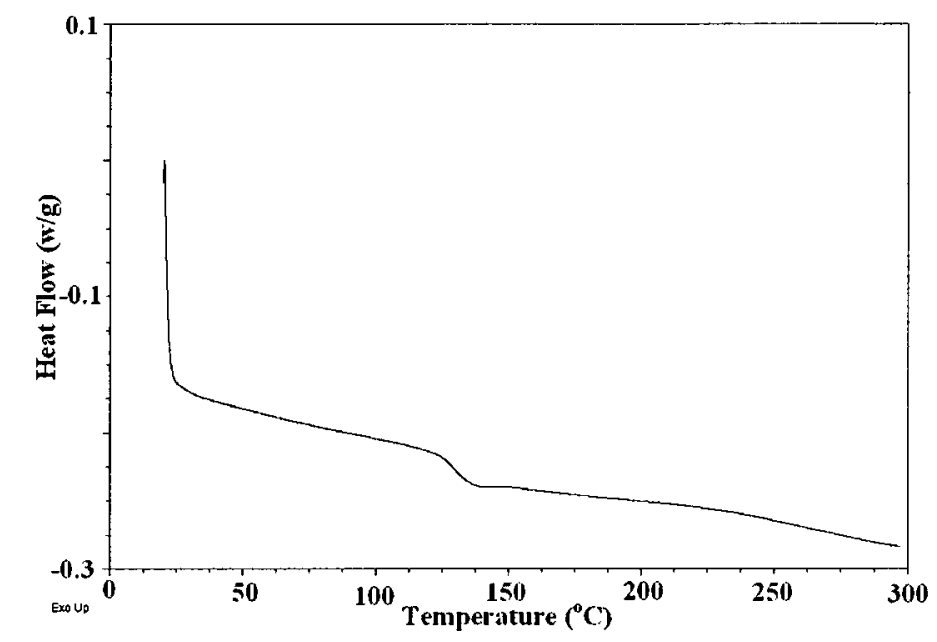

Fig.40) DSC results of the composite sample after curing

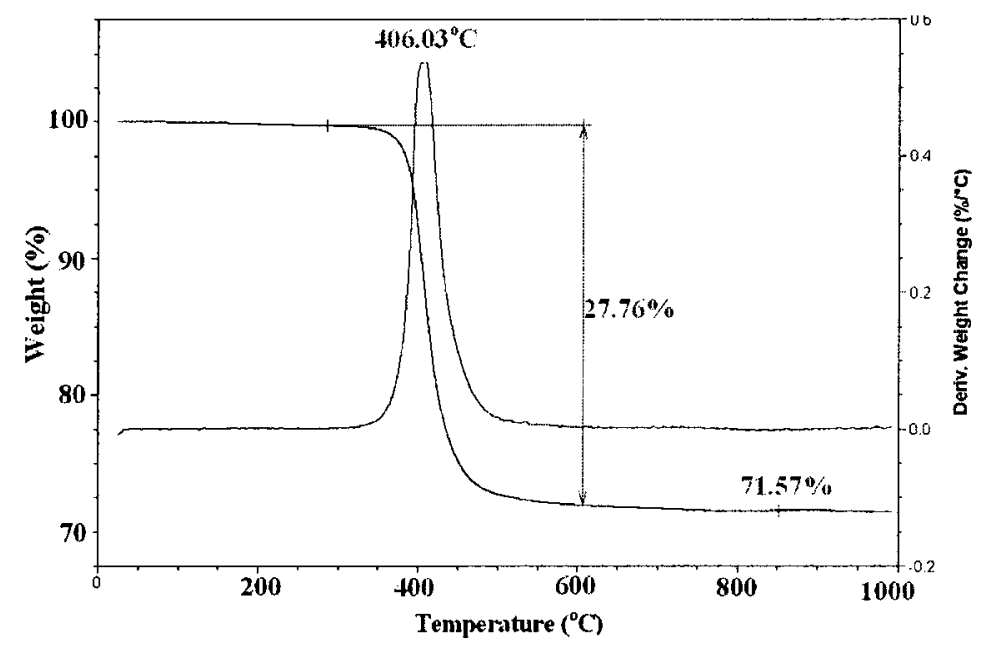

Fig.41) TGA result of the composite sample after curing 
From these results, it can be concluded that the curing process is good, and the heat flow shown in DSC curve is related to the $\mathrm{T}_{\mathrm{g}}$ (Glass transition temperature). Also according to TGA result, the degradation point of this epoxy is around $403^{\circ} \mathrm{C}$. By calculating the weight loss of the composite and by knowing the density of the primary materials, the volume fraction of the fibers was determined to be almost $53 \%$.

\subsection{Nanotube dispersion in epoxy resin}

To untangle and disperse the nanotubes within the epoxy to make a network of sensors, two methods were considered; acetone sonication and calendering. The results of electrical conductivity and optical microscope images (Figure 42) show the improved dispersion obtained by calendering which results in higher electrical conductivity. Electrical conductivity values for nanotubes dispersed in epoxy using acetone sonication and calendering methods were $7.8 \times 10^{-8}$ and $4.8 \times 10^{-5} \mathrm{~S} / \mathrm{cm}$, respectively.

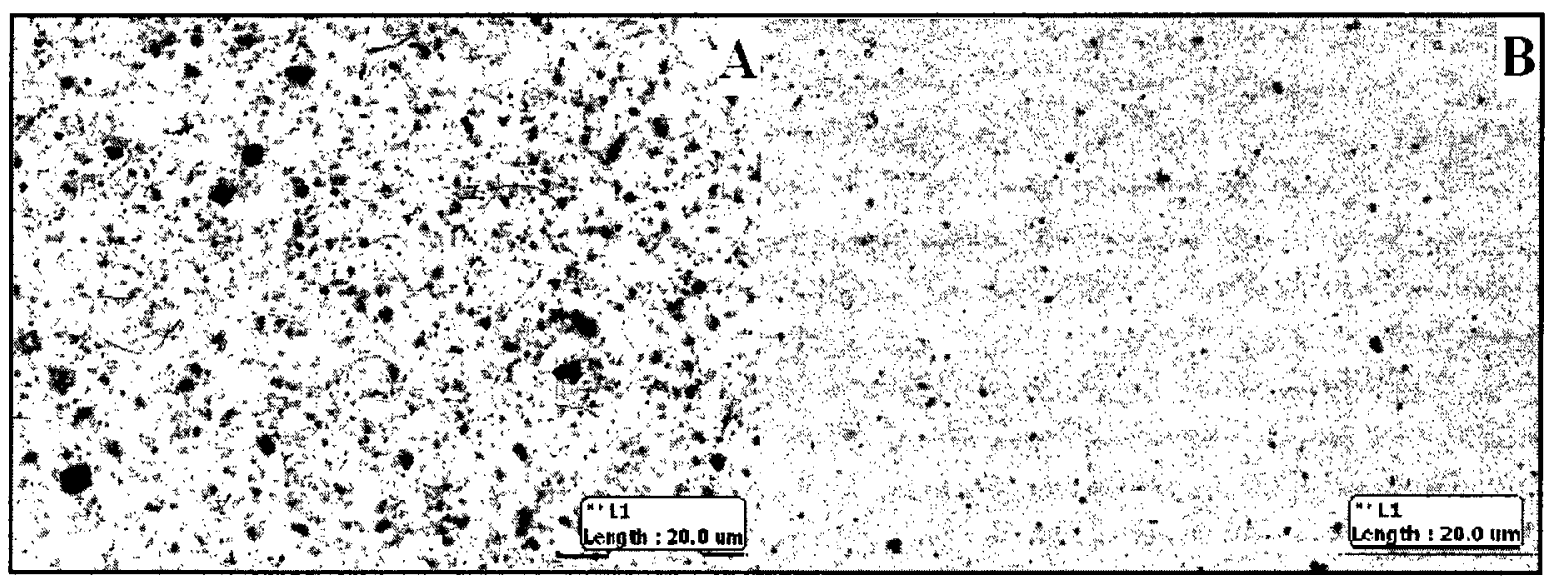

Fig. 42) Nanotube dispersion within epoxy by means of $(A)$ acetone sonication and (B) calendering

Subsequently, the calendering method was utilized for dispersion of the nanotubes. 
Figure 43 shows the scanning electron microscopy (SEM) micrograph of carbon namotubes (shown with arrows) within epoxy. From this micrograph, it can be observed that the namotubes are well covered with epoxy. This shows that, there is a good interface between carbon nanotubes and epoxy.

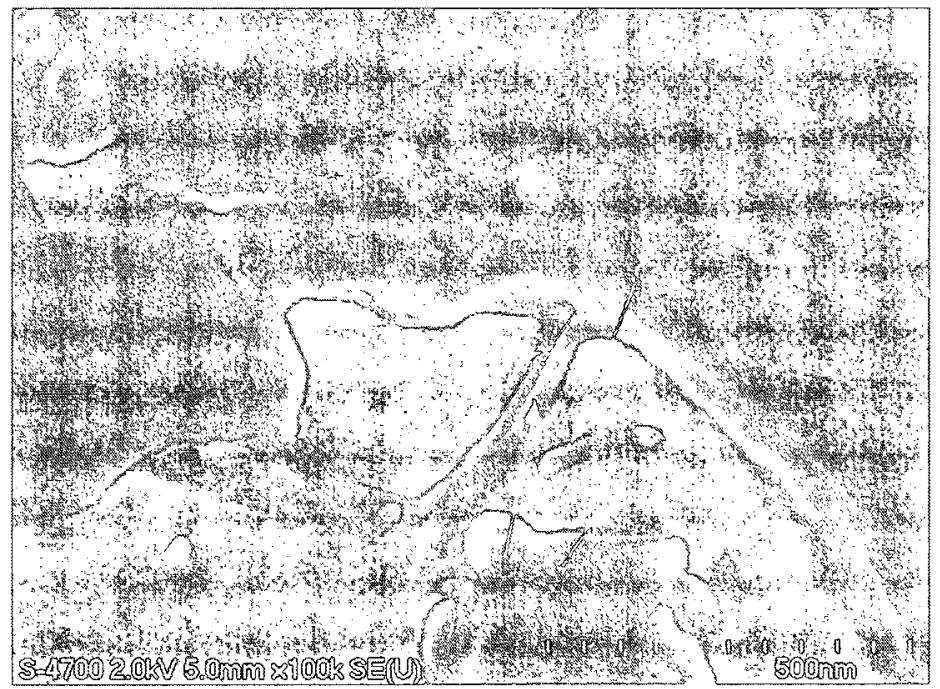

IFig.433) Scanning electron microscopy of the matrix including nanotubes.

The interconnection and number of contacts of the nanotubes produce electrical conductivity through the insulating epoxy after am optimum dispersion [85-87]. Applying static or cyclic loads would cause loss of contacts and increase the manotube separation distance, due to the appearance of different types of damage such as cracks or delamination. This is the main reason for electrical resistance increase in a polymer matrix composite sample under load. 


\subsection{Tensile test}

\subsubsection{Tensile test while measuring electrical resistance along the sample}

Figure 44 shows load vs. strain and resistance change vs. strain measurements. The load strain curve increases linearly until a point where a change of slope occurs in the range of 2000-3000 N. This change of slope happens at the same value in the resistance-strain curve. This point of slope change can be called the elastic limit of the sample. The resistance increase may be related to the formation of some damage in the sample that will subsequently cause failure. This result shows a good agreement with previous work that has been conducted so far in damage appearance and mechanical degradation monitoring $[10,20,21$, and 22].
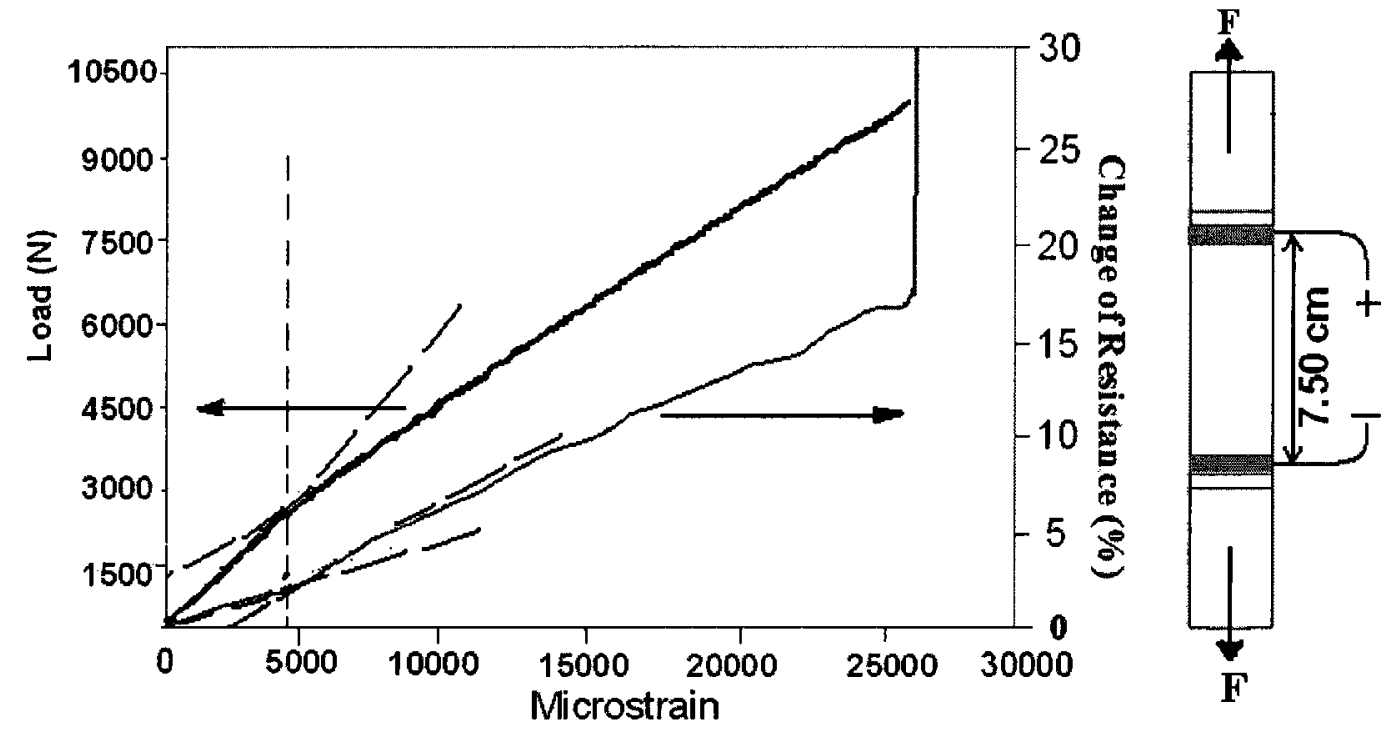

Fig. 44) Change of resistance in tension for 1 wt $\%$ nanotube-glass fiber-epoxy composite 


\subsubsection{Tensile test while measuring electrical resistance in three zones of a sample}

Using the phenomenon of resistance increase during loading, the idea of identifying the failure location in a sample under tensile loading becomes feasible. In a subsequent tensile test, in addition to bonding the electrical probes near both end tabs of the sample, two other probes were bonded on the sample's surface, equally spaced between both ends as shown in Figure 45. Before doing any mechanical test, the value of the electrical current was between 8-10 $\mu \mathrm{A}$. The electrical resistance was calculated, by knowing that the applied voltage was $10 \mathrm{mV}$.

By applying the tensile load and measuring the resistance between two adjacent probes, it was seen that in each region of the sample the resistance increases respectively (Figure 45). The change of slope in the load-strain curve occurs in the range of 2000-3000 N and at the same time the resistance starts to increase at a higher rate in all three zones. In Figure $45 \mathrm{a}$, it is shown that the resistance change between points 2 and 3 increases more rapidly and final fracture did indeed take place between these points.

Figure $45 \mathrm{~b}$ shows another case in which failure has taken place between points 1 and 2 and again the results of resistance increase are in agreement with the failure location.

In the tensile tests shown in Figure 45, the resistance changes in all three zones of each sample reflect well the occurrence and propagation of cracks and defects in the samples. In Figures $45 \mathrm{a}$ and $45 \mathrm{~b}$, it is shown that the resistance change between points $2-3$ and points $1-2$, respectively, correlates well to damage accumulation in these two regions. At the same time, the resistance changes in the other regions increase at a lower rate, which also correlates well with less crack detection in these two regions. 

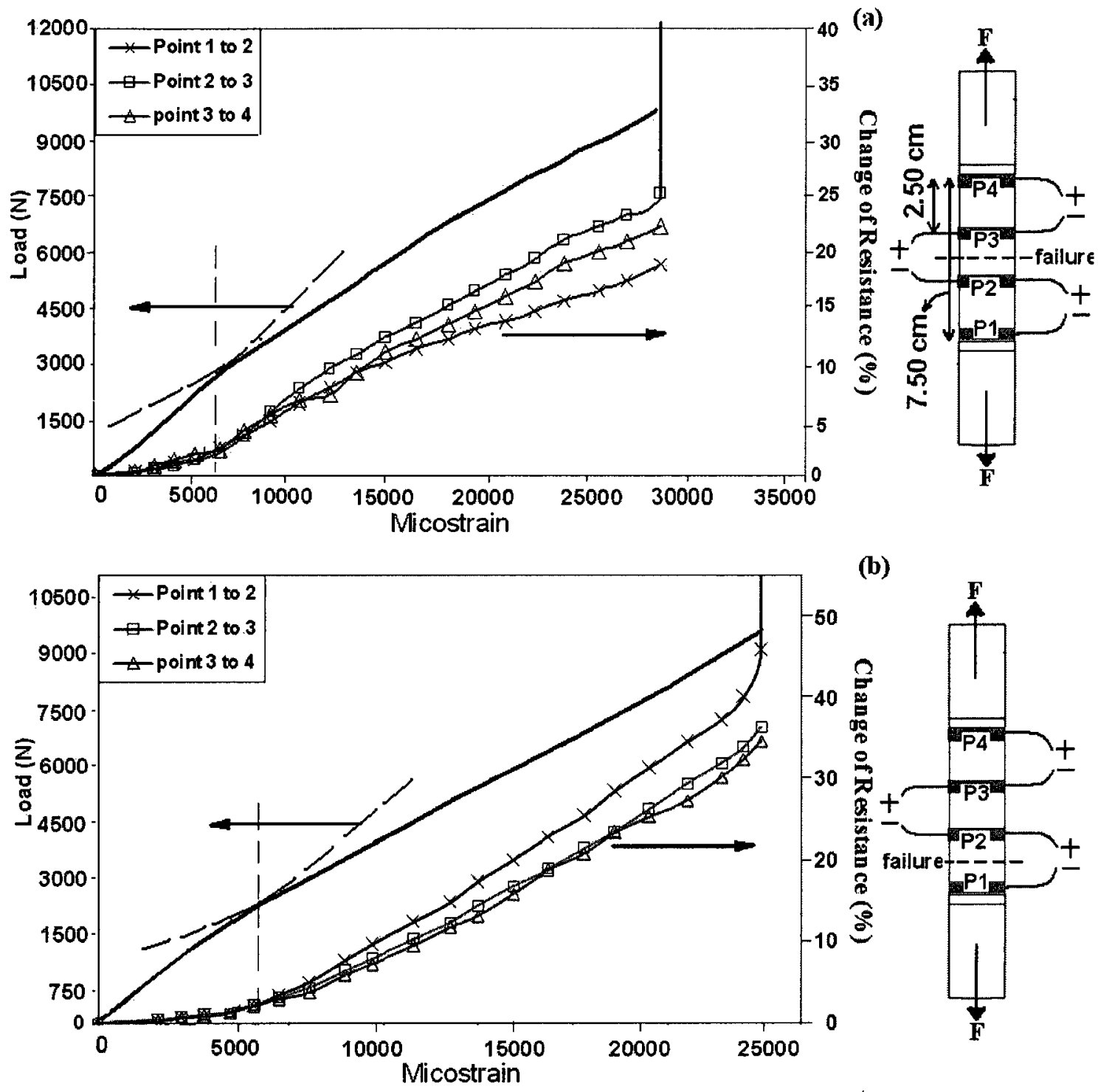

Fig.45) Change of resistance $v s$. strain by multi point resistance measurement during tensile test (a) failure has occurred between points 2-3, and (b) points 1-2.

\subsection{Fatigue test}

\subsubsection{Fatigue test while measuring electrical resistance along the sample}

To explore the potential of a nanotube network to monitor crack accumulation and ply delamination in a fatigue test, high cycle fatigue was performed on tension test samples.

The minimum applied load was $150 \mathrm{~N}$ in all cases and a range of maximum loads were 
used $(6000,4000,3500,2500$, and $1500 \mathrm{~N})$. Initial fatigue tests were carried out and resistance change was measured continuously as cycling occurred. Figure 46 shows results for a cyclic fatigue test performed with a maximum load of $6000 \mathrm{~N}$. A sharp increase in resistance is observed within the first cycles and afterwards the resistance increases at a lower but more constant rate. According to the load-strain curve shown in Figures 44 and 45, $6000 \mathrm{~N}$ is more than 50 percent of the fracture load, and is beyond the elastic limit shown there, hence the sharp increase of resistance within the initial cycles. Figure 47 shows the resistance change during fatigue testing with a maximum load of $4000 \mathrm{~N}$ compared with the one subjected to $6000 \mathrm{~N}$ maximum load. The number of cycles to failure for a maximum load of $4000 \mathrm{~N}$ is approximately ten times that for 6000 $\mathrm{N}$. In both results, it is seen that the resistance increases with the number of cycles. It is also shown that the resistance change depends on the magnitude of the maximum cyclic load. According to the load-strain curve (Figure 44), it is clear that for loads above the mentioned elastic limit, there is a sharp increase in resistance change within the initial loading cycles. In Figure 47, this sharp increase is still present but to a lower magnitude for a maximum load of $4000 \mathrm{~N}$ which is also above that limit. 


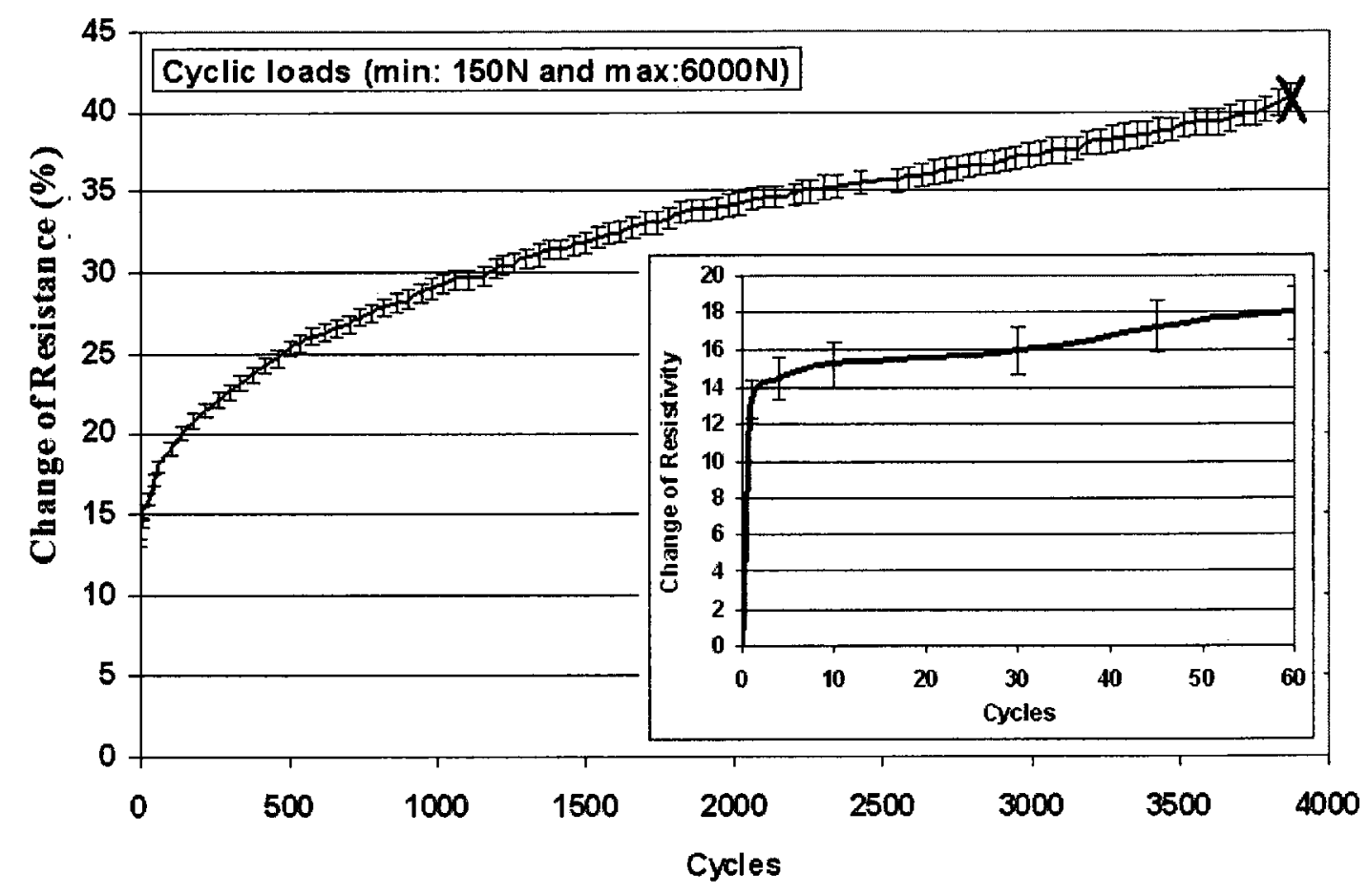

Fig. 46) Change of resistance vs. cycles under fatigue testing with maximum load of $6000 \mathrm{~N}$

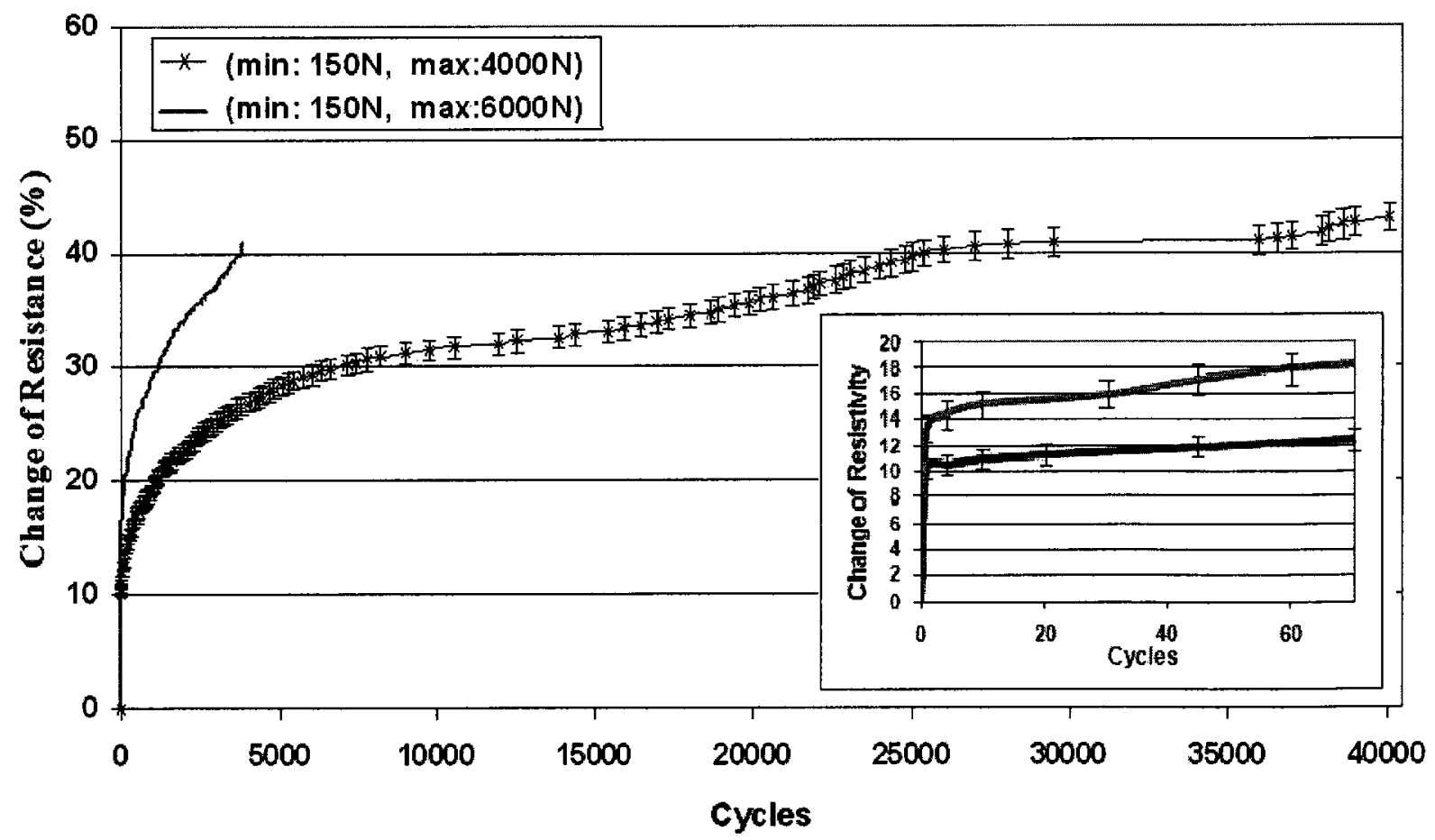

Fig. 47) Change of resistance vs. cycles under fatigue testing with maximum load of 4000 comparing with $6000 \mathrm{~N}$ 
To investigate this sharp initial change of resistance within the first few cycles, other maximum cyclic loads were applied. Figure 48 shows the resistance changes within 500 load cycles at $6000,4000,3500,2500$, and $1500 \mathrm{~N}$ maximum loads. As shown, the magnitude of the initial increase of resistance is significantly smaller for maximum loads below the elastic limit range. For all loading scenarios, there is some increase in resistance upon initial loading. This remarkable shift in resistance of almost 50 percent of the ultimate resistance change can be due to the onset of damage such as micro cracks and/or delamination.

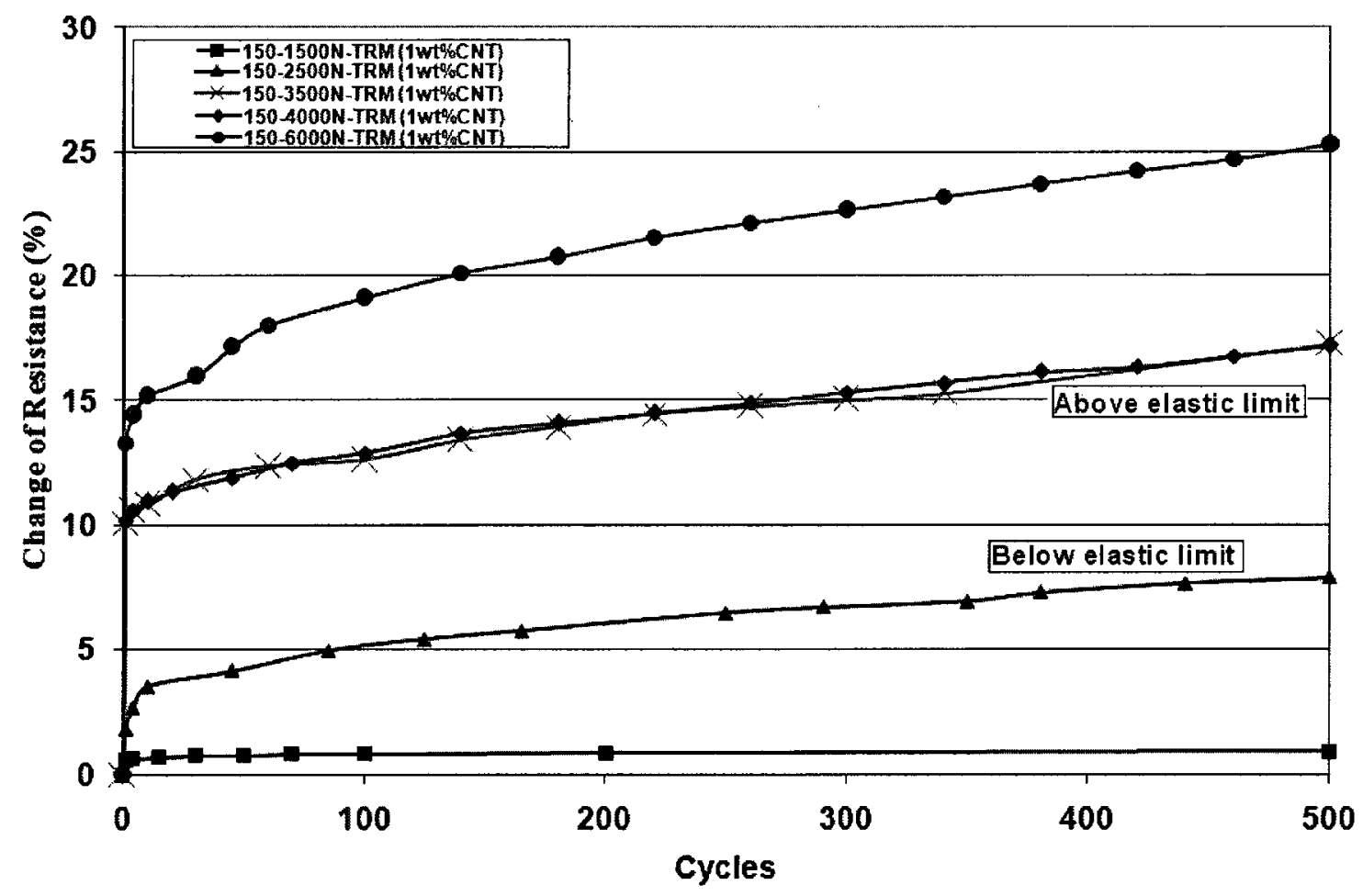

Fig. 48) Change of resistance vs. cycles with maximum applied loads of 6000, 4000, 3500,2500 , and $1500 \mathrm{~N}$ within 500 cycles. 


\subsubsection{Comparison of electrical resistance and strain gauges during cyclic loading}

To investigate the elastic limit region $(2000-3000 \mathrm{~N})$ shown in Figures 44 and 45, fatigue testing has been conducted up to 100 cycles at 6 different maximum loads $(6000,4500$, $3500,2500,1500$, and $500 \mathrm{~N}$ ). The resistance and strain have been measured after every four cycles while the sample is unloaded (Figure 49).
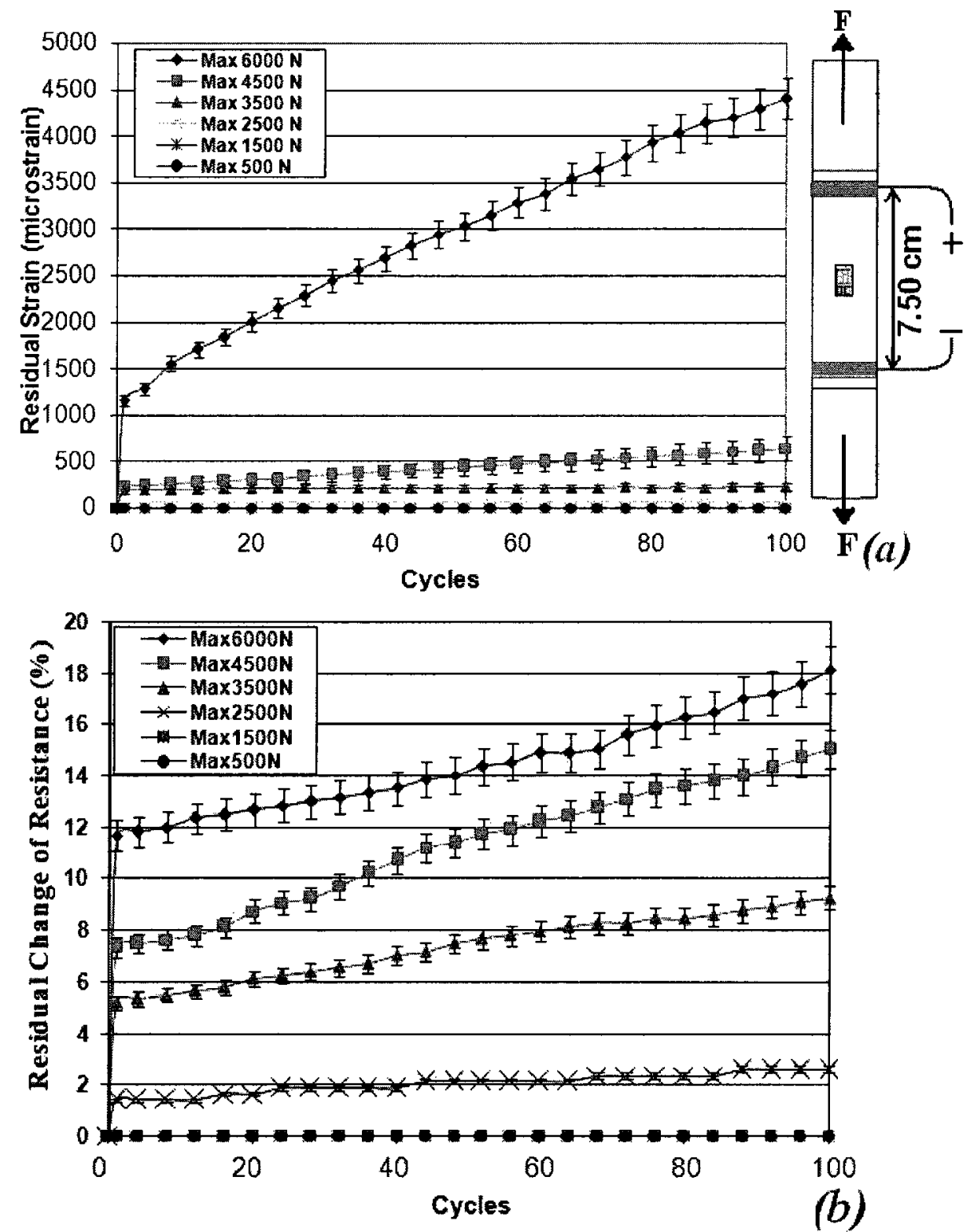

Fig. 49) (a) Residual strain using strain gauge and (b) residual change of resistance measured for 6 maximum loads in first 100 cycles 
In this case, the results will give residual resistance change and residual strain after every 4 cycles up to 100 cycles. These residual measurements at 6 different maximum loads are shown in Figure 49. For maximum loads of 500 and $1500 \mathrm{~N}$ which are below the elastic limit, no residual resistance change and residual strain were observed.

By increasing the maximum load above $2500 \mathrm{~N}$, the residual resistance change and strain appeared and increased with increasing cycles. For the maximum load of $2500 \mathrm{~N}$, these residual values are less remarkable than that of 3500,4500 , and $6000 \mathrm{~N}$. When compared to strain gauge readings, resistance change measurements show more sensitivity in identifying the crack initiation according to the proportional increase of residual resistance change for different maximum cyclic loads.

Figure $50 \mathrm{a}$ and $50 \mathrm{~b}$ show the residual resistance change and the residual strain versus the maximum applied cyclic loads after 4 and 100 cycles. As shown in Figures 44 and 45, the transition load range, (named the elastic limit), was in the range of 2000-3000 N. This transition load range is clear by strain and resistance measurements shown in Figure 50. After 4 cycles, for maximum cyclic loads above this elastic limit, there is a sharp increase in residual strain and residual resistance change due to the high initial loading. These residual measurements continuously increase on further cycling up to 100 cycles. 

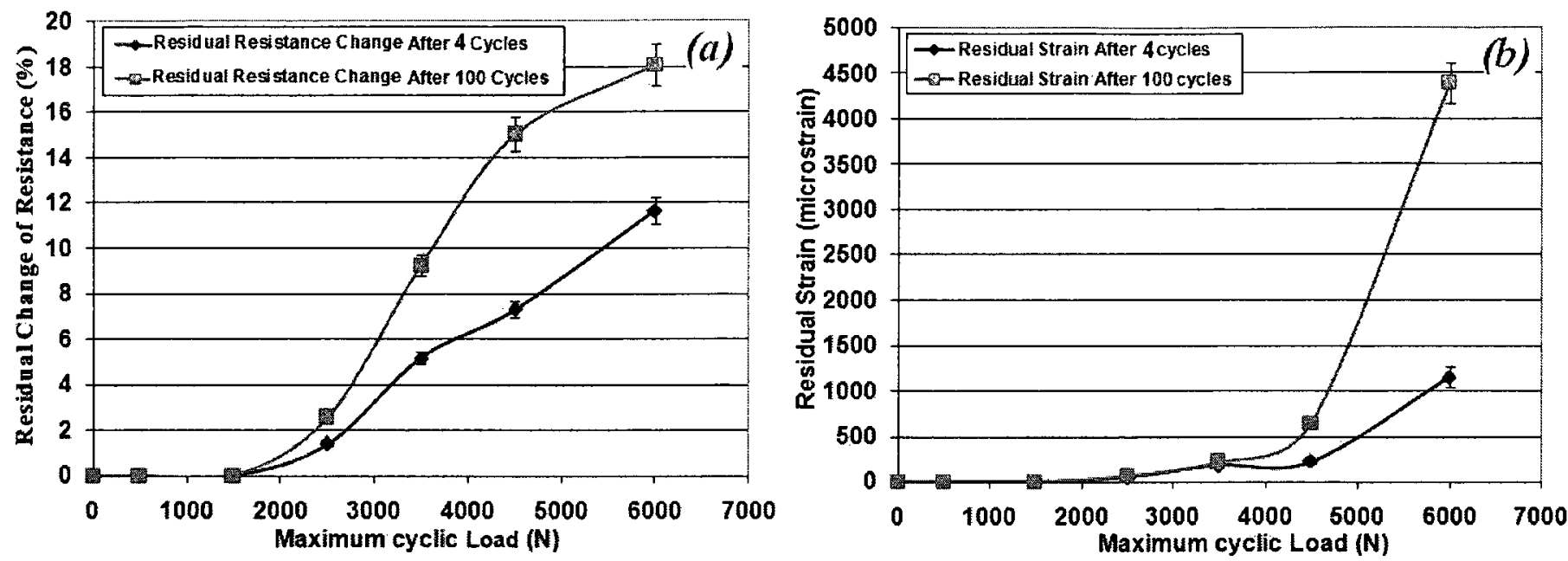

Fig. 50) (a) Residual change of resistance and (b) residual strain $v$ s. maximum applied cyclic loads

As shown in Figure 49 as well, for loads below the elastic limit range, there is no residual strain and resistance change within the first 100 cycles which suggests reversible elastic deformation.

\subsubsection{Optical microscopy of fatigued samples up to 100 cycles:}

Three cross sections of each sample, fatigued up to 100 cycles with maximum cyclic loads of $6000,4500,3500,2500,1500$, and $500 \mathrm{~N}$, were investigated by optical microscopy to try to identify any permanent damage such as micro cracks or delamination. Figure 51 shows optical micrographs of samples, fatigued at 3 different maximum cyclic loads. For the fatigued samples loaded below and up to the elastic limit $(500,1500$, and $2500 \mathrm{~N})$, no significant defects were detected. However, for the samples with maximum loads beyond the limit $(3500,4500$, and $6000 \mathrm{~N})$, in some parts some cracks in the matrix between the fibers were observed. Moreover, for the samples under maximum loads of 4500 and $6000 \mathrm{~N}$, delamination between the layers is also seen. 

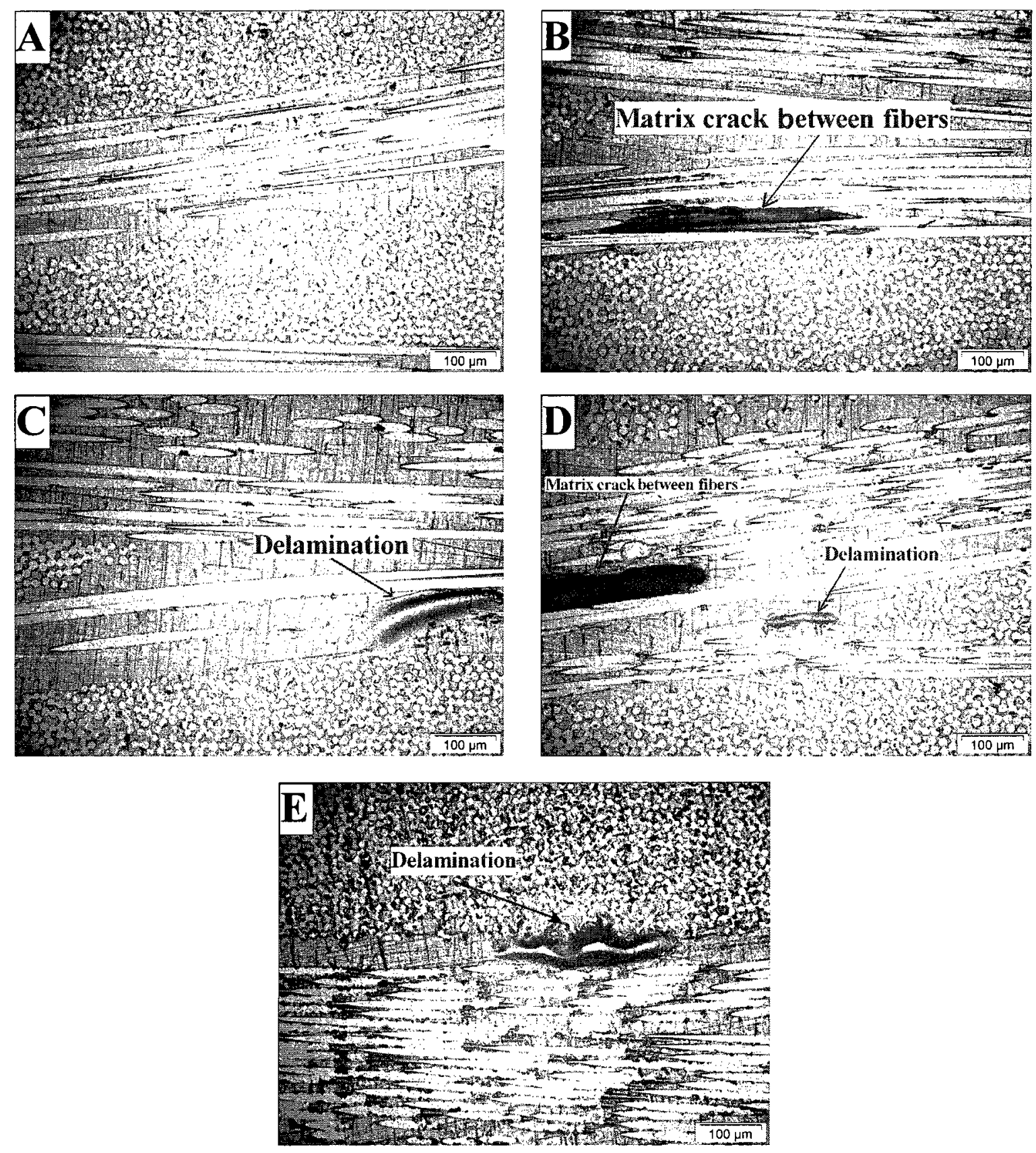

Fig. 51) Optical micrograph of fatigued samples after maximum cyclic loads of (A) 2500 $N,(B \& C) 4500 N(D \& E), 6000 N$.

This damage causes the disconnection of nanotubes and subsequently decreases electrical current flow through the matrix. 
As discussed, in Figures 44 and 45, a change of slope in the load-strain curve occurred at about 2000-3000 N. A higher rate of resistance increase was observed above this load range. This load range may be called the elastic limit which may be related to the crack and delamination launch and formation of permanent defects in this polymer matrix composite. Figures 49 and 50 which show the residual resistance change and residual strain every 4 cycles in fatigue testing, can illustrate this fact. As shown, for maximum loads below this elastic limit range, no residual resistance change and strain appeared. This can be due to elastic recovery. On the other hand, while applying maximum cyclic loads beyond this limit, the residual resistance change and residual strain increase. This is thought to be due to some permanent damage such as initiation and growth of cracks or delamination within the sample. Considering Figure 48, the resistance increase is

recorded during continuous fatigue testing without unloading. Even below the elastic limit, resistance increases after a number of cycles. The resistance change for samples loaded in the elastic region (below the elastic limit) is presumed to be due to extension of the bonds and temporary disconnection of nanotubes. On unloading, shown in Figures 49 and 50, the electrical current flows again through the network of nanotubes after recovery which results in no permanent resistance change.

\subsubsection{Measurements in two regions during fatigue with unloading every four cycles}

In order to explore the sensitivity of electrical resistance measurements and strain gauges, on predicting the failure region during fatigue testing, another electrical probe was attached in the middle of the samples. This makes two regions on the sample for 
electrical resistance and strain measurements (each region is about $3.75 \mathrm{~cm}$ in length). As shown in Figure 39, three types of samples were tested:

Type I) Three samples without artificial defects,

Type II) Two samples with a cut in the lower region on the cured sample, and

Type III) Two samples prepared with 3 layers of glass fiber fabrics, in which the mid layer was cut in the lower region prior to curing.

Electrical resistance and strain measurements during fatigue testing of these 3 types of samples were recorded every four cycles upon unloading. After recording the data for a definite number of cycles, a tensile test was conducted to find the final failure location, which takes place mainly due to the critical damage produced during the fatigue process. Maximum cyclic loads of 4500 and 6000 N, 2000 and 3000 N, and $6000 \mathrm{~N}$ were applied for Type (I), (II), and (III) samples, respectively. It is expected that damage created by cyclic loading, accumulates over the cycles and the zone with the most accumulated damage will be the zone in which final fracture will occur. This region can not be identified prior to testing. The measurement of resistance change is thought to be a realtime indicator of this damage occurrence and thus the region of higher resistance change would be the region in which the final fracture would occur.

\subsubsection{Fatigue testing of type I}

In type I, three samples were tested. As shown in Figure 52a for the first sample, in the first several cycles of fatigue testing under the maximum load of $6000 \mathrm{~N}$, the sharp increase of resistance and strain appears in both regions. Residual strain results show almost a constant increase between points $1-2$ and $2-3$ up to 100 cycles, with a slightly increasing rate between points 1-2 in the latter cycles (Figure 52a). 

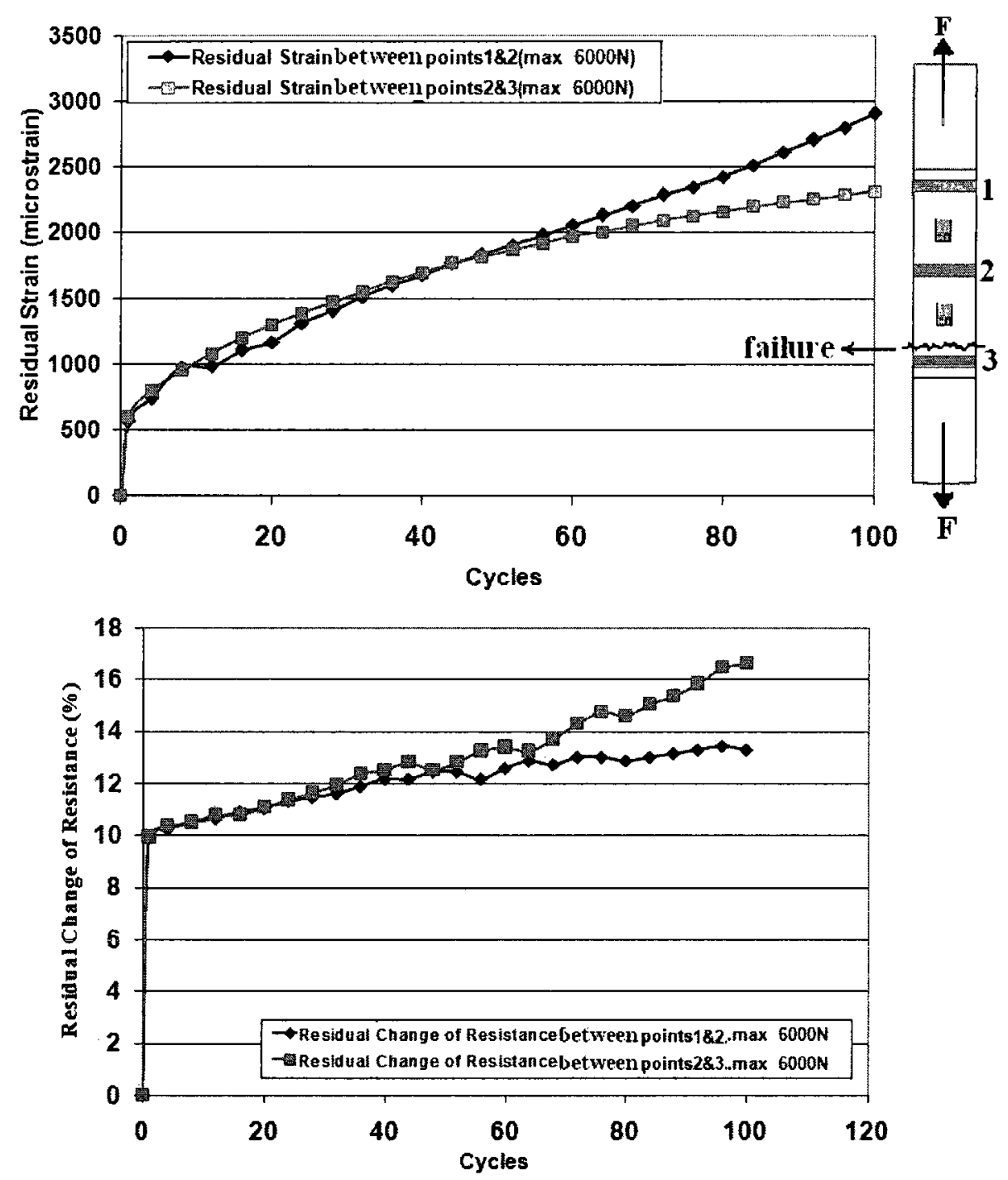

Fig. 52a) Residual change of resistance and residual strain in two regions, after 100 fatigue cycles with maximum load of $6000 \mathrm{~N}$ (type I, sample 1)

At the same time, as the number of cycles progresses, the residual resistance graph shows a higher rate of change between points 2-3. As shown in Figure 52a, the sample failed close to point 3 and away from the strain gauge. Figure 52b shows another sample tested in the same condition but with a maximum cyclic load of $4500 \mathrm{~N}$. Although not as obvious as in previous tests, the trend at higher cycles shows the higher rate of resistance change between points $1-2$. In fact, a maximum load of $4500 \mathrm{~N}$ needed more cycles to 
accrue sufficient damage and further cycles would probably have been more indicative of damage sufficient to cause failure.
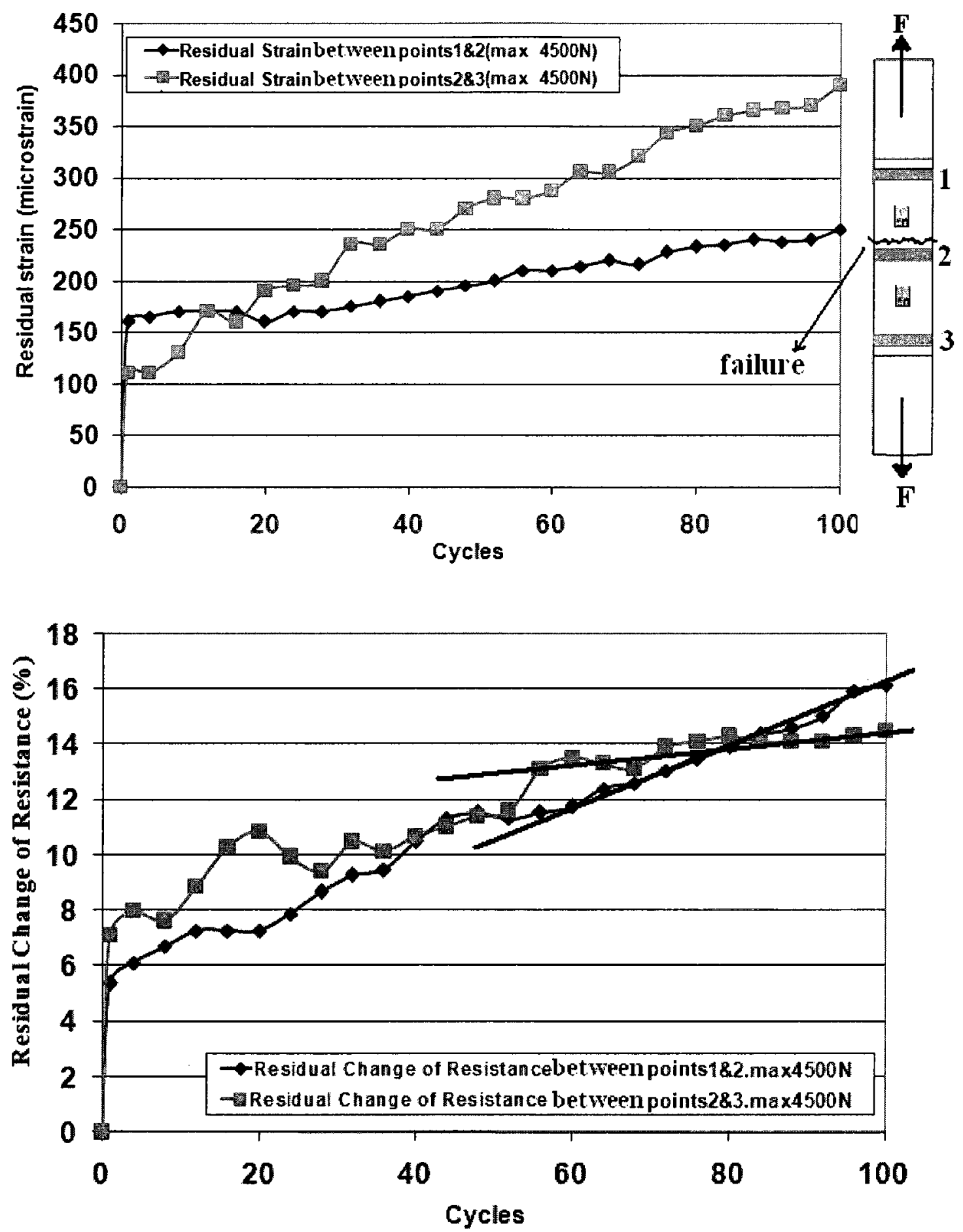

Fig. 52b) Residual change of resistance and residual strain in two regions, after 100 fatigue cycles with maximum load of $4500 \mathrm{~N}$ (type I, sample 2) 
In this case, failure took place between points 1-2 and closer to point 2. During fatigue testing, strain data between points 2-3 increase more than between points 1-2. Resistance results show a higher rate of increase between points $1-2$. The failure location again has a clear distance to the strain gauge between points $2-3$ (nearly $1 \mathrm{~cm}$ ). This result again shows that residual resistance change correlates well with the consequent failure location. The graphs for the third sample tested in the same condition with $4500 \mathrm{~N}$ maximum cyclic load are shown in Figure 52c. After conducting the tensile test, failure occurred between points 1-2 which was very close to the upper strain gauge (almost 1-2 mm). In this case both strain and resistance show higher changes between points 1-2 (again, measured every 4 cycles when the sample is unloaded). 

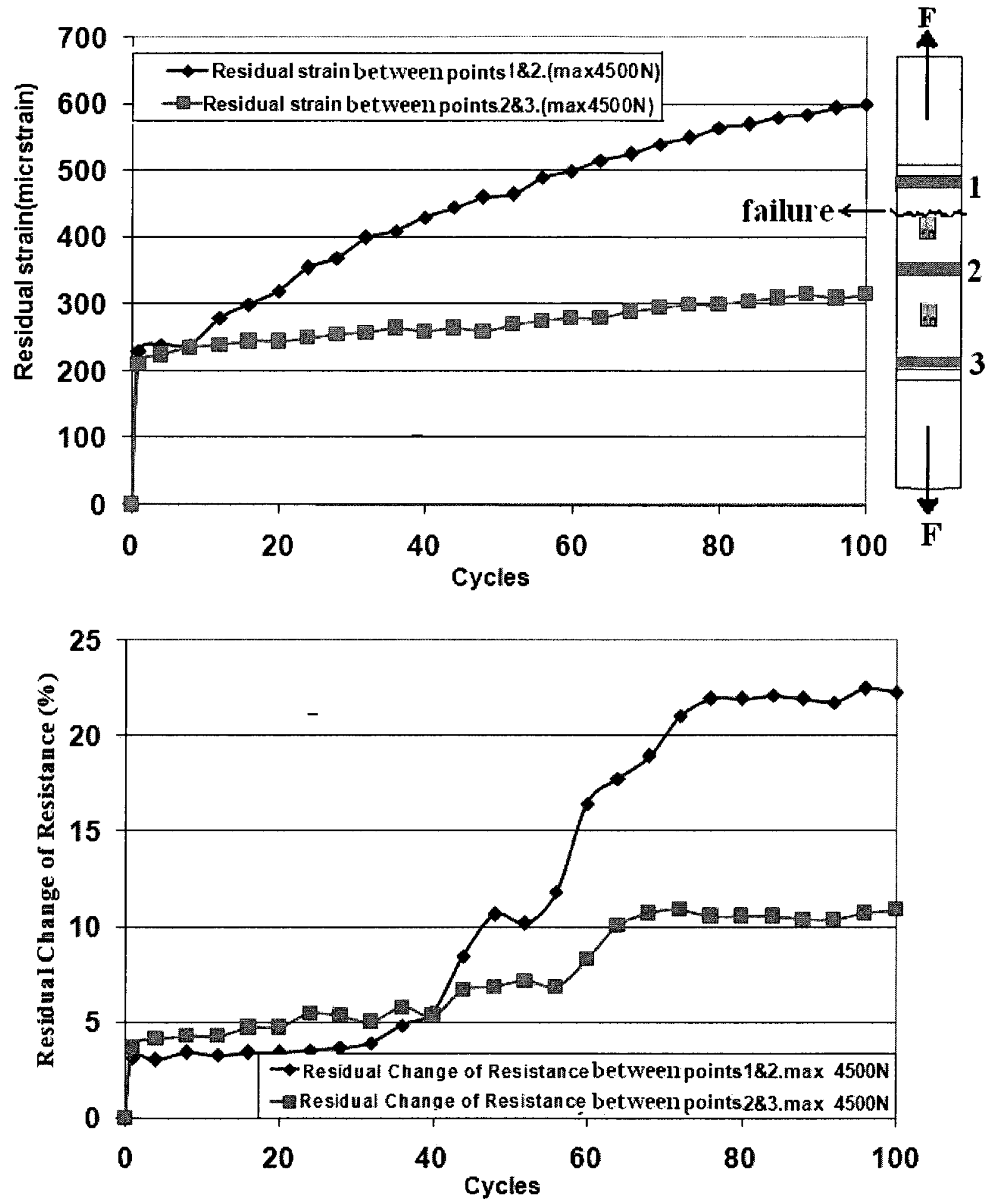

Fig. 52c) Residual change of resistance and residual strain in two regions, after 100 fatigue cycles with maximum load of $4500 \mathrm{~N}$ (type I, sample 3) 


\subsubsection{Fatigue testing of type II samples}

Similar tests were carried out on 2 samples of type II. Since a cut has been made in the lower region between points 2-3, to decrease the effect of local deformation around that cut, a strain gauge was placed at a distance of $2.5 \mathrm{~cm}$ from point 3 (Figure 53a and 53b). Fatigue testing was implemented with maximum cyclic loads of 2000 and $3000 \mathrm{~N}$, knowing that the failure would occur in the defective part (failure occured in the defective part nearly $2.5 \mathrm{~cm}$ from the strain gauge, between points 2-3). As shown in Figures 53a and 53b, strain is increasing almost constantly in both parts of both samples. On the other hand, the resistance measurements show higher rate of change between points $2 \& 3$ in which the failure initiation takes place.

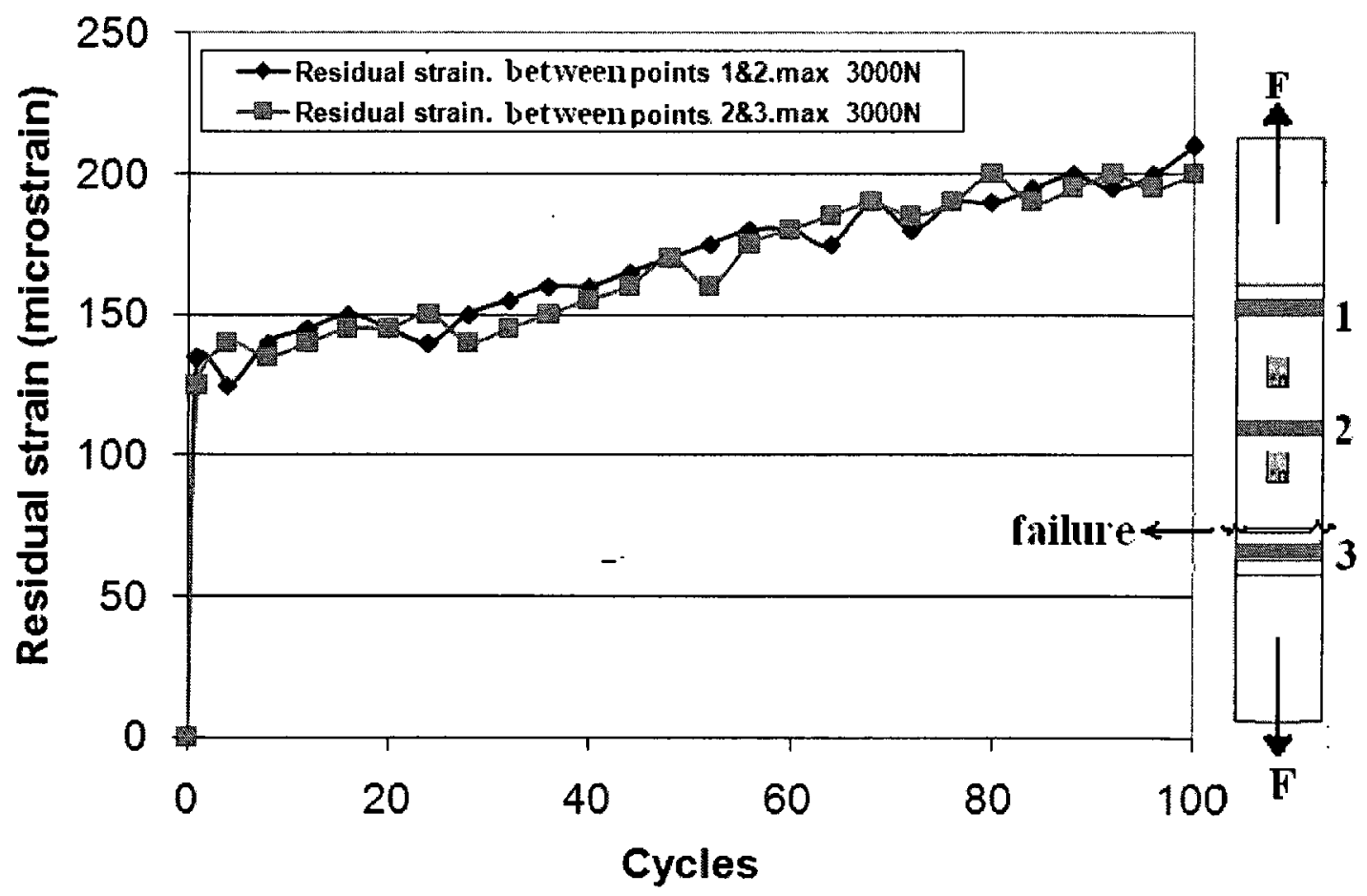




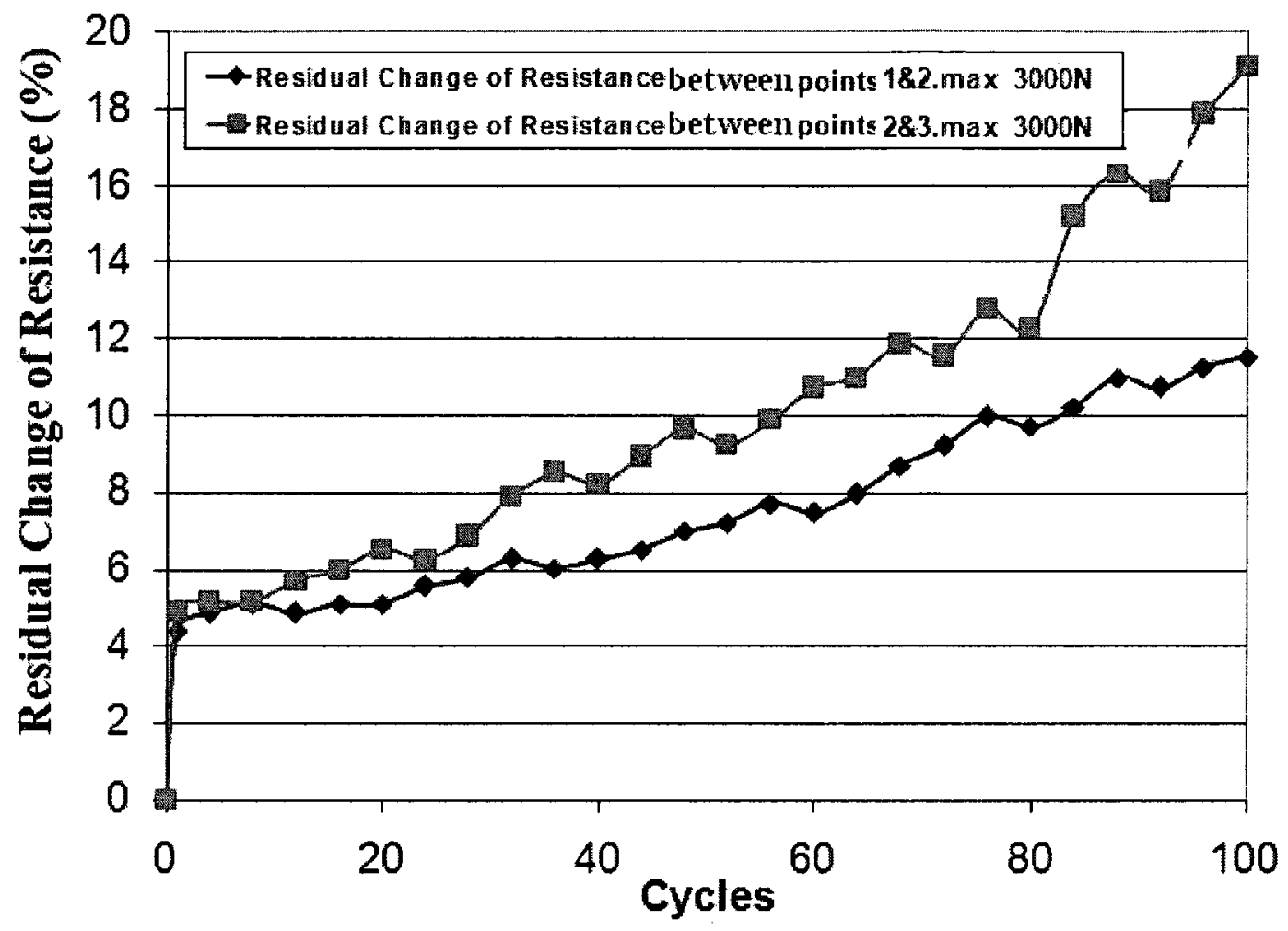

Fig. 53a) Residual change of resistance and residual strain in two regions, after 100 fatigue cycles with maximum load of $2000 \mathrm{~N}$ (type II, sample 1)

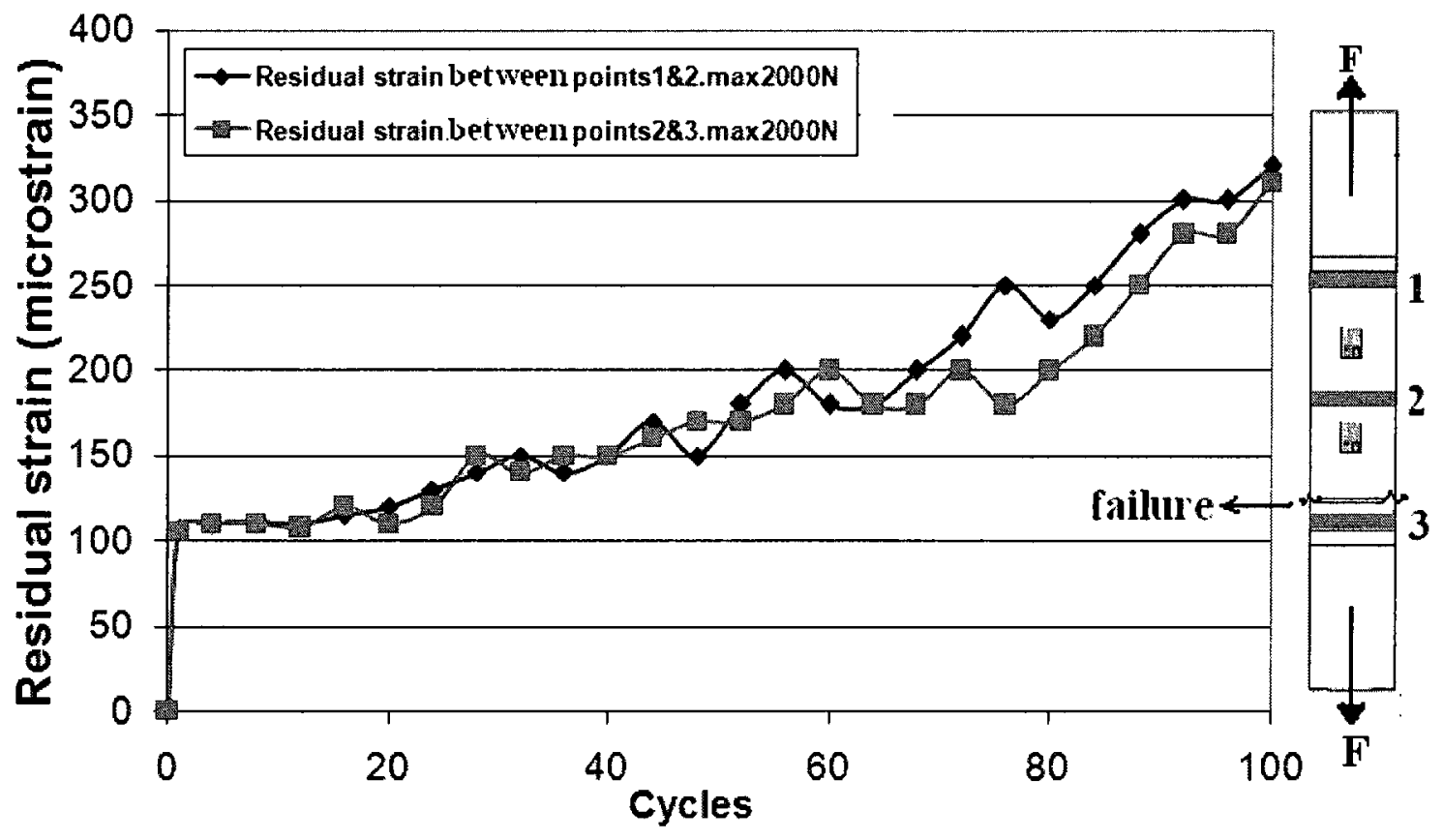




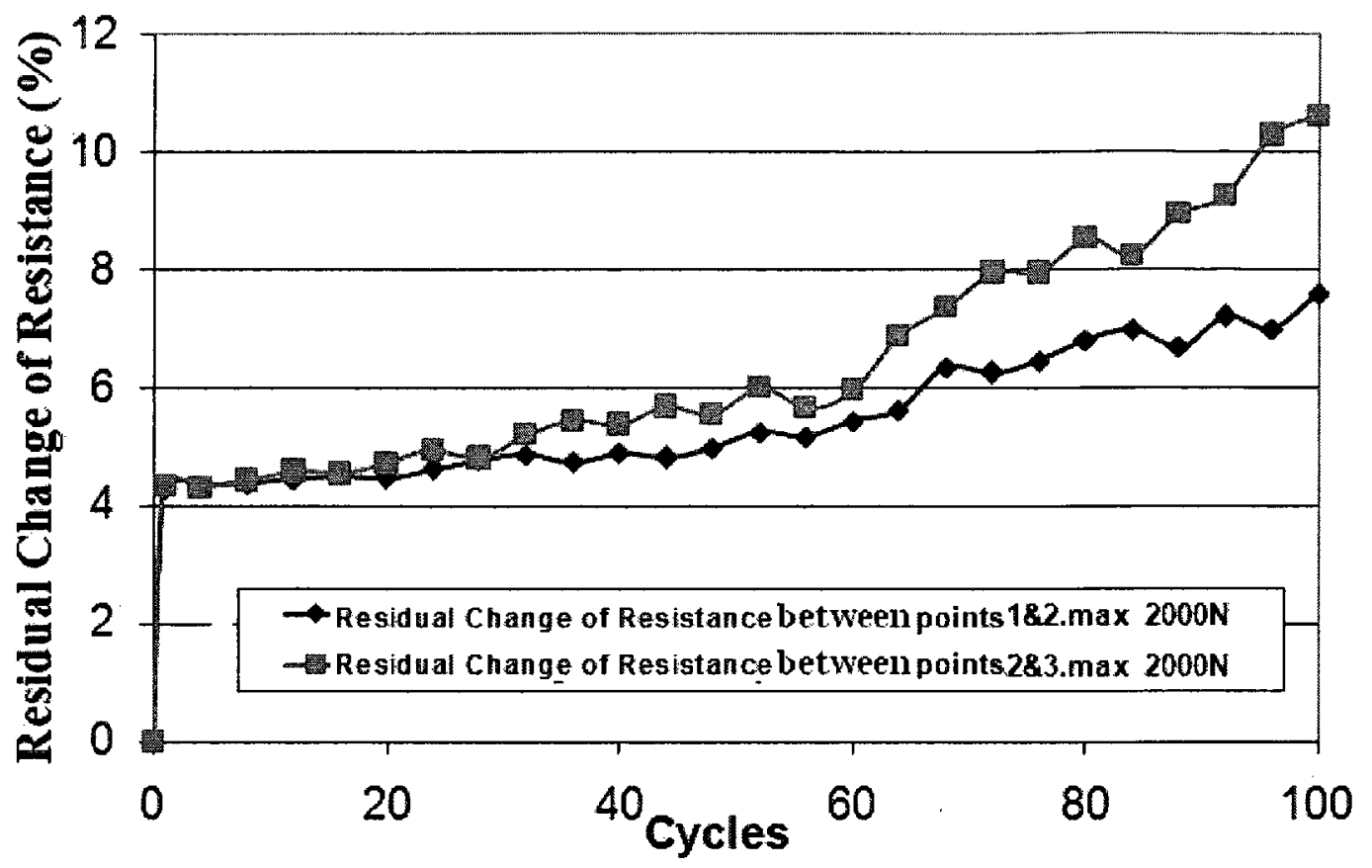

Fig. 53b) Residual change of resistance and residual strain in two regions, after 100 fatigue cycles with maximum load of $3000 \mathrm{~N}$ (type II, sample 2)

\subsubsection{Fatigue testing of type III samples}

Two samples of type III as depicted in Figures 54a and 54b were fatigued with a maximum load of $6000 \mathrm{~N}$. For these samples, a blend of epoxy and nanotubes were embedded into three layers of woven glass fiber fabrics. The mid layer was transversely cut in the lower region of each sample (2-3 $\mathrm{mm}$ below the positioned strain gauge, where the failure occurs) prior to curing to initiate a crack and to investigate its effect on resistance change and strain (every 4 cycles while the sample is unloaded), up to 150 cycles. Figures $54 \mathrm{a}$ and $54 \mathrm{~b}$ show that with increasing the number of cycles, the residual strain between points $2-3$ increases more than that between points 1-2. The resistance increases at the same time within that region. 

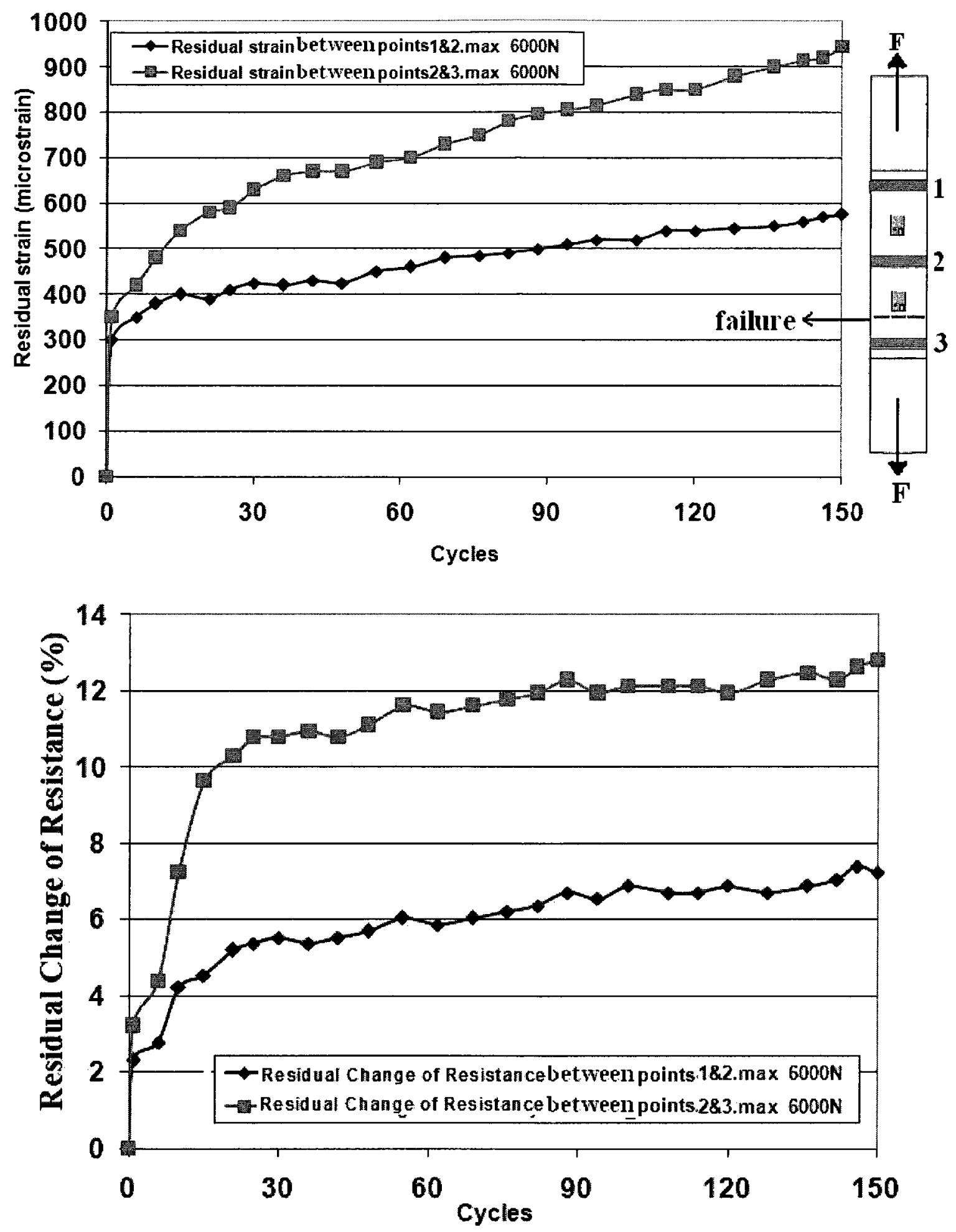

Fig. 54a) Residual change of resistance and residual strain in two regions, after 150 fatigue cycles with maximum load of $6000 \mathrm{~N}$ (type III, sample 1) 

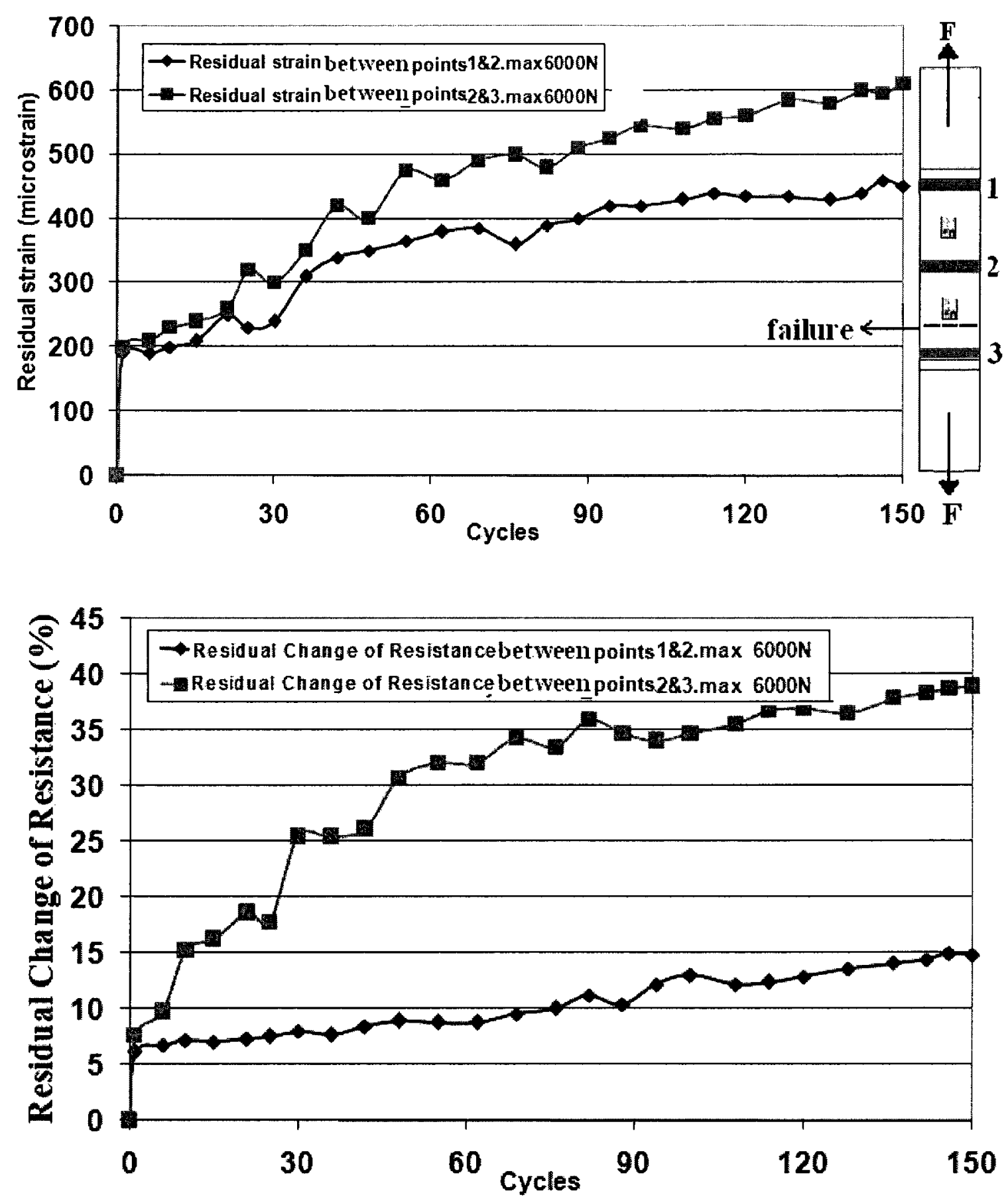

Fig.54b) Residual change of resistance and residual strain in two regions, after 150 fatigue cycles with maximum load of $6000 \mathrm{~N}$ (type III, sample 2)

As shown, cyclic fatigue tests were conducted on three types of samples while measuring the resistance and strain in two regions of each sample every 4 cycles upon unloading 
(Figures 52-54). These experiments were implemented in order to explore the sensitivity of each of these two different measurement techniques on predicting the failure region. The applied maximum loads for all samples are above the elastic limit. For Types I and II, resistance measurements show more sensitivity compared to that of strain gauges. It can be seen in Figures 52 and 53 that strain measurements sometimes reflect the appearance of the damage (Figure 52c) and sometimes not (Figures 52a, 52b, 53a, and 53b) but, the resistance measurements always reflect the occurrence of cracks and damage. This shows that the electrical resistance measurements are more consistent than those of strain gauges. However, for Type III samples, both resistance and strain measurements correlate well with the final failure location of each sample (Figure 54). In Type III samples, the cut was made before curing in the mid glass fiber layer and the strain gauge in the defective region (lower region) is close to the defect $(2-3 \mathrm{~mm})$. Subsequently, larger strain change is seen in the lower region as compared to the upper region. The resistance also increases at a higher rate in the lower region which again shows a good consistency with failure location.

According to these results, strain gauges sometimes correlate well with the occurrence of crack and sometimes not due to following reasons:

1) Occurrence of cracks away from and perpendicular to the strain gauge can relax the stress field around the gauge and the gauge reading is reduced after crack occurrence.

2) A matrix crack parallel to the load direction can transfer more loads to the fibers. These fibers in turn can introduce more strain on the adjacent area to where the gauge is bonded. On the other hand, since the nanotube networks are connected all over the 
sample, the occurrence of any defect or damage, can cause disconnection of nanotubes and a resulting increase in resistance along the sample, regardless of the location of failure. By partitioning the sample with electrical probes, the part that shows a higher resistance, will have more damage accumulation and hence will be the failure location.

The above points show that carbon nanotubes have the potential to monitor the strength degradation during static and dynamic loading and to predict failure before it happens. This self-sensing method using nanotube as a network of sensors can also be proposed for failure location prediction in polymer matrix composites.

This effect has a potential application as a network sensor device. When a polymer composite panel structure is under a certain load, by making an equally spaced network of probes on the surface of the panel, the resistance between all pairs of probes can be measured through the network of nanotubes within the polymer matrix. These measurements could be made periodically and if after a period, higher resistance change is recorded in a definite area, it means that certain damage has accumulated there and a damage accumulation history map could be built up. 


\section{CHAPTER 6: CONCLUSIONS}

Towards the development of a new method to monitor failure under static and dynamic loads, multiwall carbon nanotubes were incorporated in an epoxy matrix to form a network of sensors. During static tensile loading, failure zone could be determined based on higher electrical resistance change in one zone compared to the other zones.

A higher rate of resistance increase was observed above the elastic limit of the laminated composite and a lower rate of increase below that limit. On the other hand, below the limit upon unloading, no residual strain and resistance change were detected due to elastic recovery.

There is also a change in resistance during long term cyclic loading.

Also in different zones, by applying cyclic loads and comparing the resistance change with strain gauge measurements, it was seen that the electrical resistance measurements show more consistency in correlation with failure location. Failure zone can be predicted by higher increase of resistance change in a region compared to other regions of the sample. The formation of matrix cracks causes disconnection of nanotubes and subsequent reduction of the electrical current flow through them. These results show that nanotube networks have the potential to be used for monitoring the integrity of composite laminates during both cyclic and static loads and also are more sensitive than strain gauge measurements in case of monitoring the failure and crack detection. 


\section{Contributions}

The main achievement of this work was using nanotubes as a network of sensors to detect the cracked area and failure zone by measuring the electrical resistance. At the same time compared to the strain gauge, using nanotube network of sensors shows more sensitivity to crack appearance and monitoring the failure zone. This method can be a sensitive way for monitoring the strength degradation and failure for polymer matrix composites. 


\section{Suggestions for future work}

According to this work, some suggestions can be recommended for the future:

1) Making electrical formulations according to the resistance change along different lengths of a sample. Also, investigating the dependency of nanotubes content on the electrical resistance change through formulation and computer modeling of interconnection of nanotubes and resistance changes while the sample is under load in both elastic and permanent deformation range.

2) Measuring the resistance change along more divisions in a sample under different types of loadings to locate the failure location and to figure out the precise location of the damage.

3) Comparing other health monitoring methods like acoustic emission rather than strain gauge with electrical resistance measurements. 


\section{REFERENCES}

[1] Wong EW, Sheehan PE, Lieber CM. "Nanobeam mechanics: elasticity, strength, and toughness of nanorods and nanotubes". Science 1997;277: 1971-1975.

[2] Yu M, Lourie O, Dyer MJ, Kelly TF, Ruoff RS. "Strength and breaking mechanism of multiwalled carbon nanotubes under tensile load". Science 2000;287:637-640.

[3] Yu MF, Files BS, Arepalli S, Ruoff RS. "Tensile loading of ropes of single wall carbon nanotubes and their mechanical properties". Physical Review Letters June 2000;84(24):5552-5555.

[4] Ruoff RS, Lorents DC. "Mechanical and thermal-properties of carbon nanotubes". Carbon 1995;33(7):925-930.

[5] Mintmire JW, White CT. "Electronic and structural-properties of carbon nanotubes" .Carbon 1995;33(7):893-902.

[6] Wildoer JWG, Venema LC, Rinzler AG, "Smalley RE, Dekker C. Electronic structure of atomically resolved carbon nanotubes". Nature 1998;391:59-62.

[7] Li C, Chou TW. "A structural mechanics approach for the analysis of carbon nanotubes". International Journal of Solids and Structures 2003;40(10):2487-2499.

[8] Falvo MR, Clary GJ, Taylor II RM, Chi V, Brooks FP, Washburn S, "Bending and buckling of carbon Nanotubes under large strain", Nature 1997;389:582-584.

[9] Iijima S, Brabec C, Mati A, Bernholc J. "Structural flexibility of carbon nanotubes", Journal of Chemistry Physics 1996;104(5):2089-2092.

[10] Thostenson E. T., Chou T. W. "Carbon Nanotube Networks: Sensing of Distributed Strain and Damage for Life Prediction and Self Healing", Advance Materials 2006;18: 2837-2841.

[11] Li Z, Dharap P, Nagarajaiah S, Barrera EV, Kim JD. "Carbon nanotube film sensors". Advance Materials 2004;16(7):640-643.

[12] Dharap P, Li Z, Nagarajaiah S, Barrera E V. "Nanotube film based on single-wall carbon nanotubes for strain sensing", Nanotechnology 2004;15:379-382.

[13] Zhang W, Suhr J, Koratkar N, "Carbon nanotube/polycarbonate composites as multifunctional strain sensors", Journal of Nanoscience \& Nanotechnology. 2006;6:960 964.

[14] Weber I, Schwartz P, "Monitoring bending fatigue in carbon-fibre/epoxy composite 
strands: a comparison between mechanical and resistance techniques", Composites Science and Technology 2001;61:849-853.

[15] Kupke M, Schulte K, Schuler R, "Non-destructive testing of FRP by dc and ac electrical methods", Composites Science and Technology 2001;61:837-847.

[16] Schueler R, Joshi S. P., Schulte K, "Damage detection in CFRP by electrical conductivity mapping", Composites Science and Technology 2001;61:921-930.

[17] Parka J. M., Kima D. S., Leeb J. R., Kim T. W. "Nondestructive damage sensitivity and reinforcing effect of carbon nanotubelepoxy composites using electromicromechanical technique". Materials Science and Engineering C 2003;23:971-975.

[18] http://www.vishay.com.

[19] Chou T. W. "Microstructural Design of Fiber Composites", Cambridge University Press, Cambridge, UK 1992.

[20] Zhang W., Sakalkar V., Koratkar N., "In situ health monitoring and repair in composites using carbon nanotube additives", Applied Physics Letters 2007; 91(13):1-3.

[21] Giang T.P., Park YB, Liang Z., Zhang C., Wang B., "Processing and modeling of conductive thermoplastic/carbon nanotube films for strain sensing", Composites Part B: Eng, 2008;39:209-216.

[22] Böger L, Wichmann M. H. G., Meyer L. O., Schulte K., "Load and health monitoring in glass fibre reinforced composites with an electrically conductive nanocomposite epoxy matrix", Composites Science and Technology 2008; 68:18861894.

[23] Jang B. Z., "Advanced Polymer Composites: Principles and Applications", ASM International, Materials Park, Ohio, 1994.

[24] Reinhart T. J., "Engineered Materials Handbook", Volume 1: Composites, ASM International, Metals Park, Ohio, 1987.

[25] Callister W.D., "Materials Science \& Engineering: An Introduction", 7th edition, J. Wiley, 2007, pp. 577-607.

[26] http://www.osha.gov/dts/osta/otm/otm_iii/otm_iii_1.html, as on 8 Jan. 2008 (OSHA technical manual)

[27] Lin L. Y., Lee J. , Hong C. E. , Yoo G. H., Advani S. G., "Preparation and characterization of layered silicate/glass fiber/epoxy hybrid nanocomposites via vacuumassisted resin transfer molding (VARTM)", Composites Science and Technology 2006;66:2116-2125. 
[28] G. Gulowski T., “Advanced composites manufacturing”, John Wiley and Sons, New York, 1997, pp. 22-39.

[29] Dresselhaus MS, Dresselhaus G, Eklund PC., "Science of fullerenes and carbon nanotubes", San Diego: Academic Press; 1996.

[30] Thostenson ET, Ren ZF, Chou T. W., "Advances in the science and technology of carbon nanotubes and their composites: a review", Composites Science and Technology 2001;61(13):1899-912.

[31] Krishnan A., Dujardin E., Ebbesen T.W., Yianilos P.N., Treacy M.M.J., "Young's modulus of single-walled nanotubes", Physical Review B 1998;58:14013.

[32] Chunyu Li, Chou T. W., "Modeling of elastic buckling of carbon nanotubes by molecular structural mechanics approach", Mechanics of Materials 2004;36:1047-1055.

[33] E. T. Thostenson, C. Y. Li, Chou T. W., "Nanocomposites in context", Composites Science and Technology 2005:65, 491 _516.

[34] http://en.wikipedia.org/wiki/Image:Graphit_gitter.png

[35] Iijima S., "Helical microtubules of graphitic carbon", Nature 1991;354:56-58.

[36] Iijima S., Ichihashi T., "Single-shell carbon nanotubes of 1-nm diameter", Nature 1993;363:603-605.

[37] Bethune D.S., Kiang C.H., M.S. de Vries, Gorman G., Savoy R., Vasquez J., Beyers R., "Cobalt-catalysed growth of carbon nanotubes with single-atomic-layer walls", Nature 1993;363:605-607.

[38] Chunyu Li, Tsu-Wei Chou, "Elastic moduli of multi-walled carbon nanotubes and the effect of van der Waals forces", Composites Science and Technology 2003; 63:15171524.

[39] Thostenson ET, Chou TW., "On the elastic properties of carbon nanotube-based composites: modeling and characterization", Journal of Physics D: Applied Physics 2003;36 (5):573-82.

[40] Li CY, Chou TW., "Elastic moduli of multi-walled carbon nanotubes and the effect of van der Waals forces", Composites Science and Technology 2003; 63(11):1517-24.

[41] Gojny FH, Wichmann MHG, Kopke U, Fiedler B, Schulte K., "Carbon nanotubereinforced epoxy-composites: enhanced stiffness and fracture toughness at low nanotube content", Composites Science and Technology 2004;64(15):2363-71. 
[42] Miyagawa H, Mohanty AK, Drzal LT, Misra M., "Nanocomposites from biobased epoxy and single-wall carbon nanotubes: Synthesis, and mechanical and thermophysical properties evaluation", Nanotechnology 2005;16(1):118-24.

[43] Zhan GD, Kuntz JD, Wan JL, Mukherjee AK., "Single-wall carbon nanotubes as attractive toughening agents in alumina-based nanocomposites", Nat Mater $2003 ; 2(1): 38-42$.

[44] Miyagawa H, Drzal LT., "Thermo-physical and impact properties of epoxy nanocomposites reinforced by single-wall carbon nanotubes", Polymer 2004;45(15):5163-70.

[45] Fidelus JD, Wiesel E, Gojny FH, Schulte K, Wagner HD., "Thermomechanical properties of randomly oriented carbon/epoxy nanocomposites", Composites Part A: 2005;36 (11):1555-61.

[46] Rajoria $\mathrm{H}$, Jalili N., "Passive vibration damping enhancement using carbon nanotube-epoxy reinforced composites", Composites Science and Technology 2005;65(14):2079-93.

[47] Koratkar NA, Suhr J, Joshi A, Kane RS, Schadler LS, Ajayan P.M., "Characterizing energy dissipation in single-walled carbon nanotube polycarbonate composites", Applied Physics Letters 2005; 87 (6): 063102.

[48] Suhr J, Koratkar N, Keblinski P, Ajayan P., "Viscoelasticity in carbon nanotube composites", Nat Mater 2005;4(2):134-7.

[49] CES software, "The Cambridge Engineering Selector", Granta Design, Rustat House, 62 Clifton Road, Cambridge CB1 7EG, UK. Available from: www.grantadesign.com.

[50] Journet C, Maser WK, Bernier P, Loiseau A, de la Chapelle ML, Lefrant S., "Largescale production of single-walled carbon nanotubes by the electric-arc technique", Nature 1997; 388:756-8.

[51] Rinzler AG, Liu J, Dai H, Nikolaev P, Huffman CB, Rodriguez- Macias FJ., "Large-scale purification of single-wall carbon nanotubes: Process, product and characterization", Applied Physics A 1998; 67 (1):29-37.

[52] Nikolaev P, Bronikowski MJ, Bradley RK, Fohmund F, Colbert DT, Smith KA., "Gas-phase catalytic growth of single-walled carbon nanotubes from carbon monoxide" Chemical Physics Letters 1999;313 (1-2):91-7.

[53] Ren ZF, Huang ZP, Xu JW, Wang DZ, Wen JG, Wang JH., "Growth of a single freestanding multiwall carbon nanotube on each nanonickel dot", Applied Physics Letters 1999;75 (8):1086-8. 
[54] Ren ZF, Huang ZP, Xu JW, Wang JH, Bush P, Siegal MP., "Synthesis of large arrays of well-aligned carbon nanotubes on glass", Science 1998;282:1105-7.

[55] Xiao K.Q., Zhang L.C., Zarudi I., "Mechanical and rheological properties of carbon nanotube-reinforced polyethylene composites", Composites Science and Technology 2007;67:177-182.

[56] Thostenson E. T., Chou T.W., "Nanotube buckling in aligned multi-wall carbon nanotube composites", Carbon 2004;42:3003-3042.

[57] Shen J., Huang W., Wu L., Hu Y., Ye M., "Thermo-physical properties of epoxy nanocomposites reinforced with amino-functionalized multi-walled carbon nanotubes", Composites: Part A 2006;38(5):1331-1336.

[58] Hone J, Whitney M, Piskoti C, Zettl A. "Thermal conductivity of single-walled carbon nanotubes", Physical Review B 1999;59(4):2514-6.

[59] Hone J, Llaguno MC, Nemes NM, Johnson AT, Fischer JE, Walters DA., "Electrical and thermal transport properties of magnetically aligned single wall carbon nanotube films", Applied Physics Letters 2000;77(5):666-8.

[60] Berber S, Kwon YK, Tomanek D., "Unusually high thermal conductivity of carbon nanotubes", Physical Review Letters 2000;84(20): 4613-6.

[61] Che JW, Cagin T, Goddard WA., "Thermal conductivity of carbon nanotubes", Nanotechnology 2000;11 (2):65-9.

[62] ASTM D257-99. "Standard test methods for DC resistance or conductance of insulating materials", ASTM Annual Book of Standards Volume: 10.01. Philadelphia, PA, USA. ASTM International, 2005.

[63] Dai J., Wang Q., Li W., Wei Z., Xu G., "Properties of well aligned SWNT modified poly (methyl methacrylate) nanocomposites", Materials Letters 61 (2007) 27-29.

[64] Zhou Z., Wang S., Lu L., Zhang Y., Zhang Y., "Preparation and rheological characterization of poly(methyl methacrylate)/functionalized multi-walled carbon nanotubes composites", Composites Science and Technology 2006;67(19): 1861-1869.

[65] Li C., Chou T. W., "Multiscale Modeling of Carbon Nanotube Reinforced Polymer Composites", Journal of Nanoscience \& Nanotechnology2003;3(6):423-430.

[66] Thostenson E. T., Chou T. W., "Aligned multi-walled carbon nanotube-reinforced composites: processing and mechanical characterization", Journal of Physics D: Applied Physics 2002;35: 77-80. 
[67] Coleman J. N., Cadek M., Ryan K. P., Fonseca A., Nagy Janos B., Blau Werner J., Ferreira Mauro S., "Reinforcement of polymers with carbon nanotubes. The role of an ordered polymer interfacial region. Experiment and modeling", Polymer2006;47: 85568561.

[68] Sandler J, Shaffer MSP, Prasse T, Bauhofer W, Schulte K, Windle AH., "Development of a dispersion process for carbon nanotubes in an epoxy matrix and the resulting electrical properties", Polymer 1999;40(21):5967-71.

[69] Bryning MB, Islam MF, Kikkawa JM, Yodh AG., "Very low conductivity threshold in bulk isotropic single-walled carbon nanotube-epoxy composites", Advance Materials 2005;17(9):1186-91.

[70] Lau KT, Lu M, Lam CK, Cheung HY, Sheng FL, Li HL., "Thermal and mechanical properties of single-walled carbon nanotube bundlereinforced epoxy nanocomposites: The role of solvent for nanotube dispersion", Composites Science and Technology 2005;65(5):719-25.

[71] Kim B, Lee J, Yu IS. "Electrical properties of single-wall carbon nanotube and epoxy composites", Journal of Applied Physics 2003;94(10):6724-8.

[72] Dyke CA, Tour JM. "Covalent functionalization of single-walled carbon nanotubes for materials applications", Journal of Physical Chemistry A 2004;108(51):11151-9.

[73] Fiedler B., Gojny Florian H., Wichmann M. H.G., Nolte Mathias C.M., Schulte K., "Fundamental aspects of nano-reinforced composites", Composites Science and Technology 2006;66:3115-3125.

[74] Wagner HD, Vaia RA., "Nanocomposites: issues at the interface", Materials Today 2004;7(11):38-42.

[75] Sinnott SB. "Chemical functionalization of carbon nanotubes", Journal of Nanoscience \& Nanotechnology 2002;2(2):113-23.

[76] Gojny FH, Schulte K., "Functionalisation effect on the thermomechanical behaviour of multi-wall carbon nanotubelepoxy composites", Composites Science and Technology 2004;64(15):2303-8.

[77] Liu J, Rinzler AG, Dai HJ, Hafner JH, Bradley RK, Boul PJ, "Fullerene pipes", Science 1998;280(5367):1253-6.

[78] Sen R, Zhao B, Perea D, Itkis ME, Hu H, Love J, "Preparation of single-walled carbon nanotube reinforced polystyrene and polyurethane nanofibers and membranes by electrospinning", Nano Letters 2004;4(3):459-64. 
[79] Hamon MA, Hui H, Bhowmik P, Itkis HME, Haddon RC., "Ester-functionalized soluble single-walled carbon nanotubes", Applied Physics A 2002;74(3):333-8.

[80] Schadler LS, Jiang K, Andrews R, Eitan A., "Nanotube reinforced polymer composites: tailoring the interface for improved mechanical properties", In proceeding of the 14th International conference on composite materials (ICCM-14), San Diego; 2003, Paper no. 422.

[81] Gojny FH, Nastalczyk J, Roslaniec Z, Schulte K., "Surface modified multi-walled carbon nanotubes in CNT/epoxy-composites", Chemical Physics Letters 2003;370(56):820-4.

[82] Crespi VH, Chopra NG, Cohen ML, Zettl A, Radmilovic V., "Site-selective radiation damage of collapsed carbon nanotubes", Applied Physics Letters 1998;73(17):2435-7.

[83] Ma P. C., Kim J.K., Tang B. Z., "Functionalization of carbon nanotubes using a silane coupling agent", Carbon 2006;44:3232-3238.

[84] Yaping Z, Zhang Aibo, Chen Qinghua, Zhang Jiaoxia, Ning Rongchang, "Functionalized effect on carbon nanotubelepoxy nano-composites", Materials Science and Engineering A. 2006;435-436:145-149.

[85] Aneli N, Zaikov GE, Khananashvili LM, "Effects of Mechanical Deformations on the Structurization and Electric Conductivity of Electric Conducting Polymer Composites", Journal of Applied Polymer Science 1999; 74:601-621.

[86] Das NC, Chaki TK, Khastgir D, "Effect of axial stretching on electrical resistance of short carbon fiber and carbon black filled conductive rubber composites". Polymer International 2002; 51:156-163.

[87] Knite M, Teteris V, Kiploka A, kaupzs J,. "Polysioprene-carbon black nanocomposites as tensile and and pressure sensor materials", Sensors Actuators 2004; 110: $142-149$.

[88] Li C., Thostenson Erik T., Chou Tsu-Wei, "Sensors and actuators based on carbon nanotubes and their composites: A review", Composite science and technology 2008;68: 1227-1249.

[89] Hu N., Karube Y., Yan C., Masuda Z., Fukunaga H., "Tunneling effect in a polymer/carbon nanotube nanocomposites strain sensor", Acta Materialia 2008;56(13):2929-2936.

[90] Kang I., Heung Y. Y., Kim J. H., Lee J. W., Gollapudi R., Subramaniam S., Narasimhadevara S., Hurd D.,Kirikera G.R., Shanove V., Schulz M. J., Shi D., Boerio J., 
Mall J., Ruggles-Wren M., "Introduction to carbon nanotube and nanofiber smart materials", Composites: part B 2006;37:382-394.

[91] Thostenson Erik T., Chou Tsu-Wei, "Processing-structure-multi-functional property relationship in carbon nanotube/epoxy composites”, Carbon 2006;44:3022-3029.

[92] http://www.resins.com/resins/am/pdf/RP4048.pdf

[93] http://www.exakt.de/en/dreiwalzwerke.htm

[94] http://www.2spi.com/catalog/misc_lab/cell4.shtml 